Uso de meta-aprendizado na recomendação de metaheurísticas para o problema do caixeiro viajante 

SERVIÇO DE PÓS-GRADUAÇ̃̃O DO ICMC-USP

Data de Depósito:

Assinatura:

\title{
Uso de meta-aprendizado na recomendação de meta- heurísticas para o problema do caixeiro viajante
}

\author{
Jorge Yoshio Kanda
}

Orientador: Prof. Dr. André Carlos Ponce de Leon Ferreira de Carvalho Coorientador: Prof. Dr. Carlos Manuel Milheiro de Oliveira Pinto Soares

Tese apresentada ao Instituto de Ciências Matemáticas e de Computação - ICMC-USP, como parte dos requisitos para obtenção do título de Doutor em Ciências - Ciências de Computação e Matemática Computacional. VERSÃO REVISADA. 
Ficha catalográfica elaborada pela Biblioteca Prof. Achille Bassi e Seção Técnica de Informática, ICMC/USP, com os dados fornecidos pelo(a) autor(a)

\begin{tabular}{|c|c|}
\hline \multirow[t]{3}{*}{$\mathrm{K} 16 \mathrm{u}$} & $\begin{array}{l}\text { Kanda, Jorge Yoshio } \\
\text { Uso de meta-aprendizado na recomendação de meta- } \\
\text { heurísticas para o problema do caixeiro viajante / } \\
\text { Jorge Yoshio Kanda; orientador André Carlos Ponce } \\
\text { de Leon Ferreira de Carvalho; co-orientador Carlos } \\
\text { Manuel Milheiro de Oliveira Pinto Soares. -- São } \\
\text { Carlos, } 2012 \text {. } \\
\quad 147 \text { p. }\end{array}$ \\
\hline & $\begin{array}{l}\text { Tese (Doutorado - Programa de Pós-Graduação em } \\
\text { Ciências de Computação e Matemática Computacional) } \\
\text { Instituto de Ciências Matemáticas e de Computação, } \\
\text { Universidade de São Paulo, } 2012 .\end{array}$ \\
\hline & $\begin{array}{l}\text { 1. APRENDIZADO DE MÁQUINA. I. de Carvalho, André } \\
\text { Carlos Ponce de Leon Ferreira, orient. II. Soares, } \\
\text { Carlos Manuel Milheiro de Oliveira Pinto, co-orient. }\end{array}$ \\
\hline
\end{tabular}


A minha esposa Kátia Kely e meus filhos Rafael e Beatriz. 



\section{Agradecimentos}

- A Deus, pelas Bênçãos que tenho recebido todos os dias de minha Vida.

- Ao meu orientador, Prof. Dr. André Carlos Ponce de Leon Ferreira de Carvalho, por sua dedicação e confiança que me permitiu desenvolver este trabalho com muita alegria.

- Aos meus coorientadores Prof. Dr. Eduardo Hruschka e Prof. Dr. Carlos Soares, por suas importantes contribuições por meio de sugestões de pesquisas e revisões dos nossos artigos.

- Aos professores Ricardo Campello, Franklina Toledo e Estevam Hruschka Júnior que participaram da banca examinadora da minha qualificação, contribuindo com excelentes sugestões e ideias para o desenvolvimento desta pesquisa.

- Aos professores: Marcos Arenales, Maristela Santos, Oswaldo Oliveira Júnior, Valtencir Zucolotto, Roseli Romero e Rodrigo Mello, pela permissão concedida a mim para eu assistir como ouvinte algumas de suas aulas.

- Ao prof. Altigran Soares da Silva por ter me incentivado a cursar o doutorado e recomendado o prof. André de Carvalho para ser o meu orientador.

- A todos os colegas do Laboratório BioCom, por suas dicas e conhecimentos, que me permitiram resolver rapidamente diversos problemas.

- A todos os colegas do LIAAD, por terem me acolhido com muita alegria durante o meu estágio de doutoramento realizado na Universidade do Porto.

- Aos colegas Carlos Soares, Arthur Aiguzhinhov e Cláudio Sá, por terem disponibilizado algoritmos adaptados para o aprendizado de rankings. 
- Às bibliotecárias do ICMC, em especial, Sandra, Beatriz e Giselda, pela gentileza e disposição em me ajudar durante o primeiro ano em que estive sem minha família em São Carlos.

- Ao Sr. Paulo Celestini, responsável pela assistência técnica administrativa do ICMC, que providenciou os corrimãos instalados no prédio onde está localizado o Laboratório BioCom.

- À Angela Giampedro pelos encontros semanais nos quais foi discutida a estrutura gramatical de diversos textos científicos escritos em língua inglesa.

- À Universidade Federal do Amazonas (UFAM), por me liberar das minhas atividades profissionais para a realização do curso de doutorado.

- Aos colegas professores do Instituto de Ciências Exatas e Tecnologia (ICET) da UFAM, por assumirem as turmas que seriam destinadas a mim durante os semestres letivos correspondentes ao meu afastamento.

- Às agências de fomentos FAPEAM e CAPES, pelo apoio financeiro a mim concedido durante o período desta pesquisa.

- Aos meus pais, irmãos e amigos que sempre me apoiaram e acreditaram nas minhas conquistas.

- À minha esposa Kely e meus filhos Rafael e Beatriz, pelo amor incondicional que sempre demonstraram em todos os momentos. 


\section{Resumo}

O problema do caixeiro viajante (PCV) é um problema clássico de otimização que possui diversas variações, aplicações e instâncias. Encontrar a solução ótima para muitas instâncias desse problema é geralmente muito difícil devido o alto custo computacional. Vários métodos de otimização, conhecidos como meta-heurísticas (MHs), são capazes de encontrar boas soluções para o PCV. Muitos algoritmos baseados em diversas MHs têm sido propostos e investigados para diferentes variações do PCV. Como não existe um algoritmo universal que encontre a melhor solução para todas as instâncias de um problema, diferentes MHs podem prover a melhor solução para diferentes instâncias do PCV. Desse modo, a seleção a priori da MH que produza a melhor solução para uma dada instância é uma tarefa difícil. A pesquisa desenvolvida nesta tese investiga o uso de abordagens de meta-aprendizado para selecionar as MHs mais promissoras para novas instâncias de PCV. Essas abordagens induzem meta-modelos preditivos a partir do treinamento das técnicas de aprendizado de máquina em um conjunto de meta-dados. Cada meta-exemplo, em nosso conjunto de meta-dados, representa uma instância de PCV descrita por características (meta-atributos) do PCV e pelo desempenho das MHs (meta-atributo alvo) para essa instância. Os meta-modelos induzidos são usados para indicar os valores do meta-atributo alvo para novas instâncias do PCV. Vários experimentos foram realizados durante a investigação desta pesquisa e resultados importantes foram obtidos.

Palavras-chaves: meta-aprendizado, aprendizado de máquina, problema de seleção de algoritmos, problema do caixeiro viajante, meta-heurísticas. 



\section{Abstract}

The traveling salesman problem (TSP) is a classical optimization problem that has several variations, applications and instances. To find the optimal solution for many instances of this problem is usually a very hard task due to high computational cost. Various optimization methods, known as metaheuristics (MHs), are capable to generate good solutions for the TSP. Many algorithms based on different MHs have been proposed and investigated for different variations of the TSP. Different MHs can provide the best optimization solution for different TSP instances, since there is no a universal algorithm able to find the best solution for all instances. Thus, a priori selection of the MH that produces the best solution for a given instance is a hard task. The research developed in this thesis investigates the use of meta-learning approaches to select the most promising MHs for new TSP instances. These approaches induce predictive meta-models from the training of machine learning techniques on a set of meta-data. In our meta-data, each meta-example is a TSP instance described by problem characteristics (meta-features) and performance of MHs (target meta-features) for this instance. The induced meta-models are used to indicate the values of the target meta-feature for new TSP instances. During the investigation of this research, several experiments were performed and important results were obtained.

Keywords: machine learning, meta-learning, meta-heuristics, algorithm selection problem, traveling salesman problem. 



\section{Lista de Figuras}

1.1 Diagrama esquemático para a indução de um meta-modelo que recomende as meta-heurísticas mais promissoras para uma instância de PCV. . . . . . . . . . . . . . . . . 28

1.2 Diagrama esquemático para o uso do meta-modelo recomendador de meta-heurísticas para o PCV. . . . . . . . . . . . . 29

2.1 Exemplo de grafo. . . . . . . . . . . . . . . . . 38

2.2 Representação de um grafo orientado. . . . . . . . . . . . . 39

2.3 Exemplo de PCV modelado por grafo. . . . . . . . . . . . . 40

2.4 Restrições de cardinalidade. . . . . . . . . . . . . . . 41

3.1 Modelo básico para o problema da seleção de algoritmos adaptado de (Rice, 1976). . . . . . . . . . . . . . . . . 56

3.2 Modelo de Rice (1976) para a seleção de algoritmos com a identificação de atributos do problema. . . . . . . . . . . . . 57

5.1 Acurácia dos modelos de classificação nos conjuntos de PCV sintéticos resultantes da aplicação de três técnicas de classificação multirrótulo. . . . . . . . . . . . . . . 86

5.2 Número de instâncias de PCV geradas a partir de arquivos da bibllioteca TSPLIB em que cada meta-heurística $(\mathrm{MH})$ obteve o melhor desempenho de otimização. . . . . . . . . . . . . . . 89

5.3 Três abordagens de rede neural artificial para recomendar ranking de MHs. . . . . . . . . . . . . . . . 96

5.4 Média do desempenho preditivo do meta-modelo mensurado pelo coeficiente de Spearman para os rankings de MHs - cenário revisitando clientes. . . . . . . . . . . . . . . 101

5.5 Média do desempenho preditivo do meta-modelo mensurado pelo coeficiente de Spearman para os rankings de MHs - cenário prospectando novos clientes. . . . . . . . . . . . . . . 102 
5.6 Valor normalizado da solução média para PCV versus tempo médio normalizado para encontrar a solução usando a estratégia que executa as MHs Top $-N-$ cenário revisitando clientes. . . . 103

5.7 Valor normalizado da solução média para PCV versus tempo médio normalizado para encontrar a solução usando a estratégia que executa as MHs Top $-N$ - cenário prospectando novos clientes. . . . . . . . . . . . . . . . . . . . . 104

5.8 Média do coeficiente de Spearman que mensura o desempenho preditivo dos meta-modelos induzidos a partir de diferentes conjuntos de meta-atributos - Cenário simétrico e fortemente conectado. . . . . . . . . . . . . . . . . . . . 107

5.9 Média do coeficiente de Spearman que mensura o desempenho preditivo dos meta-modelos induzidos a partir de diferentes conjuntos de meta-atributos - Cenário assimétrico e fortemente conectado. . . . . . . . . . . . . . . . . . . 108

5.10 Média do coeficiente de Spearman que mensura o desempenho preditivo dos meta-modelos induzidos a partir de diferentes conjuntos de meta-atributos - Cenário simétrico e fracamente conectado. . . . . . . . . . . . . . . . . . . . . . . 109

5.11 Média do coeficiente de Spearman que mensura o desempenho preditivo dos meta-modelos induzidos a partir de diferentes conjuntos de meta-atributos - Cenário assimétrico e fracamente conectado. . . . . . . . . . . . . . . . . . 110

5.12 Média do coeficiente de Spearman que mensura o desempenho preditivo dos meta-modelos induzidos a partir de uma árvore de decisão e meta-atributos selecionados em quatro cenários de PCV. 114 5.13 Média do tempo de geração dos meta-atributos para o cenário simétrico e fortemente conectado. . . . . . . . . . . . 117

A.1 Abordagem básica para construir um modelo de classificação. . . 135

A.2 Erros de modelagem: underfitting e overfitting. . . . . . . . . . 135 


\section{Lista de Tabelas}

4.1 Meta-atributos (MA) para PCV baseados em medidas de custo de vértice e de aresta. . . . . . . . . . . . . . . . . . 69

4.2 Meta-atributos (MA) baseados em medidas que caracterizam as meta-heurísticas. ............... . 70

4.3 Meta-atributos (MA) extraídos a partir da caracterização de landmarkers. . . . . . . . . . . . . . . . 73

4.4 Meta-atributos (MA) baseados em medidas para caracterizar redes complexas. . . . . . . . . . . . . . . . . 75

5.1 Quantidade de instâncias geradas de PCV por grupo de características: simetria, grau de conectividade e sinal do laço. . . . . . . 81

5.2 Número de instâncias de PCV geradas empiricamente em que as MHs obtiveram o melhor desempenho de otimização em cada grupo de características do problema.

5.3 Meta-atributos de PCV usados para induzir meta-modelos classificadores de MHs - experimentos preliminares. . . . . . . . 83

5.4 Acurácia e AUC dos classificadores para a abordagem de decomposição de instâncias multirrótulo - instâncias de PCV geradas empiricamente. . . . . . . . . . . . . . 84

5.5 Acurácia e AUC dos classificadores para a abordagem de eliminação de instâncias multirrótulo - instâncias de PCV geradas empiricamente.................. 8

5.6 Acurácia e AUC dos classificadores para a abordagem de transformação baseada em rótulos — instâncias de PCV geradas empiricamente.

5.7 Resultado de medidas específicas para a classificação multirrótulo baseada em rótulos — instâncias de PCV geradas empiricamente. ...................... 86 
5.8 Ranking dos classificadores de acordo com o desempenho preditivo medido pela acurácia - instâncias de PCV geradas empiricamente.

5.9 Ranking dos classificadores de acordo com o desempenho preditivo medido pela AUC - instâncias de PCV geradas empiricamente. 88

5.10Desempenho das MHs mensurado pelo número relativo de instâncias em que a melhor solução foi obtida para instâncias de PCV geradas a partir de arquivos da biblioteca TSPLIB. . . . . . 89

5.11 Acurácia e AUC dos classificadores para a decomposição de instâncias multirrótulo - instâncias de PCV geradas a partir de arquivos do TSPLIB. . . . . . . . . . . . . . . . 90

5.12 Acurácia e AUC dos classificadores para a eliminação de instâncias multirrótulo - instâncias de PCV geradas a partir de arquivos do TSPLIB. . . . . . . . . . . . . . . . 990

5.13Acurácia e AUC dos classificadores para a transformação baseada em rótulos - instâncias de PCV geradas a partir de arquivos do TSPLIB. . . . . . . . . . . . . . . . . . . . . . 90

5.14 Ranking dos classificadores de acordo com o desempenho preditivo medido pela acurácia - instâncias de PCV geradas a partir de arquivos do TSPLIB. . . . . . . . . . . . . . . . . 92

5.15Ranking dos classificadores de acordo com o desempenho preditivo medido pela AUC - instâncias de PCV geradas a partir de arquivos do TSPLIB. . . . . . . . . . . . . . . . . . . . 92

5.16Frequência relativa dos rankings de desempenho das MHs para instâncias de PCV geradas a partir de arquivos do TSPLIB. . . . . 93

5.17 Meta-atributos (MA) usados para a indução do modelo de metaaprendizado para ranquear rótulos. . . . . . . . . . . . . 94

5.18Configuração da RNA que obteve o menor erro quadrático médio para os meta-exemplos de validação em três abordagens diferentes. 96

5.19Desempenho preditivo dos meta-modelos no conjunto de teste mensurado por Coeficiente de Spearman. . . . . . . . . . . 97

5.20Desempenho preditivo dos meta-modelos no conjunto de teste mensurado por Coeficiente de Goodman-Kruskal Ponderado. . . .

5.21 Resultados do teste t para comparar o desempenho preditivo de meta-modelos usando diferentes conjuntos de meta-atributos Cenário simétrico e fortemente conectado. . . . . . . . . . . . 107

5.22 Resultados do teste t para comparar o desempenho preditivo de meta-modelos usando diferentes conjuntos de meta-atributos Cenário assimétrico e fortemente conectado. 
5.23Resultados do teste t para comparar o desempenho preditivo de meta-modelos usando diferentes conjuntos de meta-atributos Cenário simétrico e fracamente conectado. . . . . . . . . . . . . . . 110

5.24 Resultados do teste $\mathrm{t}$ para comparar o desempenho preditivo de meta-modelos usando diferentes conjuntos de meta-atributos Cenário assimétrico e fracamente conectado. . . . . . . . . . . 111

5.25Taxa do tempo economizado ao gerar meta-atributos ao invés de executar todas as MHs candidatas - Cenário simétrico e fortemente conectado.

5.26 Taxa do tempo economizado ao gerar meta-atributos ao invés de executar todas as MHs candidatas - Cenário assimétrico e fortemente conectado. . . . . . . . . . . . . . . . 113

5.27Taxa do tempo economizado ao gerar meta-atributos ao invés de executar todas as MHs candidatas - Cenário simétrico e fracamente conectado.

5.28Taxa do tempo economizado ao gerar meta-atributos ao invés de executar todas as MHs candidatas - Cenário assimétrico e fracamente conectado. . . . . . . . . . . . . . . . . . 114

5.29 Meta-atributos selecionados para os diferentes cenários de PCV. . 115

5.30Taxa do tempo economizado para quatro cenários de PCV ao gerar a seleção de 10 meta-atributos ao invés de executar todas as meta-heurísticas candidatas. . . . . . . . . . . 116

5.31 Taxa do tempo economizado para quatro cenários de PCV ao gerar a seleção de 10 meta-atributos ao invés de processar todos os meta-atributos MVA. ................ 116

A.1 Uma ilustração de conjunto de dados com exemplos multirrótulo. 142

A.2 Transformação dos exemplos multirrótulo baseada no método de classificação binária dos rótulos. . . . . . . . . . . . . . . . . 143

A.3 Transformação dos exemplos multirrótulo baseada no método de decomposição dos rótulos. . . . . . . . . . . . . . . . . . . . . . 143

A.4 Transformação dos exemplos multirrótulo baseada no método de eliminação dos exemplos multirrótulo. . . . . . . . . . . . . . . . 143 



\section{Lista de Algoritmos}

1 Heurística Construtiva . . . . . . . . . . . . . . . . . . 44

2 Heurística Busca Local . . . . . . . . . . . . . . . . . . 45

3 Busca Tabu (Glover et al., 1993) . . . . . . . . . . . . . . . 46

4 GRASP (Feo e Resende, 1995) . . . . . . . . . . . . . . 48

5 Função Construção do GRASP . . . . . . . . . . . . . . . . . . . 48

6 Recozimento Simulado (Kirkpatrick et al., 1983) . . . . . . . . . 50

7 Algoritmo Genético (Holland, 1973) . . . . . . . . . . . . 51

8 Otimização baseada em Colônia de Formigas (Dorigo e Gambar-

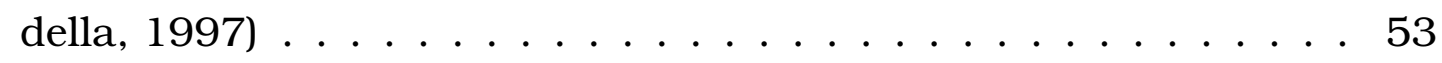





\title{
Lista de Abreviaturas
}

\author{
PCV Problema do Caixeiro Viajante \\ MH Meta-heurística \\ BT Busca Tabu \\ GRASP Greedy Randomized Adaptive Search Procedure \\ SA Simulated Annealing \\ AG Algoritmo Genético \\ OCF Otimização baseada em Colônia de Formigas \\ AM Aprendizado de Máquina \\ TSPLIB Biblioteca de arquivos do PCV \\ K-NN K-Nearest-Neighbor \\ $\mathrm{AD} \quad$ Árvore de Decisão \\ NB Nä̈ve Bayes \\ SVM Support Vector Machine \\ RNA Rede Neural Artificial \\ MLP Multilayer Perceptron \\ PMX Partial Mapped Crossover \\ ERX Edge Recombination Crossover \\ ROC Receiver Operating Characteristic \\ AUC Area Under the ROC Curve \\ CS Coeficiente de Spearman \\ GKP Coeficiente de Goodman-Kruskal Ponderado \\ MVA Medidas de Vértices e de Arestas \\ $\mathrm{PMH} \quad$ Propriedades das Meta-heurísticas \\ CLM Caracterização a partir de Landmarkers \\ MRC Medidas para Caracterizar Redes Complexas
}





\section{Sumário}

1 Introdução $\quad 23$

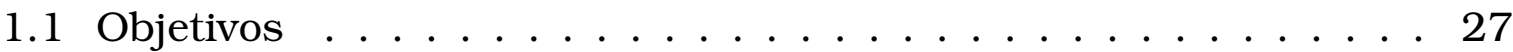

1.2 Principais contribuições . . . . . . . . . . . . . 30

1.3 Organização da tese . . . . . . . . . . . . . . 31

2 Problema do Caixeiro Viajante 33

2.1 Contextualização . . . . . . . . . . . . . . . . 33

2.2 Notação matemática para problemas de otimização . . . . . . . 37

2.2 .1 Grafos . . . . . . . . . . . . . . 38

2.2.2 Definição formal do $\mathrm{PCV}$. . . . . . . . . . . . . . 40

2.2.3 Variações do PCV . . . . . . . . . . . . . . . . . . 42

2.3 Abordagens para resolver o PCV . . . . . . . . . . . . . 44

2.3.1 Busca tabu . . . . . . . . . . . . . . 46

2.3.2 Greedy randomized adaptive search procedure - GRASP . . 47

2.3.3 Recozimento simulado . . . . . . . . . . . . . . . . . . . 49

2.3.4 Algoritmos genéticos . . . . . . . . . . . . 51

2.3.5 Otimização baseada em colônia de formigas . . . . . . . . 52

2.4 Considerações finais . . . . . . . . . . . . . . . . . . 54

3 Meta-Aprendizado $\quad \mathbf{5 5}$

3.1 Definição do problema de seleção de algoritmos . . . . . . . . . . . 55

3.2 Aprendizado de máquina para o problema de seleção de algoritmos 58

3.3 Elementos de meta-aprendizado . . . . . . . . . . . . . 60

3.3.1 Meta-dados ................. 61

3.3 .2 Formas de recomendação . . . . . . . . . . . . 63

3.4 Considerações Finais . . . . . . . . . . . . . . 65

4 Meta-atributos para o PCV 67

4.1 Meta-atributos baseados em custo de vértice e de aresta . . . . . 68

4.2 Meta-atributos baseados em características das meta-heurísticas 69 
4.3 Meta-atributos baseados em landmarkers . . . . . . . . . . 72

4.4 Meta-atributos baseados em características de redes complexas . 74

4.5 Considerações finais . . . . . . . . . . . . . . . . 77

5 Experimentos $\quad 79$

5.1 Classificação multirrótulo em exemplos sintéticos de PCV . . . . 80

5.1 .1 Geração de meta-exemplos . . . . . . . . . . . . 80

5.1 .2 Indução dos meta-modelos . . . . . . . . . . . . . . . 82

5.1 .3 Resultados experimentais . . . . . . . . . . . . . . 84

5.2 Classificação multirrótulo em exemplos de PCV gerados a partir de arquivos da biblioteca TSPLIB . . . . . . . . . . 88

5.2 .1 Geração de meta-exemplos . . . . . . . . . . . . 88

5.2 .2 Indução dos meta-modelos . . . . . . . . . . . . . . . 89

5.2 .3 Resultados experimentais . . . . . . . . . . . . 90 90

5.3 Recomendação de ranking de $\mathrm{MHs} \ldots \ldots$. . . . . . . . 91

5.3.1 Geração de meta-exemplos . . . . . . . . . . . . . . 92

5.3 .2 Indução dos meta-modelos . . . . . . . . . . . . . . . 95

5.3.3 Resultados experimentais . . . . . . . . . . . . . . 95

5.4 Classificação por ranking de MHs para diferentes cenários de PCV 98

5.4.1 Geração de meta-exemplos . . . . . . . . . . . . 98

5.4 .2 Indução dos meta-modelos . . . . . . . . . . . . . . 99

5.4 .3 Resultados experimentais . . . . . . . . . . . . 100

5.5 Investigação de diferentes meta-atributos . . . . . . . . . 104

5.5 .1 Geração de meta-exemplos . . . . . . . . . . . 105

5.5 .2 Indução dos meta-modelos . . . . . . . . . . . . . 106

5.5.3 Resultados experimentais . . . . . . . . . . . . . 106

5.6 Considerações finais . . . . . . . . . . . . . . 118

6 Conclusões $\quad 119$

6.1 Contribuições. . . . . . . . . . . . . . . . . . . . 119

6.2 Trabalhos futuros . . . . . . . . . . . . . . 122

$\begin{array}{ll}\text { Referências } & 123\end{array}$

A Técnicas de AM Preditivas 133

A. 1 Métodos baseados em distâncias . . . . . . . . . . . . . . . . . 135

A.2 Métodos probabilísticos . . . . . . . . . . . . . . 137

A.3 Métodos baseados em procura . . . . . . . . . . . . . . . 138

A.4 Métodos baseados em otimização . . . . . . . . . . . . . . . . . 139

A.5 Classificação multirrótulo . . . . . . . . . . . . . . . . 141

$\begin{array}{ll}\text { B Resumo sobre seleção de atributos } & 145\end{array}$ 


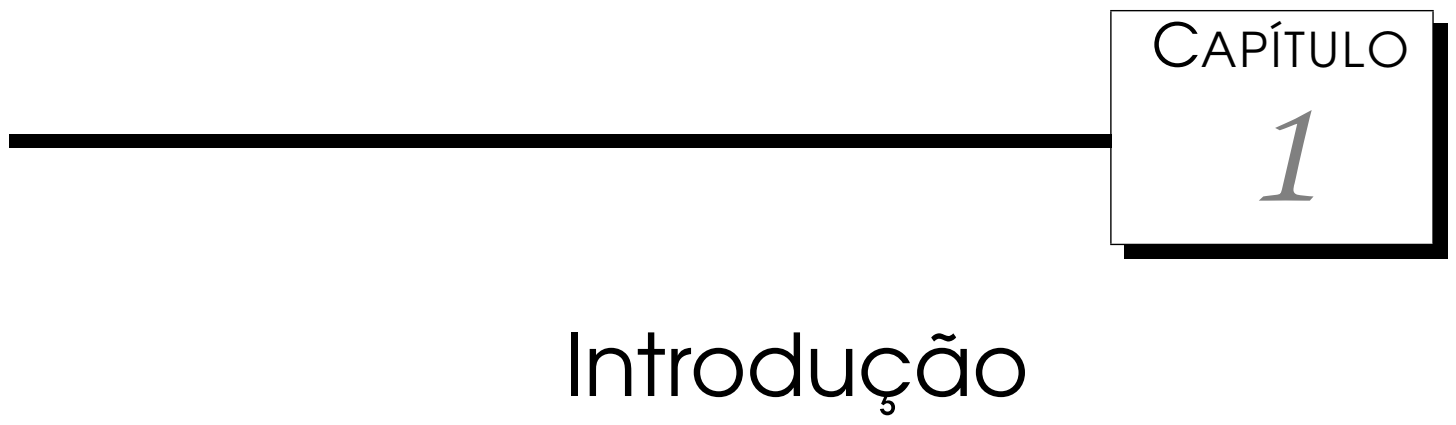

Em nossa vida cotidiana estamos sempre diante de situações em que é necessário realizar escolhas, e de preferência, escolhas corretas. A decisão sobre algo pode ser feita a partir de informações previamente analisadas e/ou baseadas em experiências anteriores.

A decisão baseada em informações é o resultado de um processo que identifica todas as possiveis alternativas e prevê as consequências de cada uma de acordo com um dado objetivo (Choo, 2003). No entanto, em situações emergenciais, pode não ser possível realizar todo esse processo devido a necessidade de uma decisão imediata. Nesse caso, as experiências adquiridas em situações parecidas podem ser muito relevantes para realizar a escolha que gere os melhores resultados.

Existem diversas situações em que a resolução de um problema depende da escolha da ferramenta apropriada, uma vez que o uso de outras ferramentas pode não proporcionar os resultados desejáveis. Por exemplo, usar um canhão para matar uma formiga pode até resolver o problema, mas com um custo muito maior comparado a ferramentas alternativas que resolvam o mesmo problema. Por outro lado, usar um estilingue para caçar um leão não é o mais recomendável, pois dificilmente o êxito desejado será alcançado.

Quando não sabemos antecipadamente qual a melhor ferramenta para um dado problema, muitas vezes recorremos a pessoas com experiência que já tenham resolvido problemas similares. Por exemplo, quando alguém fica doente, um médico deve ser consultado para indicar o tratamento mais apropriado para o reestabelecimento da saúde. Antes de indicar o melhor tratamento, o médico prepara um diagnóstico da doença baseado nos sintomas observados, resultados dos exames realizados e experiências de casos similares. 
Em diversas situações, muitas ferramentas podem estar à disposição para serem aplicadas a um problema particular, mas nem sempre é possivel recorrer a especialistas que tenham pleno conhecimento do problema. Nesses casos, é muito útil ter um sistema automatizado que auxilie a tomada de decisão com as melhores recomendações possíveis. Esse sistema pode realizar a recomendação a partir do conhecimento de diversas informações a respeito do problema. Segundo Tan et al. (2006), esse conhecimento é constituído por um conjunto de características relevantes do problema e pelos resultados obtidos por diferentes ferramentas quando aplicadas em problemas semelhantes.

A partir do advento dos sistemas computacionais, boas soluções para muitos problemas do mundo real puderam ser obtidas, uma vez que sua capacidade de armazenamento e processamento de informações é superior a do cérebro humano. O avanço contínuo da tecnologia, mais especificamente o aumento da velocidade dos processadores e a expansão da memória nos dispositivos de armazenamento, permitem que tais soluções sejam fornecidas mais rapidamente. No entanto, ainda existem muitos problemas como os de otimização em que, mesmo usando os computadores de última geração, não é possivel obter a melhor solução exata, denominada solução ótima global, em um intervalo de tempo aceitável.

Problemas de otimização podem ser encontrados em diversas aplicações, tais como: roteamento de veículos, fabricação de circuitos integrados, processo de cortes de materiais, dentre outros (Arenales et al., 2007). O sistema econômico capitalista, predominante nos dias atuais, impulsiona as empresas atuantes no mercado para a busca de boas soluções para seus problemas de otimização, tais como: a maximização das vendas de seus produtos e/ou serviços comercializados e a minimização dos custos de produção desses produtos e/ou serviços.

No mundo dos negócios, todo tempo é precioso e por isso as melhores ações estratégicas precisam ser decididas rapidamente. Logo, não é interessante para uma empresa esperar um longo período por um processamento computacional que indique a melhor decisão para um dado problema. A competitividade entre as empresas do mesmo ramo é tão grande que todas buscam se antecipar aos concorrentes e aos clientes com ações fortes de marketing. Essas ações buscam a conquista de novos clientes e a fidelidade dos clientes atuais. Em alguns ramos de negócio, o atendimento ao cliente é feito in loco, sendo necessário o deslocamento até o ponto onde o cliente está localizado. Por exemplo, uma empresa distribuidora de bebidas deve atender diariamente um subconjunto de seus clientes. Para realizar esse atendimento, a empresa deve planejar uma rota para visitar esses clientes, maximizando a satisfação dos mesmos e, sobretudo, minimizando os custos inerentes a essas visitas. 
Esse é um típico problema de roteamento de veículos para o qual pode ser usado uma formulação matemática que considere as variáveis e as restrições do problema. Esse problema real é, geralmente, formulado como um Problema do Caixeiro Viajante (PCV), com restrições adicionais.

O PCV é um problema clássico de otimização intensamente estudado para o qual existem diversas variações, aplicações e instâncias. Cada variação representa a combinação de diferentes propriedades do PCV, tais como: simetria dos custos de viagem, nível de conectividade entre as cidades, número de caixeiros, coleta de prêmios e restrição do tempo de atendimento e de viagem. Informalmente, uma instância de PCV é dada por um conjunto de cidades, um conjunto de conexões entre pares de cidades e valor do custo de viagem associado a cada conexão. Uma solução factível para o PCV é um ciclo hamiltoniano. Um ciclo é hamiltoniano se a rota inicia em uma das cidades do problema, visita as demais cidades uma única vez e retorna para a cidade inicial (Gutin e Punnen, 2002). Portanto, a melhor solução é o ciclo hamiltoniano de menor custo, que pode ser obtido por uma função objetivo que avalie cada solução representada por uma combinação de valores para as variáveis do problema (Arenales et al., 2007).

Devido à simplicidade em sua definição, a variação de PCV mais pesquisada pela comunidade científica é aquela que tem um único caixeiro, existe uma conexão para todo par de cidades, e o custo de viagem entre duas cidades é simétrico. A simetria de custo indica que o custo de sair de uma cidade A para uma cidade B é o mesmo de sair de B para A. Dentre as variações mais comuns, podemos ter o múltiplo PCV e o PCV com bônus. O primeiro indica a existência de incluir vários caixeiros, que no mundo real podem representar diferentes veículos usados ao mesmo tempo para atender diferentes subconjuntos de clientes (Bektas, 2006). O segundo contém um valor de benefício concedido ao caixeiro ao visitar cada cidade. Na prática, esse benefício pode representar um valor financeiro que deve ser recebido do cliente durante a visita (Balas, 2004).

Computacionalmente, o PCV pertence à classe dos problemas conhecida como NP-Difícil, porque o tempo computacional é não polinomial para encontrar a solução ótima para qualquer instância do PCV (Papadimitriou, 1977). A única garantia de obter uma solução ótima seria explorar todas as soluções factíveis e extrair uma das que tivessem gerado o melhor resultado de otimização. O número de diferentes soluções factíveis para uma instância de PCV simétrica e fortemente conectada é o resultado da função fatorial $(n-1)$ !/2, em que $n$ é o número de cidades (Winston, 1994). Por exemplo, para uma instância de PCV simétrica e fortemente conectada com apenas 20 cidades, existem aproximadamente $6,08 \times 10^{16}$ soluções factíveis, cujo processamento terminaria 
após 19 séculos em um computador com capacidade de processar um milhão de soluções por segundo. Esse resultado sugere que, mesmo usando os recursos computacionais mais avançados atualmente, uma busca exaustiva não é viável para ser aplicada para a maioria dos exemplos reais de $\mathrm{PCV}$.

Existem basicamente duas amplas abordagens para resolver um PCV: métodos exatos e métodos heurísticos. Os métodos exatos resolvem o problema de maneira exata procurando uma solução ótima global em todo o espaço de busca. Por isso, o uso desses métodos para as instâncias fortemente conectadas deve ficar restrito a instâncias com poucas cidades. Os métodos heurísticos tentam encontrar uma boa solução, não necessariamente a ótima global, no menor tempo possível. Desse modo, a escolha do método a ser aplicado para uma instância de PCV depende da variável que se deseja otimizar: qualidade da solução ou tempo de processamento. Essas variáveis representam, respectivamente, às seguintes questões: Qual o tempo de execução até que uma solução satisfatória seja obtida? Quão boa é a solução gerada após um tempo fixo de execução?

Muitos métodos heurísticos são capazes de encontrar boas soluções para diferentes instâncias do PCV (Gendreau e Potvin, 2010), sendo que cada um possui sua própria estratégia de busca. Um método heurístico pode ser visto como sendo um processo algorítmico que usa um procedimento de decisão particular baseado em uma estrutura de controle repetitivo (Burke et al., 2003). Uma subclasse de métodos heurísticos, denominada meta-heurística $(\mathrm{MH})$, é um método de solução que promove uma interação entre os processos de melhoria local e estratégias de pesquisa robusta no espaço de soluções com a finalidade de escapar das soluções ótimas locais de baixa qualidade (Gendreau e Potvin, 2010).

Dentre as principais MHs utilizadas para encontrar uma solução rápida para as diferentes variações e instâncias do PCV podem ser citadas: Busca Tabu (BT) (Glover et al., 1993), Greedy Randomized Adaptive Search Procedure (GRASP) (Feo e Resende, 1995), Recozimento Simulado, (SA, do inglês Simulated Annealing) (Kirkpatrick et al., 1983; Cerny, 1985), Algoritmos Genéticos (AGs) (Holland, 1973; Goldberg, 1989; Reeves e Yamada, 1998), Otimização baseada em Colônia de Formigas (OCF) (Dorigo e Gambardella, 1997) e Iteracted Local Search (ILS) (Besten et al., 2001).

Se diversas MHs são capazes de encontrar boas soluções de otimização para o PCV, qual MH deve ser selecionada para obter a melhor solução possível para uma nova instância de PCV? Essa questão é um típico problema de seleção de algoritmos (Rice, 1976). Como selecionar o algoritmo mais promissor, se é difícil saber com antecedência a solução que cada uma irá produzir para a instância desejada? Fazer uma escolha conservadora, selecionando sempre 
o mesmo algoritmo, pode não ser o mais apropriado, uma vez que nem sempre esse algoritmo irá produzir o melhor resultado para todas as instâncias. Essa afirmação é baseada no Teorema "No Free Lunch" (Wolpert e Macready, 1997), que garante a inexistência de um algoritmo universal capaz de sempre resolver, de melhor maneira que os demais, qualquer tipo de problema. O desempenho de qualquer algoritmo será sempre melhor para um determinado subconjunto de instâncias do problema e pior para os outros subconjuntos.

Uma maneira que pode conduzir a escolha correta do melhor algoritmo seria executar todos os algoritmos disponíveis para a instância desejada e, em seguida, selecionar aquele que tenha gerado a melhor solução. No entanto, a realização desse procedimento implica em um elevado custo computacional, que torna sua aplicação inviável em problemas reais. Diante desse contexto, um sistema de recomendação capaz de sugerir as MHs mais promissoras de maneira rápida e com elevado nivel de confiabilidade pode ser de grande utilidade. Basicamente, esse sistema deve ser capaz de aprender a partir de experiências anteriores e ter uma boa capacidade de prever qual a MH mais promissora para uma nova instância descrita por um conjunto de características fornecidas ao sistema.

\subsection{Objetivos}

Nesta tese, o problema de recomendação das MHs para novas instâncias de PCV é tratado como uma tarefa de aprendizado de máquina (AM). O objetivo principal dessa pesquisa é criar um sistema de recomendação de MHs baseado em meta-aprendizado capaz de predizer, com a maior acurácia preditiva possivel, as MHs mais promissoras para novas instâncias de PCV. O diagrama mostrado na Figura 1.1 ilustra as etapas necessárias para a construção do sistema recomendador de MHs. Cada etapa corresponde a um objetivo específico que deve ser alcançado para o sucesso deste trabalho.

Devido às inúmeras variações do PCV, o escopo desta pesquisa foi delimitado ao conjunto de exemplos de PCV fortemente ou fracamente conectados, podendo ser simétricos ou assimétricos. A primeira etapa da pesquisa consiste em selecionar as instâncias de PCV. Como a tarefa de indução de um modelo classificador requer uma grande quantidade de exemplos, optamos por gerar diversos subproblemas diferentes de PCV a partir de arquivos extraídos da biblioteca TSPLIB (Reinelt, 1991). Arquivos dessa biblioteca são geralmente usados para avaliar o desempenho de novos métodos de otimização.

A partir do conjunto de subproblemas do PCV, inicia-se a etapa da obtenção de meta-conhecimento, que consiste na extração de características do problema e na execução de um conjunto de MHs para obter as soluções para 


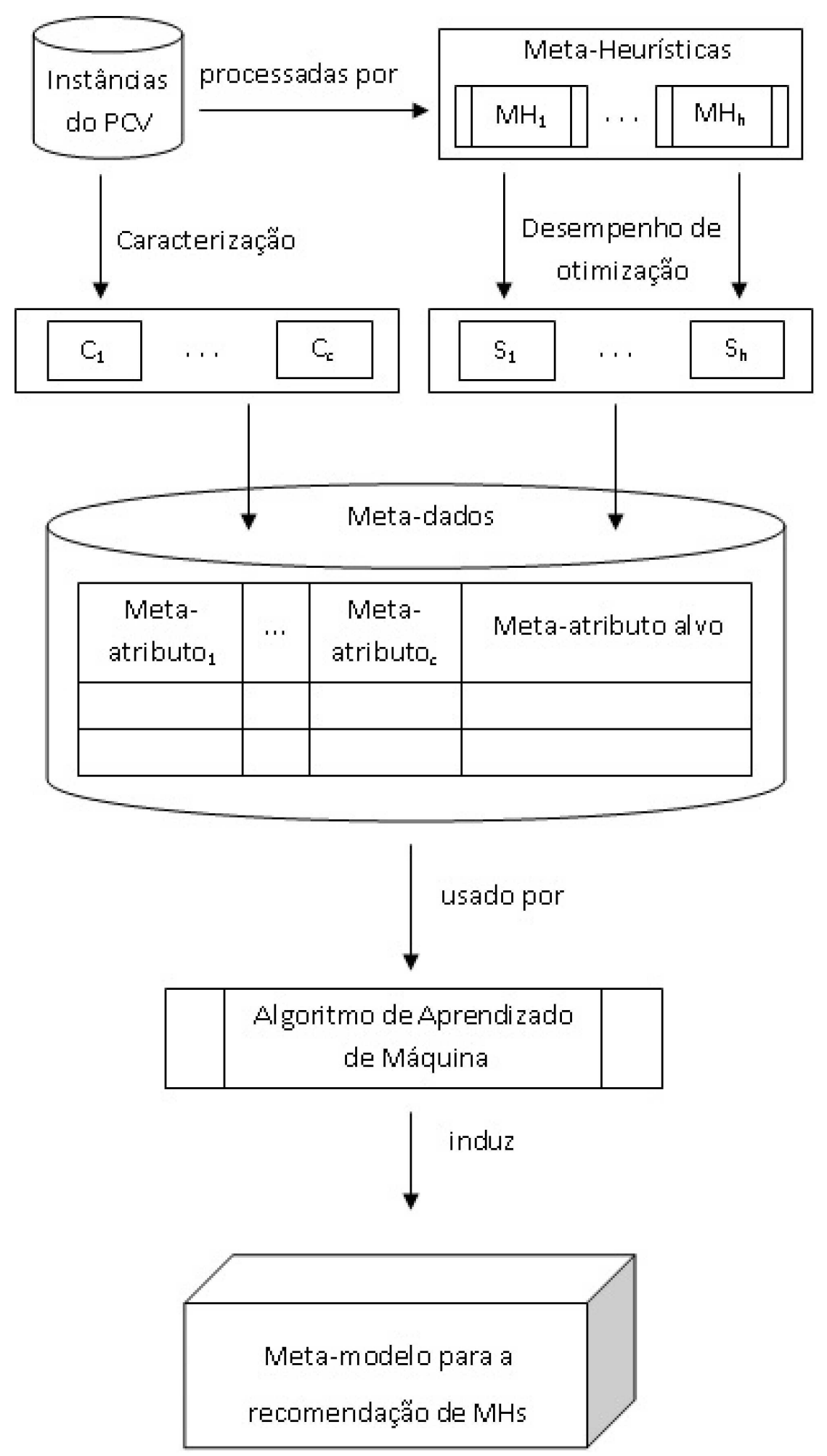

Figura 1.1: Diagrama esquemático para a indução de um meta-modelo que recomende as meta-heurísticas mais promissoras para uma instância de PCV.

os subproblemas gerados.

A etapa seguinte diz respeito à criação do conjunto de meta-dados representados por uma matriz cujas linhas são meta-exemplos e colunas são os meta-atributos preditivos e o meta-atributo alvo. Cada meta-exemplo corresponde a uma instância particular do PCV e os meta-atributos preditivos 
são características extraídas do problema usadas para descrever as instâncias. O meta-atributo alvo representa o desempenho de otimização das MHs de acordo com a solução provida por cada algoritmo para cada instância do PCV. Em nosso caso, o meta-atributo alvo é um conjunto ordenado das MHs mais promissoras para a instância do PCV.

Uma vez que se tenha gerado o conjunto de meta-dados, a próxima etapa é escolher um algoritmo de AM para a indução de um modelo preditivo, denominado meta-modelo. Existem diversas técnicas de AM que podem ser utilizadas para induzir um meta-modelo, porém cada uma tem o seu viés indutivo (Mitchell, 1997). Por isso, em nossa pesquisa, investigamos experimentalmente as técnicas de AM que são geralmente usadas na tarefa de aprendizado, tais como: K-vizinhos-mais-próximos (K-NN, do inglês K-Nearest-Neighbor), Árvore de Decisão (AD), Nä̈ve Bayes (NB), Máquina de Vetor de Suporte (SVM, do inglês Support Vector Machine) e Rede Neural Artificial (RNA) (Tan et al., 2006). Os algoritmos baseados nessas técnicas, que usamos em nossos experimentos preliminares, foram aqueles disponíveis no Software Weka (Hall et al., 2009). Em outros conjuntos de experimentos, usamos o Software R (Ihaka e Gentleman, 1996) para executar os algoritmos de AM e construir os meta-modelos.

O meta-modelo induzido pode ser usado para predizer o valor do metaatributo alvo para novas instâncias do PCV (Figura 1.2). Os resultados fornecidos pelo meta-modelo para cada meta-exemplo podem ser ordenados e, assim, um ranking de MHs pode ser recomendado para a instância submetida ao meta-modelo.

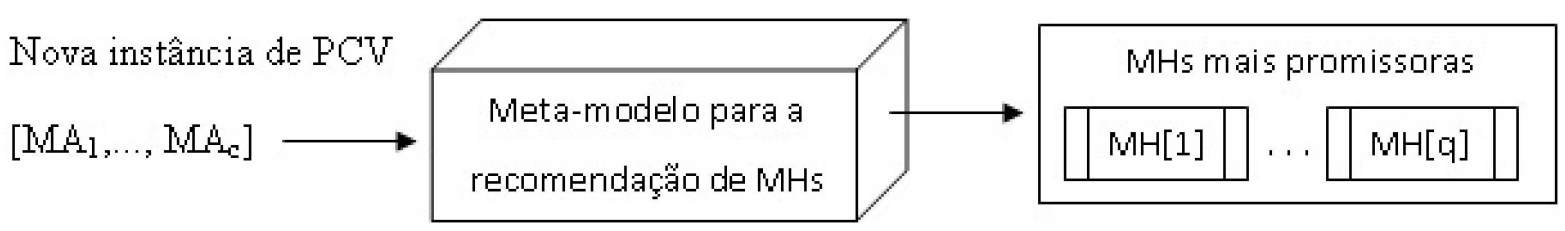

Figura 1.2: Diagrama esquemático para o uso do meta-modelo recomendador de meta-heurísticas para o PCV.

Um fator chave para ter um meta-modelo com alto desempenho preditivo é a identificação de uma função que mapeie corretamente os meta-atributos preditivos para o meta-atributo alvo. Por isso, propor e analisar diferentes conjuntos de meta-atributos preditivos para o PCV são também objetivos específicos desta tese.

Uma abordagem de seleção de heurística que se aproxima um pouco ao que foi desenvolvido nesta tese é a abordagem de hiper-heurísticas (Burke et al., 2003). Nesse trabalho, meta-aprendizado não foi explicitamente mencionado, mas as ideias subjacentes às hiper-heurísticas têm similaridades com os conceitos de AM. Nesse sentido, as hiper-heurísticas são usadas para escolher a melhor $\mathrm{MH}$ para resolver partes de um problema de otimização. Ao 
invés de ser feito uma medição das características do problema no espaço de busca, heurísticas simples são usadas para caracterizar a complexidade da instância do problema. Uma combinação linear ponderada de suas medidas de desempenho de otimização é usada para determinar a melhor MH que pode ser acionada em qualquer momento durante a busca dinâmica pela solução. Portanto, a ideia chave das hiper-heurística é aplicar MHs diferentes em etapas diferentes do processo de otimização levando em conta os pontos fortes de cada MH. No entanto, não há garantias de que sempre haverá interdependência entre as diferentes partes de um problema de otimização como o PCV.

\subsection{Principais contribuições}

O principal objetivo que foi estabelecido para este trabalho tem sido atingido. Os resultados empíricos obtidos por meios de experimentos controlados mostraram que o sistema de meta-aprendizado para recomendar MHs para o PCV tem tido um bom desempenho médio preditivo. Esse desempenho médio tem sido estatisticamente superior a de um modelo recomendador simples que, baseado no conhecimento prévio das soluções de otimização das MHs, indica as mesmas MHs para todas as instâncias de PCV. Essas MHs seriam aquelas com a melhor média de desempenho para o conjunto observado.

Dessa forma, as principais contribuições da pesquisa desenvolvida nesta tese foram:

- Uso de conceitos de meta-aprendizado para recomendar, dentre cinco MHs diferentes, a mais promissora para novas instâncias do PCV.

- Criação de conjuntos de meta-dados compostos por subproblemas de PCV gerados a partir de exemplos extraídos da biblioteca TSPLIB.

- Investigação de diferentes abordagens de classificação multirrótulos para a indução dos meta-modelos classificadores.

- Recomendação de ranking de MHs por meio de meta-modelos induzidos a partir de diferentes abordagens de redes perceptron multicamada.

- Avaliação da abordagem de meta-aprendizado na recomendação do ranking de MHs para instâncias do PCV em dois cenários do mundo real: revisitando clientes e prospectando novos clientes.

- Aplicação de testes estatísticos para avaliar o desempenho preditivo dos meta-modelos recomendadores de MHs. 
- Proposta de quatro conjuntos de meta-atributos preditivos para o PCV avaliados, experimentalmente, em meta-modelos induzidos a partir de diferentes algoritmos de AM.

- Análise da qualidade dos meta-atributos por meio da investigação do tempo necessário para a geração desses meta-atributos.

- Aplicação de técnica de seleção de atributos para obter o melhor subconjunto dos meta-atributos propostos.

\subsection{Organização da tese}

O restante desta tese está organizado conforme segue. Para introduzir a notação adotada nesta tese, o Capítulo 2 define o problema do caixeiro viajante (PCV) e explana os principais métodos heurísticos para resolvê-lo. O Capítulo 3 descreve brevemente o problema de seleção de algoritmos e apresenta alguns conceitos relacionados a meta-aprendizado. O Capítulo 4 mostra os conjuntos de meta-atributos que foram intensamente investigados nesta pesquisa. Os experimentos realizados para avaliar a proposta de pesquisa relacionada à esta tese estão detalhados no Capítulo 5, que também contém uma breve análise dos resultados obtidos. E, finalmente, o Capítulo 6 discorre sobre as considerações finais relativas à esta pesquisa, além de listar uma proposta sobre os trabalhos futuros. 


\section{$-2$ \\ Problema do Caixeiro Viajante}

Este capítulo contextualiza brevemente o Problema do Caixeiro Viajante (PCV), lista os principais trabalhos com PCV encontrados na literatura e alguns métodos heurísticos investigados para resolver instâncias desse problema. É importante salientar que não existe qualquer intenção de discutir aqui, de maneira exaustiva, todos os assuntos relacionados ao PCV, pois existem inúmeros trabalhos consolidados que analisam os diferentes aspectos do PCV de maneira detalhada. Somente para citar alguns, temos: (Applegate et al., 2011; Gutin e Punnen, 2002; Shmoys et al., 1985; Gavish, 1979). Neste capítulo é definida a notação matemática dos termos usados ao longo do texto para permitir que o leitor possa ter uma compreensão melhor sobre o assunto abordado.

\section{1 Contextualização}

Não há relatos na literatura que indiquem de maneira irrefutável a origem do Problema do Caixeiro Viajante (PCV), pois não há qualquer registro que informe quem foi o primeiro a usar o nome para esse problema (Applegate et al., 2011). No entanto, não há dúvidas entre os pesquisadores sobre o primeiro estudo divulgado para a solução desse problema. Em 1857, o matemático Willian Rowan Hamilton propôs um jogo formado por um dodecaedro no qual cada vértice representava uma importante cidade de sua região. O objetivo do jogo consistia em encontrar uma rota que iniciasse em uma dessas cidades, visitasse todas as outras cidades uma única vez e terminasse na cidade inicial. A partir dessa definição, uma solução possível para o PCV ficou conhecida como ciclo hamiltoniano (Applegate et al., 2011; Shmoys et al., 1985). 
A maneira mais simples para encontrar uma solução para o PCV foi inicialmente analisada pelo matemático Karl Menger (Menger, 1932). Em sua análise, ele não somente observou que a melhor solução do PCV poderia ser encontrada por um algoritmo que comparasse todas as possíveis soluções, como também percebeu que seria impossivel analisar todas essas soluções para as instâncias do problema com muitas cidades envolvidas. Por causa dessa impossibilidade e na tentativa de encontrar algum método para obter a melhor solução para o problema, ele usou a heurística da vizinhança mais próxima, também conhecida como heurística gulosa. O próprio pesquisador notou que, geralmente, essa estratégia não é capaz de produzir a melhor solução para todas as instâncias do problema.

Até hoje, ainda não se tem conhecimento sobre algum algoritmo eficiente que encontre rapidamente um ciclo hamiltoniano ótimo - uma solução ótima - para qualquer instância do PCV. Por essa razão, do ponto de vista computacional, o PCV é considerado um problema intratável (Winston, 1994). A definição de eficiência do algoritmo está relacionada com o tempo computacional necessário para que o algoritmo forneça a solução ótima. Desse modo, um algoritmo é eficiente quando é capaz de encontrar a solução ótima em um tempo computacional que seja igual a uma função polinomial $f(n)=c_{1} n^{g}+$ $c_{2} n^{g-1}+\ldots+c_{g}$, em que cada $c_{i}$ é uma constante e $n$ é o número que indica o tamanho da entrada do problema. O grau $g$ da função $f$ define a complexidade computacional para o algoritmo fornecer a sua solução. Essa complexidade é denotada por $O\left(n^{g}\right)$ (Edmonds, 1965). Para resolver exaustivamente uma instância do PCV, todas as soluções são investigadas e o número de soluções possiveis é igual ao resultado da função fatorial aplicado ao número de cidades envolvidas no problema. Quando $n$ assume valores grandes, temos: $n^{2}<$ $2^{n}<n$ !, indicando que o PCV é um problema de otimização combinatorial e a complexidade computacional para resolver grandes instâncias desse problema é mais que polinomial.

Boas soluções, próximas à solução ótima, para os problemas da classe $N P$-difícil (Papadimitriou, 1977) podem ser fornecidas por algoritmos baseados em métodos exatos ou em métodos heurísticos (Gendreau e Potvin, 2010). Os métodos exatos processam as soluções de forma determinística por meio de mecanismos subjacentes aos mesmos que direcionam as buscas no espaço de soluções. Os métodos heurísticos são aplicados quando não se tem um modelo exato ou quando o esforço computacional exigido para resolver o problema é superior à capacidade computacional. As heurísticas têm a vantagem de serem mais flexíveis para manipular problemas cujas características são difíceis de serem incorporadas em um modelo exato de otimização. Contudo, as heurísticas não podem garantir que uma solução ótima ou mesmo uma 
solução factível seja encontrada, pois muitas vezes não se conhece a solução ótima para comparar e avaliar a qualidade da solução gerada (Arenales et al., 2007).

Embora o PCV seja classificado como um problema $N P$-difícil, existem inúmeras aplicações no mundo real que podem ser modeladas por meio de PCV, tais como:

- planejamento de visita a clientes (Bell e McMullen, 2004);

- definição da rota de ônibus escolar (Park e Kim, 2010);

- indicação da rota para a entrega de cartas (Pearn e Chou, 1999);

- inspeções em plataformas petrolíferas (Cook et al., 1998);

- sequenciamento de DNA (Ben-Dor e Chor, 1997);

- agendamento de máquinas (Gilmore e Gomory, 1964);

- planejamento de cortes em indústria de vidros (Madsen, 1988);

- manufatura de circuitos de microchips (Barbagallo et al., 1996);

- processo de perfuração em dispositivos eletrônicos (Magirou, 1986);

- movimentação automática de telescópios para observações de fenômenos espaciais (Chlond, 2002);

- recolhimento de dados sísmico geofísico (Gutin et al., 2005);

- agrupamento de dados (Lenstra, 1974);

- organização de lista de reprodução de música em um dispositivo portátil (Pohle et al., 2005).

O PCV é um dos problemas de otimização combinatória mais bem conhecidos na área de pesquisa operacional. Existem inúmeros trabalhos sobre o PCV e suas variações. Uma busca com o termo "traveling salesman problem" no portal de periódicos da CAPES encontrou, em 10/10/2012, 7.693 resultados. Essas pesquisas geralmente enfatizam diferentes aspectos, tais como: criação de repositório com vários exemplos para cada tipo de PCV disponível na biblioteca TSPLIB (Reinelt, 1991), que também fornece o valor da solução ótima ou o valor da melhor solução obtida experimentalmente para muitos desses problemas.

Muitos estudos também têm sido publicados com a finalidade de apresentar novas técnicas de otimização para o PCV ou melhorar o desempenho de 
outras que já estão consolidadas pela comunidade científica, como por exemplo, a adaptação da heurística Lin-Kernighan (Kernighan e Lin, 1970) descrita em (Karapetyan e Gutin, 2011) para resolver o PCV generalizado. Para esse tipo de PCV, os autores também propõem novos algoritmos de busca local para identificar novos vizinhos de uma solução (Karapetyan e Gutin, 2012). Em (Patvichaichod, 2011), exemplos de PCV com arestas cujo valor do peso varia com o tempo são resolvidos a partir de um novo algoritmo genético específico para esse contexto. Liu (2010) discute a eficiência dos algoritmos genéticos para gerar diferentes soluções iniciais para o PCV probabilístico. Han e Zhu (2006) descrevem um método para resolver um PCV por meio da aplicação de técnicas de codificação de DNA. Modelos de PCV usados em um caso real são apresentados em (Donati et al., 2008), no qual o tempo é uma restrição fundamental no planejamento de rotas de veículos. O problema da identificação das melhores rotas para veículos que fazem entregas e coletas seletivas é formulado por meio de programação linear em (Gribkovskaia et al., 2008). Uma abordagem construtiva baseada em recozimento simulado para problemas de agendamento modelados a partir do PCV está descrita em (Mirabi, 2011).

Atualmente, os métodos mais eficientes para o problema de roteamento de veículos (PRV) são baseados em algoritmos Iterated Local Search (ILS) e algoritmos genéticos (Subramanian et al., 2012; Penna et al., 2011; Subramanian et al., 2010).

Outros trabalhos comparam diferentes técnicas de otimização. Rego et al. (2011) reportam resultados obtidos por diferentes algoritmos em um conjunto diversificado de PCV simétricos e assimétricos. Oncan et al. (2009) descrevem uma análise comparativa entre 24 formulações diferentes do PCV assimétrico. Kim e Jeong (2009) apresentam um mapeamento de uma rede de rodovias a partir da comparação da solução de otimização obtida por vários algoritmos. Gutin e Punnen (2002) analisam os aspectos de robustez, escalabilidade e qualidade da solução de diferentes heurísticas para PCV simétricos.

Embora exista um grande número de técnicas de otimização que podem ser utilizadas em PCV, a seleção da técnica mais promissora para uma dada instância do PCV é um problema em aberto. Dentre as alternativas propostas para essa seleção, podemos destacar as hiper-heurísticas (Burke et al., 2003), uma abordagem para escolher o melhor algoritmo para ser aplicado em uma determinada etapa da solução de um problema de otimização. A ideia principal inerente à hiper-heurística é aplicar diferentes MHs para diferentes partes ou fases do processo de solução de acordo com o ponto forte de cada uma. Uma possível desvantagem das hiper-heurísticas é a não garantia de que as melhores decisões isoladas irão proporcionar sempre uma boa solução para um problema de otimização. A abordagem descrita nesta tese parte do 
princípio de que apenas uma $\mathrm{MH}$, preferencialmente a mais promissora, será aplicada durante todo o processo de geração da solução.

\subsection{Notação matemática para problemas de otimi- zação}

Otimizar significa encontrar a melhor solução dentre todas as soluções possiveis que possam ser usadas para resolver um determinado problema. No mundo real, problemas de otimização podem ser encontrados em diversos domínios de aplicação, tais como: transporte, telecomunicações, indústrias, finanças e planejamento (Goldbarg e Luna, 2005). Dependendo da natureza do problema, a otimização pode ser um problema de minimização (ex.: menor custo de produção) ou de maximização (ex.: maior número de peças em um processo de corte) (Arenales et al., 2007).

A definição padrão de um problema de otimização linear (no caso, minimização) é dada por uma função linear $f$ a ser minimizada (Equação 2.1), além do conjunto de restrições descritas nas $m$ equações lineares (2.2) e das condições de não-negatividade das variáveis do problema (2.3).

$$
\operatorname{Minimizarf}\left(x_{1}, x_{2}, \ldots, x_{n}\right)=c_{1} x_{1}+c_{2} x_{2}+\ldots+c_{n} x_{n}
$$

sujeito a:

$$
\begin{gathered}
a_{11} x_{1}+a_{12} x_{2}+\ldots+a_{1 n} x_{n}=b_{1} \\
a_{21} x_{1}+a_{22} x_{2}+\ldots+a_{2 n} x_{n}=b_{2} \\
\vdots \\
a_{m 1} x_{1}+a_{m 2} x_{2}+\ldots+a_{m n} x_{n}=b_{m} \\
x_{1} \geq 0, x_{2} \geq 0, \ldots, x_{n} \geq 0 .
\end{gathered}
$$

em que:

- $x_{1}, x_{2}, \ldots$ e $x_{n}$ são variáveis;

- $c_{1}, c_{2}, \ldots$ e $c_{n}$ são custos;

- $a_{11}, \ldots, a_{1 n}, \ldots, a_{m 1}, \ldots$ e $a_{m n}$ são coeficientes;

- $b_{1}, b_{2}, \ldots$ e $b_{m}$ são termos independentes; 
Uma solução para um problema de otimização (minimização ou maximização) é denominada factivel $\left(x_{1}, x_{2}, \ldots, x_{n}\right)$ quando satisfaz todas as restrições pertinentes ao problema. Uma solução factivel é uma solução ótima $\left(x_{1}^{*}, x_{2}^{*}, \ldots\right.$, $x_{n}^{*}$ ) para um problema de minimização quando a função $f$ aplicada à solução ótima fornece um valor menor ou igual ao valor da mesma função quando aplicada a qualquer outra solução factível (2.4).

$$
f\left(x_{1}^{*}, x_{2}^{*}, \ldots, x_{n}^{*}\right) \leq f\left(x_{1}, x_{2}, \ldots, x_{n}\right)
$$

Se o problema de otimização é de maximização, uma solução ótima corresponde ao valor máximo da função objetivo $f$, que deve ser maior ou igual ao valor resultante dessa função quando aplicada a qualquer outra solução factível.

Um dos tipos de otimização linear é a otimização discreta ou otimização combinatória, também conhecida como otimização linear inteira, uma vez que as variáveis assumem somente valores inteiros. Um exemplo clássico de problema de otimização linear inteira é o PCV, em que as variáveis assumem valores binários, indicando se duas cidades são ou não adjacentes na rota indicada pela solução. Geralmente, um exemplo de PCV é representado por meio de grafo. Os conceitos básicos de grafos, necessários para este trabalho, são descritos na próxima seção.

\subsubsection{Grafos}

Formalmente, um grafo é definido por um par $G=(V, E)$, onde $V=\left\{v_{1}, v_{2}\right.$, $\left.\ldots, v_{n}\right\}$ é o conjunto de nós (ou vértices) e $E=\left\{\left(v_{i}, v_{j}\right)\right\}$ é o conjunto de arestas ou arcos, tal que os elementos de $E$ são subconjuntos de 2-elementos de $V, E$ $\subseteq V \times V$. O modo usual para representar um grafo é desenhando um círculo para cada vértice $v_{i} \in V$ e uma linha unindo dois desses círculos para cada aresta $\left(v_{i}, v_{j}\right) \in E$ (Diestel, 2010). A Figura 2.1 ilustra um exemplo de grafo não direcionado ou não orientado que possui quatro vértices $V=\{1,2,3,4\}$ e seis arestas $E=\{(1,2),(1,3),(1,4),(2,3),(2,4),(3,4)\}$.

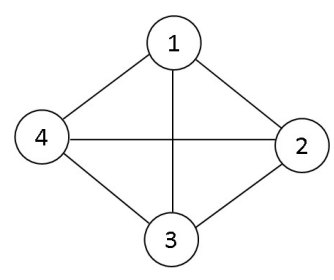

Figura 2.1: Exemplo de grafo.

Dois vértices $v_{i}, v_{j} \in V$ são adjacentes, ou vizinhos, se a aresta $\left(v_{i}, v_{j}\right) \in E$. Em um arco $\left(v_{i}, v_{j}\right)$, o vértice $v_{j}$ é adjacente ao vértice $v_{i}$, mas o vértice $v_{i}$ não é adjacente ao vértice $v_{j}$. Para $v_{i}$ também ser adjacente a $v_{j}$, o arco $\left(v_{j}, v_{i}\right)$ deve 
também pertencer ao conjunto $E$. Nesse caso, os dois arcos que conectam o mesmo par de vértices, mas com origens diferentes, formam uma aresta bidirecional ou não-orientada (Diestel, 2010). As arestas do grafo ilustrado na Figura 2.1 são exemplos de arestas bidirecionais.

Um grafo $G$ é denominado completo se para todos os pares de vértices $\left(v_{i}, v_{j}\right)$ $\in G, v_{i}$ é adjacente a $v_{j}$. Um exemplo de grafo completo é aquele ilustrado na Figura 2.1.

O grau $g\left(v_{i}\right)$ de um vértice $v_{i}$ em um grafo não orientado é igual ao número de vértices adjacentes a $v_{i}$. Se $G$ é um grafo completo, o grau $g\left(v_{i}\right)$ é o mesmo para todo $v_{i} \in \mathrm{G}$ e, nesse caso, $G$ é um grafo regular de grau $g(G)=g\left(v_{i}\right)$. O grafo ilustrado na Figura 2.1 é regular de grau $g(G)=3$. Em grafos unidirecionais, o grau de um vértice é decomposto em grau de entrada e grau de saída, que representam o número de arestas chegando ao vértice e o número de arestas saindo do mesmo vértice, respectivamente. Por exemplo, o vértice 1 do grafo ilustrado na Figura 2.2 tem grau de entrada igual a 1 e grau de saída igual a 2.

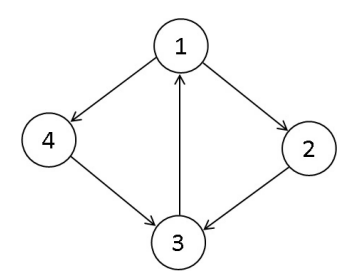

Figura 2.2: Representação de um grafo orientado.

A partir de um grafo $G=(V, E)$, pode ser obtido um subgrafo $G^{\prime}=\left(V^{\prime}, E^{\prime}\right)$ desde que $V^{\prime} \subseteq V$ e $E^{\prime} \subseteq E$. Logo, se $\left(v_{i}, v_{j}\right) \in E^{\prime}$ então $v_{i}, v_{j} \in V^{\prime}$.

Algumas definições relativas à identificação de percurso em um grafo extraídas de (Arenales et al., 2007) são descritas a seguir:

- Caminho é uma sequência de $\operatorname{arcos} C=\left\{\left(v_{1}, v_{2}\right),\left(v_{2}, v_{3}\right), \ldots,\left(v_{k-1}, v_{k}\right)\right\}$ na qual todos os $k$ vértices são distintos, tal que $k \leq n$. Em um caminho, o vértice final de cada aresta é o vértice inicial da aresta imediatamente posterior contida na sequência. Na Figura 2.1 , a sequência $C=\{(1,3),(3,4),(4,2)\}$ é um exemplo de caminho.

- Circuito é uma sequência como o caminho, mas contém uma aresta unidirecional que conecta o $k$-ésimo vértice com o primeiro vértice do caminho, como, por exemplo, a sequência $\{(1,3),(3,4),(4,1)\}$ contida no grafo da Figura 2.1.

- Cadeia é uma sequência em que um dos vértices de cada arco corresponde a um dos vértices do arco posterior. Por exemplo, a sequência $C=$ $\{(3,1),(4,3)\}$, extraída da Figura 2.2, é uma cadeia. 
- Ciclo é uma cadeia em que o último arco contém um dos vértices contido no primeiro arco, tornando a sequência fechada. Por exemplo, a cadeia $C=\{(3,1),(4,3),(1,4)\}$, no grafo da Figura 2.2, é um ciclo.

Um grafo $G$ é dito ponderado quando cada uma das arestas $\left(v_{i}, v_{j}\right) \in G$ está associada a um valor de peso $c_{i j}$.

A modelagem matemática de um grafo é geralmente feita por meio da matriz de incidência $M$ de ordem $n$, em que $n$ é o número de vértices contidos no grafo (Szwarcfiter, 1984). Um elemento $m_{i j}$ da matriz $M$ assume valor igual a 1, se $\mathrm{o}$ arco $\left(v_{i}, v_{j}\right) \in E$ e assume valor igual a 0 , caso contrário.

\subsubsection{Definição formal do PCV}

Formalmente, um exemplo clássico de PCV é definido por meio de um grafo $G=(V, E)$, em que $V=\left\{v_{1}, v_{2}, \ldots, v_{n}\right\}$ é o conjunto de vértices e $E=\left\{e_{i j}\right\}$ é o conjunto de arestas, $\forall i, j \in V$ e $i \neq j$. Cada vértice $v_{i} \in V$ representa uma cidade do problema e cada aresta $e_{i j} \in E$ indica que existe uma conexão direta entre as cidades adjacentes representadas pelos vértices $v_{i}$ e $v_{j}$. Cada aresta $e_{i j}$ está associada a um valor de peso que representa o custo de viagem $c_{i j}$ entre as cidades adjacentes $v_{i}$ e $v_{j}$ (Gutin e Punnen, 2002). Os valores de peso das arestas são resultantes da função custo $(c: E \rightarrow \Re)$, que mapeia cada aresta a um valor do conjunto dos números reais.

A Figura 2.3 ilustra um grafo que representa um exemplo de PCV com seis cidades completamente interconectadas.

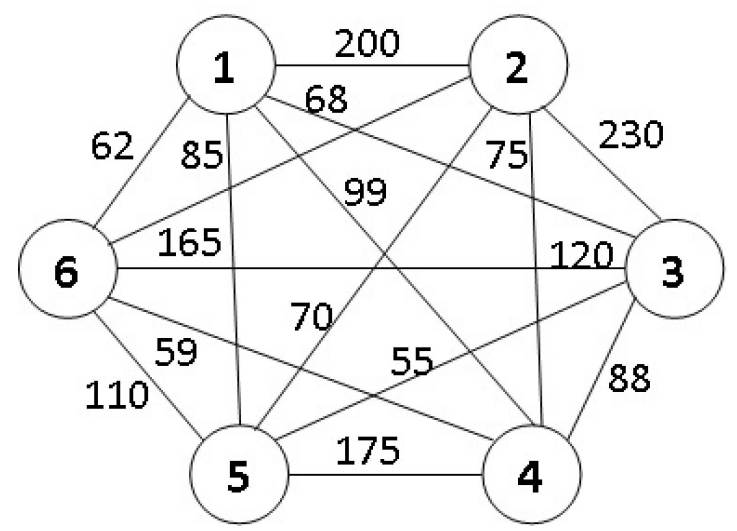

Figura 2.3: Exemplo de PCV modelado por grafo.

Uma formulação matemática do PCV simétrico descrita em (Arenales et al., 2007) é dado a seguir:

$$
\text { Minimizarf }=\sum_{i=1}^{n} \sum_{j>i}^{n} c_{i j} x_{i j}
$$

sujeito a: 


$$
\begin{array}{cl}
\sum_{i=1}^{n} x_{i j}=1 & \forall j \in V \\
\sum_{j=1}^{n} x_{i j}=1 & \forall i \in V \\
\sum_{i, j \in S} x_{i j} \leq|S|-1 & \forall S \subset G, S \neq \emptyset \\
x_{i j} \in\{0,1\} & \forall i, j \in V
\end{array}
$$

em que:

$x_{i j}$ é uma variável binária que assume valor 1 , se aresta $e_{i j}$ pertence à solução do problema e 0 , caso contrário;

$c_{i j}$ é um valor que representa o custo de viagem da cidade $i$ para a cidade $j$;

$S$ é um subgrafo de $G$, em que $|S|$ corresponde ao número de vértices nesse subgrafo.

A solução ótima do PCV é dada pelo conjunto de arestas que fazem parte da rota cujo custo é o menor possível. Essas arestas minimizam a função objetivo $f(2.5)$ e não violam as restrições previamente definidas. As restrições (2.6) e (2.7) garantem que todas as cidades na solução gerada são conectadas somente a uma cidade antecessora e a uma sucessora, respectivamente. No entanto, essas duas restrições não são suficientes para garantir que a solução gerada seja um ciclo hamiltoniano, uma vez que podem existir sub-rotas desconexas da origem, conforme mostra o exemplo ilustrado na Figura 2.4a. Para evitar a formação de ciclos ou circuitos desconexos da origem, as restrições (2.8) devem ser observadas ao gerar uma solução. Essas restrições garantem que o número de arestas em um subgrafo é sempre menor que o número de vértices contidos nesse subgrafo. Desse modo, evita-se o uso da aresta que forma um ciclo no subgrafo (Figura 2.4b).
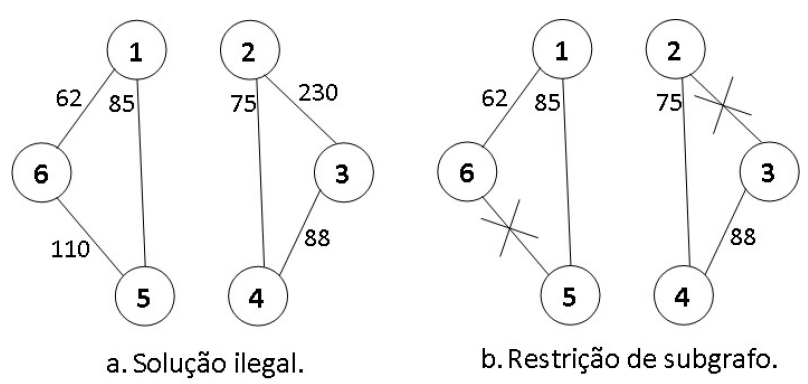

Figura 2.4: Restrições de cardinalidade. 


\subsubsection{Variações do PCV}

Apesar da definição do PCV ser bastante simples - tendo basicamente três elementos essenciais: vértices, arestas e custos - existem muitas variações para esse tipo de problema. A variação mais simples do PCV é a simétrica fortemente conectada. Uma instância de PCV é simétrica quando o custo de viagem entre duas cidades adjacentes é o mesmo independente da cidade inicial. E a instância é fortemente conectada se existe uma conexão para qualquer par de cidades. No entanto, existem outras características que também têm sido consideradas por causa da tentativa de obter modelos mais próximos do mundo real, tais como: múltiplos caixeiros, variação do custo ao longo do tempo, custo de entrega e coleta, ganho de bônus e janela de tempo (Arenales et al., 2007; Goldbarg e Luna, 2005).

Algumas variações do PCV são brevemente descritas a seguir:

- Simétrico. A viagem entre duas cidades adjacentes têm o mesmo custo, independente da cidade em que se inicia a viagem. Matematicamente, esta propriedade corresponde à $c_{i j}=c_{j i} \forall e_{i j} \in E$.

- Assimétrico. O sentido de deslocamento entre as cidades é relevante, tanto que o grafo que modela essa variação de PCV possui arestas orientadas. Em notação matemática, a assimetria é identificada por: $\exists e_{i j} \in E$ tal que $c_{i j} \neq c_{j i}$.

- Fortemente conectado. Todos os vértices são adjacentes a qualquer outro vértice. $\forall v_{i}, v_{j} \in V, \exists e_{i j} \in E$.

- Fracamente conectado. Caracterizado pela ausência de uma ou mais arestas. Existe, pelo menos, um par de vértices não adjacentes. $\exists v_{i}, v_{j} \in V$ tal que $e_{i j} \notin E$.

- Múltiplos caixeiros. Para esse tipo de PCV, vários caixeiros são considerados para uma mesma instância do problema. Os caixeiros devem realizar rotas diferentes visitando cidades diferentes. Em uma situação prática, considere uma empresa distribuidora de refrigerantes que possui vários veículos (caixeiros) para realizar a entrega em diferentes clientes (cidades). Todos os veículos iniciam suas rotas a partir do depósito da empresa (cidade inicial). Em seguida, cada um segue uma rota para visitar um subconjunto diferente de clientes e, ao final, todos retornam ao depósito (Bektas, 2006).

- Variação de custo. Para facilitar o uso de algoritmos para resolver as instâncias de PCV, normalmente, os custos de viagem entre as cidades são pré-determinadas. No entanto, a variação de custo ao longo do tempo 
pode ser considerada nos modelos dos problemas do mundo real, em que a mobilidade nas vias públicas das cidades depende de vários fatores como: horário do tráfego, interdição de vias, acidentes de trânsito, dentre outros (Patvichaichod, 2011).

- PCV com Bônus. Um bônus representa um valor de benefício que o caixeiro deve receber em cada cidade visitada. Nesse caso, o caixeiro deve visitar um subconjunto de cidades com o objetivo de minimizar o custo total e maximizar os bônus recolhidos. Na prática, essa variação de PCV pode ser usada para modelar a rota que uma empresa precisa fazer para receber pagamentos de seus clientes (Balas, 2004).

- Entrega e coleta. As paradas nos locais visitados significam que são feitas entregas e/ou coletas (Subramanian et al., 2010). O planejamento da rota consiste em minimizar os custos considerando o atendimento a todos os clientes, além das restrições da capacidade do veículo e do tempo disponível (Lim et al., 2005). Um exemplo prático para este tipo de PCV é o serviço de transporte escolar.

- Ganho de bônus. Não há necessidade de visitar todas as cidades da rota. O caixeiro ganha prêmios para cada cidade visitada e paga uma penalidade por cada cidade que deixou de visitar (Balas, 2004). O objetivo consiste em obter uma rota que minimize os custos de viagem e as penalidades, desde que tenha sido coletada uma quantidade mínima de prêmios ao fim da rota. Usando novamente o exemplo da empresa distribuidora de refrigerantes, podemos considerar que a penalidade em cada cidade é a venda não realizada por não visitar um cliente. O prejuízo gerado pela não venda pode ser insignificante para a empresa diante de uma quantidade de vendas efetivadas ao atender outros clientes (prêmios maiores).

- Janela de Tempo. O caixeiro deve chegar a cada cidade em um horário que esteja dentro de um intervalo de tempo denominado janela de tempo (Wang e Regan, 2009). Essa é uma restrição importante que influencia diretamente a ordem de visita aos clientes. Sendo assim, a função objetivo deve ser minimizada considerando o limite de cada janela de tempo previamente estabelecido para cada vértice.

- PCV Periódico. Um planejamento de rotas pode ser feito visando uma programação de visitas para vários dias. Em cada dia, vários clientes devem ser atendidos. Cada cliente pode ser visitado mais de uma vez, desde que não seja no mesmo dia. As rotas são planejadas para minimizar o custo total nos dias planejados (Hemmelmayr et al., 2009). 
- PCV com Custo de atraso. Variante do PCV, em que o custo de aresta $e_{i j}$ depende da próxima visita na rota (Silva et al., 2012).

- PCV Agrupado. Variante do PCV, em que o conjunto de vértices $V$ é particionado em grupos disjuntos (Mestria et al., 2012).

Para resolver os exemplos de PCV e suas variações, os métodos de otimização mais usados se enquadram nas seguintes abordagens: heurísticas construtivas, heurísticas de busca local e meta-heurísticas (Gutin e Punnen, 2002). A seção seguinte descreve os procedimentos inerentes a cada uma dessas abordagens.

\subsection{Abordagens para resolver o PCV}

Heurísticas construtivas são técnicas que geram uma solução a partir de um processo incremental. Esse processo consiste, em cada iteração do algoritmo, encontrar o elemento mais promissor (melhor solução local) para ser inserido na solução que está sendo construída. A heurística gulosa é um exemplo de heurística construtiva (Applegate et al., 2011). O pseudocódigo de uma heurística construtiva é ilustrado pelo Algoritmo 1. O tempo de execução é um aspecto positivo das heurísticas construtivas, porém a solução gerada para a maioria dos casos não tem uma boa qualidade. Isso ocorre porque a solução é gerada a cada iteração selecionando o elemento mais promissor de acordo com um dado critério. No entanto, à medida que a solução vai sendo construída, restringe-se os elementos que podem ser usados para compor a solução. O último elemento selecionado, em que há somente um único candidato para completar o ciclo, geralmente é o que influencia para que a solução composta não tenha uma boa qualidade.

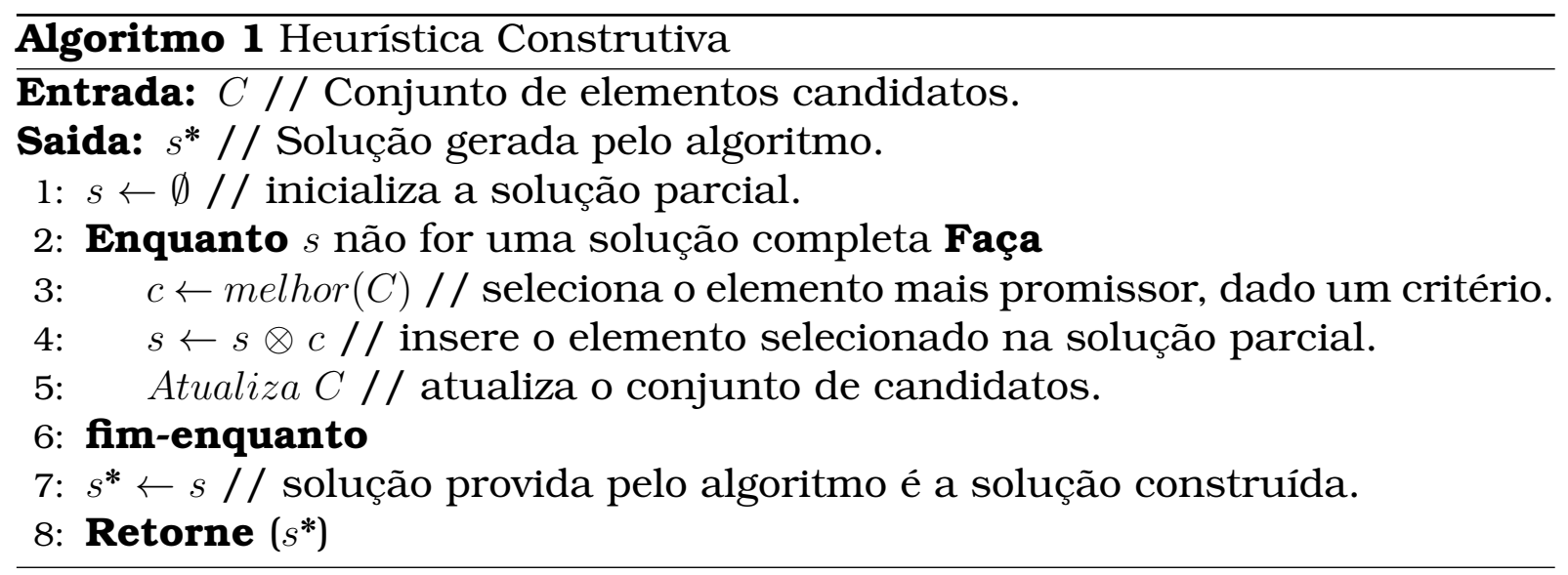

Heurísticas de busca local são técnicas que procuram por soluções melhores do que aquela obtida pela heurística construtiva. Por isso, são também 
conhecidas como heurísticas de refinamento. Para encontrar soluções melhores, são realizadas buscas na região de vizinhança $N(s)$ da solução corrente $s$. Toda solução vizinha $s^{\prime} \in N(s)$ é alcançada pela solução corrente $s$ por meio de uma operação denominada movimento. Um exemplo de heurística de busca local é a heurística 2-opt (Lin e Kernighan, 1973), que substitui duas arestas não adjacentes da solução $s$ por outras duas, de modo que a solução $s$ ' seja também factível. Se a melhor solução do conjunto de soluções vizinhas, $s^{*} \in N(s)$, for melhor que a solução corrente, $s^{* *}$ passa a ser a nova solução corrente. O processo é repetido até que não haja mais mudança na solução corrente. O Algoritmo 2 ilustra o pseudocódigo de uma heurística de busca local. Embora as soluções fornecidas por essa heurística seja, geralmente, melhores do que aquelas processadas por uma heurística construtiva, não há garantias de que uma solução ótima global seja encontrada. Além disso, o tempo computacional é maior devido a busca realizada em toda a vizinhança para cada nova solução gerada.

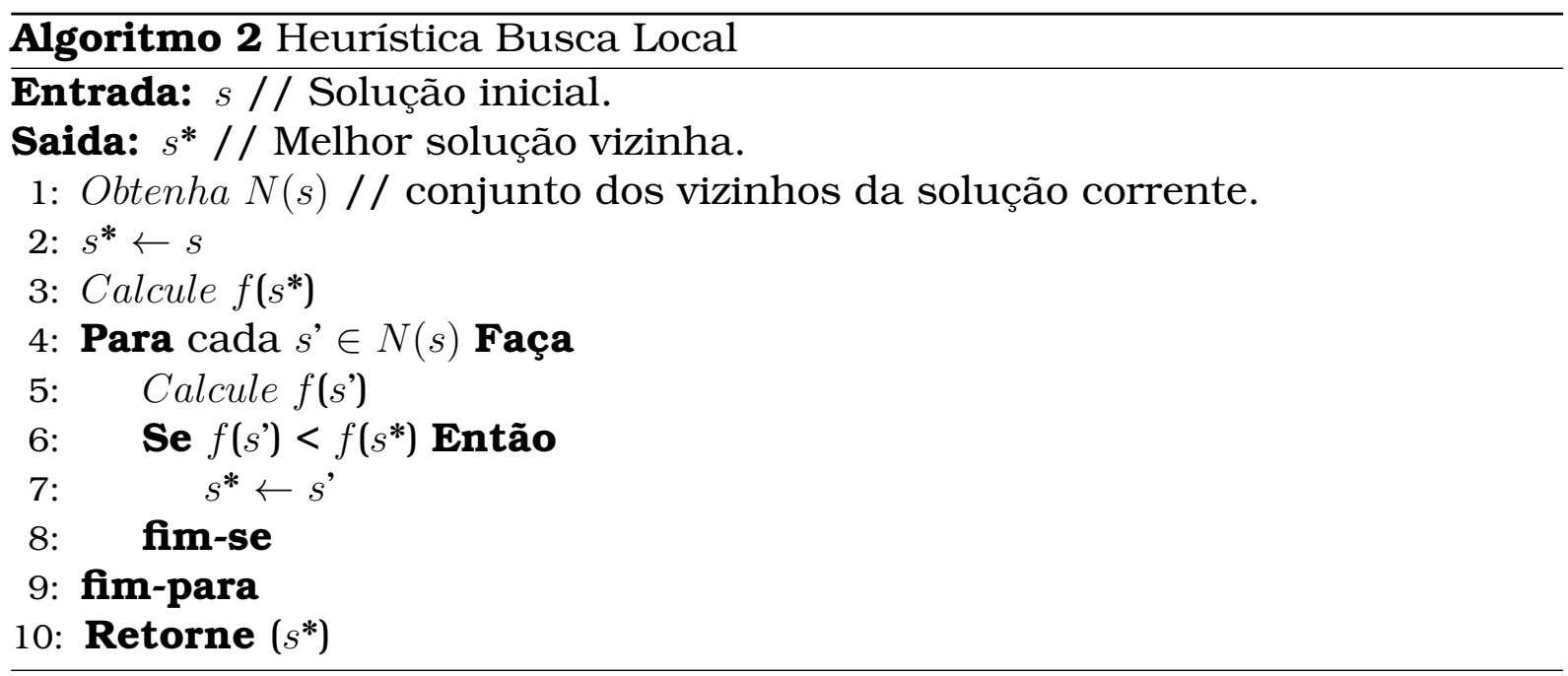

Meta-heurísticas (MHs) são estratégias de alto nível que guiam uma heurística subjacente para um problema específico a fim de aumentar o seu desempenho (Stützle, 1999). MHs são também definidas como técnicas que processam uma interação entre os procedimentos de melhoria local e estratégias de alto nível para criar um mecanismo capaz de escapar das soluções ótimas locais de baixa qualidade e realizar uma busca robusta no espaço de soluções (Gendreau e Potvin, 2010). O principal objetivo de usar MHs é tentar escapar da armadilha do ótimo local de baixa qualidade. Isso é possivel com a permissão de movimentos da solução corrente para outras piores. Muitas MHs confiam em decisões probabilísticas realizadas durante o procedimento de busca. A principal diferença entre a busca aleatória pura e as realizadas por MHs é que as MHs não usam a aleatoriedade cegamente, mas em uma forma enviesada inteligente (Burke et al., 2003). As principais MHs para o PCV usadas em nossos experimentos são descritas a seguir: 


\subsubsection{Busca tabu}

A MH busca tabu (BT) foi originalmente proposta por Glover (Glover, 1989) para resolver com boas soluções, próximas à solução ótima global, problemas de otimização combinatória como o PCV

A BT é baseada em busca local e tem como princípio básico prosseguir a busca em outras regiões mesmo que uma solução ótima local tenha sido encontrada. Esse processo, denominado diversificação, permite a movimentação da solução corrente para outras piores, evitando que a busca fique restrita a uma determinada região do espaço de soluções. Para isso, BT usa uma estrutura de memória, denominada lista tabu que armazena as últimas soluções processadas. O uso dessa memória serve para evitar que a solução se movimente para outra que já tenha sido listada em iterações recentes. $O$ pseudocódigo da BT está descrito no Algoritmo 3.

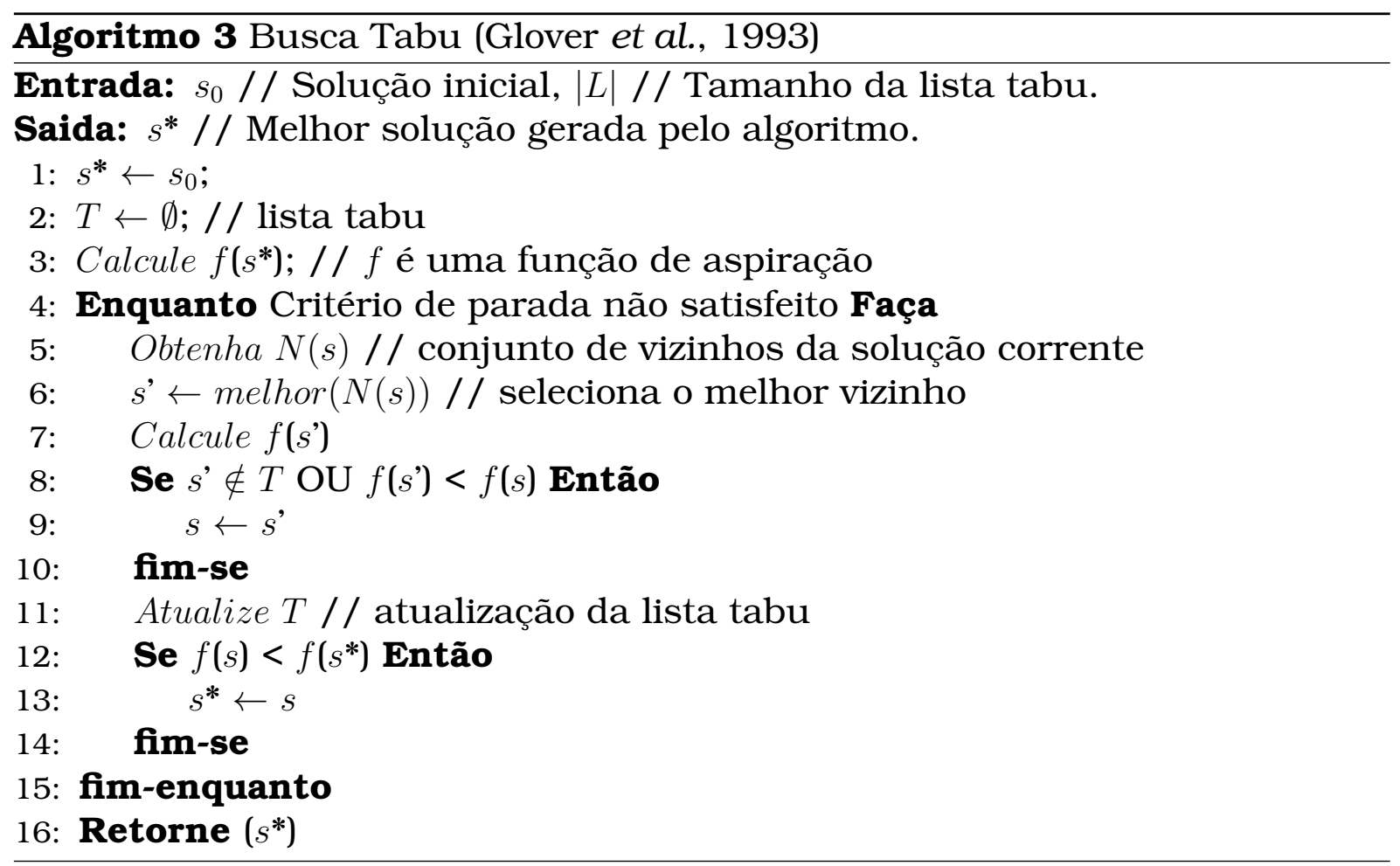

A partir de uma solução inicial, a primeira solução corrente, todas as soluções vizinhas são avaliadas e a melhor é selecionada. Se a solução vizinha selecionada não estiver na lista tabu, ela é transformada em solução corrente mesmo sendo pior do que a solução corrente. A lista tabu é uma memória de curto prazo e, normalmente, apenas uma quantidade fixa e bastante limitada de informação é gravada. Essa quantidade corresponde ao tamanho da lista tabu, que é previamente definido em um dos parâmetros de entrada do algoritmo. Enquanto as soluções estiverem na lista tabu, elas não podem ser transformadas em solução corrente. No entanto, a proibição de movimentos para soluções que estejam na lista tabu pode também impedir o movimento 
para soluções promissoras. Por isso, a condição tabu pode ser violada desde que um critério de aspiração seja satisfeito como, por exemplo, a solução vizinha ter uma qualidade melhor do que a solução corrente. Uma nova iteração do algoritmo é realizada a partir da investigação das soluções vizinhas da nova solução. Dentre os critérios de parada da busca tabu, os mais comuns são quando o algoritmo atinge um número máximo de iterações, extrapola um tempo máximo de processamento, processa um número de iterações sem melhoria na solução corrente ou encontra uma solução de qualidade superior a um dado limiar.

Dentre os aspectos positivos da BT, é possivel destacar:

- A lista tabu é usada para tentar evitar que o algoritmo gere ciclos e para permitir a exploração de outras regiões promissoras;

- O algoritmo converge rapidamente para uma solução de boa qualidade próxima a uma solução ótima.

Em relação aos seus aspectos negativos, temos:

- A busca converge rapidamente para uma solução ótimo local, mesmo que a lista tabu usada seja extensa;

- A procura não é discriminadora, ou seja, a solução gerada depende do ponto em que se inicia o processo de otimização.

\subsubsection{Greedy randomized adaptive search procedure - GRASP}

GRASP é uma MH que gera uma solução a cada iteração para resolver problemas de otimização combinatória. O procedimento de geração de soluções tem duas fases: construção e busca local (Feo e Resende, 1995). O primeiro é responsável por construir uma solução factivel e o segundo procura por soluções melhores na região de vizinhança da solução construída.

O pseudocódigo do GRASP está descrito no Algoritmo 4, enquanto os procedimentos para construir uma solução é mostrado no algoritmo 5 .

Na fase de construção, a solução inicial é um conjunto vazio, e um conjunto $C$ de elementos candidatos é gerado para compor a solução. A cada iteração, cada elemento candidato $c \in C$ é associado a um valor $g(c)$ que mensura o benefício de inserir esse elemento na solução que está sendo construída. Uma vez calculados os valores de benefício para todos os candidatos, o valor do parâmetro $\alpha \in[0,1]$ determina a lista de candidatos restritos, LCR = $\{c \in C \mid g(c) \leq \min \{g(c) \mid c \in C\}+\alpha(\max \{g(c) \mid c \in C\}-\min \{g(c) \mid c \in C\})\}$. O parâmetro $\alpha$ controla o nível de gula e aleatoriedade durante a seleção do candidato. Para problemas de minimização, quanto menor o valor de $\alpha$, maior é a chance 

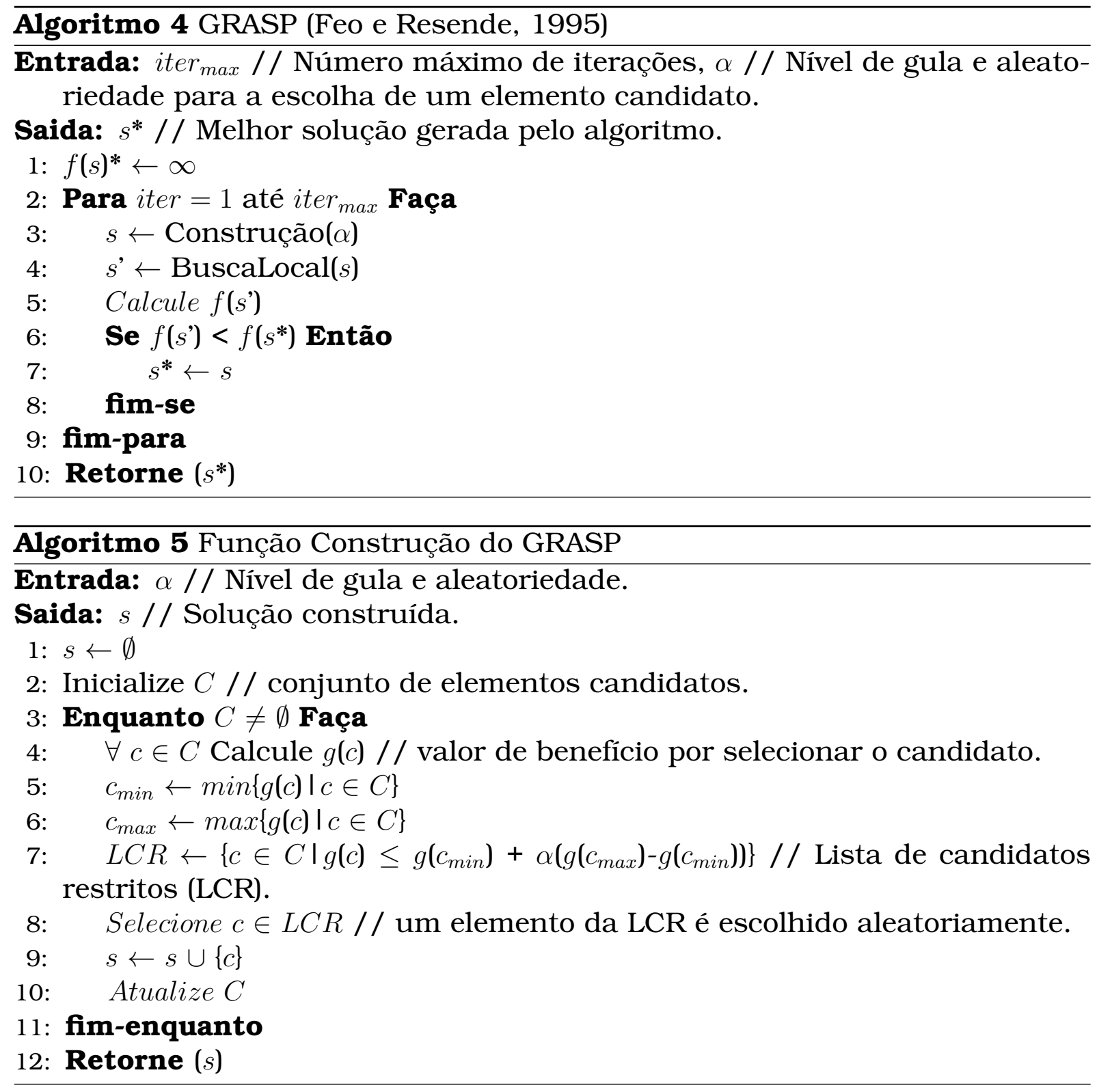

dos candidatos com maior benefício serem escolhidos por uma seleção gulosa e menor é o nível de aleatoriedade na escolha do candidato. Por outro lado, quanto maior o valor de $\alpha$, maior é a chance de um candidato ser escolhido aleatoriamente e menor é a possibilidade do procedimento guloso ser aplicado. Após a seleção do candidato, o conjunto elementos que compõem a solução e o conjunto dos candidatos são atualizados. No final, o algoritmo retorna a solução construída, que é usada como parâmetro de entrada para um algoritmo de busca local.

O algoritmo de busca local aplica uma função de refinamento para obter a melhor solução contida na região de vizinhança da solução construída. A melhor solução vizinha representa a solução gerada pelo GRASP.

Os principais aspectos positivos do GRASP são:

- Simplicidade na implementação dos algoritmos de construção e de busca local; 
- Poucos parâmetros para serem ajustados: número de iterações, tamanho da LCR e nível de gula e aleatoriedade.

\subsubsection{Recozimento simulado}

O Recozimento Simulado (SA, do inglês Simulated Annealing) é uma técnica de busca local probabilística cujo viés é baseado em princípios da termodinâmica. O procedimento de busca simula o processo de submeter certos materiais a altas temperaturas iniciais, que são gradativamente reduzidas até o equilíbrio térmico ser atingido, com pequenas variações do estado de energia. A temperatura encontrada no ponto do equilíbrio térmico torna os materiais mais consistentes e rígidos (Kirkpatrick et al., 1983; Cerny, 1985).

Um material submetido a temperaturas altas tem suas partículas totalmente dispersas. Isso corresponde a uma solução aleatória para um problema de otimização, que pode estar distante da solução ótima desejada. Uma pequena alteração nas posições de algumas dessas partículas resulta numa variação (positiva ou negativa) de energia, que equivale a uma alteração no valor da função objetivo no mesmo sentido.

Se consideramos dois estados sucessivos de energia, $E_{t}$ e $E_{t+1}$, podemos ter três situações possiveis:

- Redução de energia $\left(E_{t+1}<E_{t}\right)$, que analogamente reduz o valor da função objetivo. Se a intenção é minimizar a função objetivo, o processo continua.

- Manutenção de energia $\left(E_{t+1}=E_{t}\right)$, que corresponde a igualdade entre os resultados obtidos após a aplicação da função objetivo em duas soluções distintas.

- Aumento de energia $\left(E_{t+1}>E_{t}\right)$, que induz o aumento na velocidade das partículas do material. Após a redução gradativa da energia, essas partículas devem parar em locais apropriados. Na busca por soluções, essa variação de energia impede que a busca fique restrita apenas a determinadas soluções de mínimo local.

O pseudocódigo do SA está descrito no Algoritmo 6. Para cada valor de temperatura $t$, inicialmente elevado, uma quantidade pré-definida de iterações são executadas. Em cada iteração, uma solução que esteja na região de vizinhança da solução corrente é selecionada aleatoriamente. Se o valor da função objetivo aplicado à solução vizinha selecionada é melhor que o resultado da mesma função aplicada à solução corrente, a solução vizinha passa a ser a solução corrente. No entanto, mesmo que a solução vizinha selecionada não seja melhor que a solução corrente, existe uma probabilidade, calculada 
por meio de $e^{\left(f\left(s^{\prime}\right)-f(s)\right) / t}$, que permite a sua transformação em solução corrente. O parâmetro $t$ é a temperatura que regula a probabilidade de serem aceitas soluções piores do que a solução corrente. Essa probabilidade diminui à medida que a temperatura é reduzida, intensificando a busca em uma determinada região do espaço de soluções. Enquanto a temperatura estiver assumindo um valor positivo, um resfriamento é aplicado conforme a taxa definida por um parâmetro $\alpha$. Portanto, SA simula o equilíbrio térmico, de modo que a solução gerada pelo SA equivale à temperatura ideal para obter esse equilíbrio.

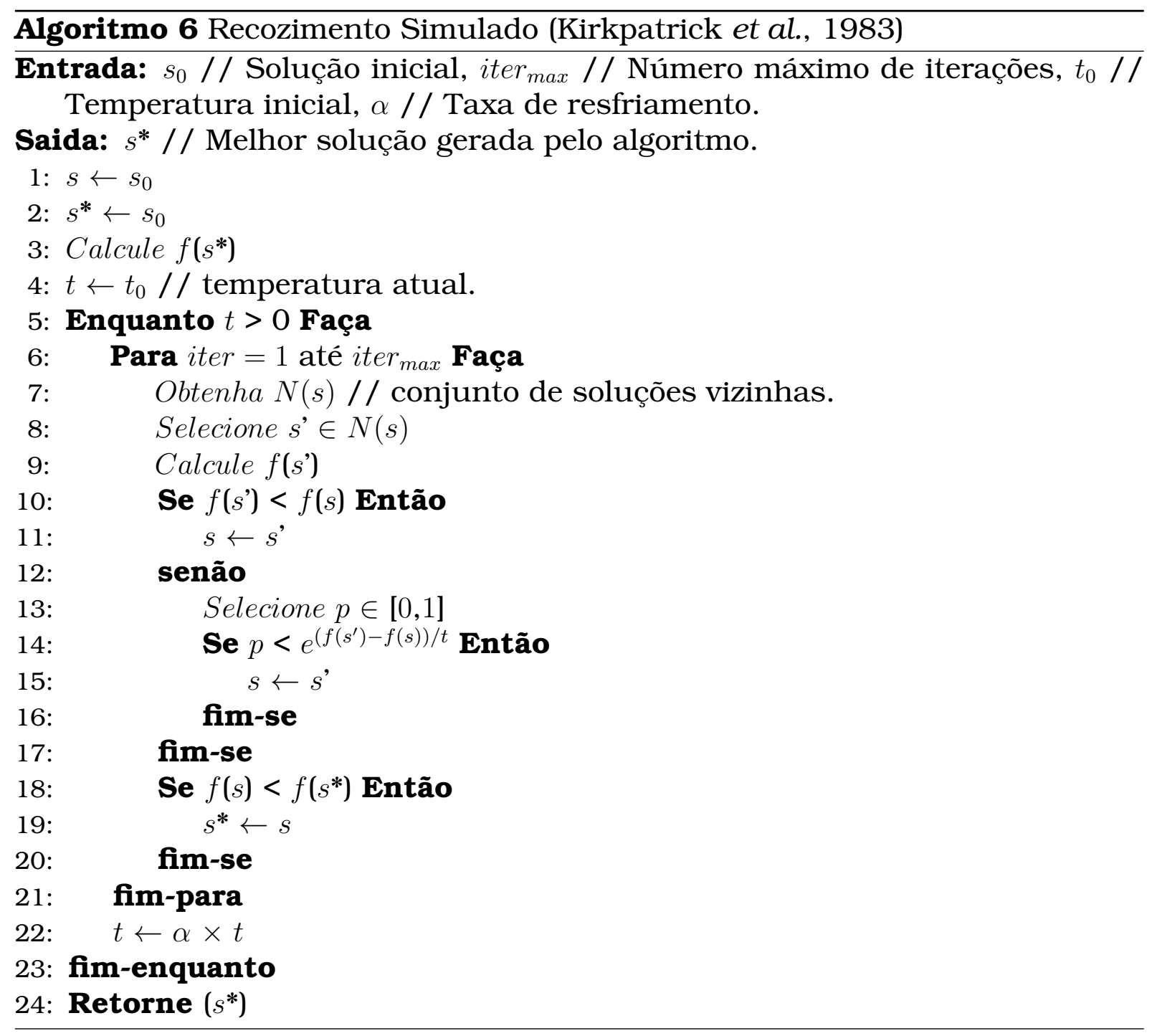

Dentre os principais aspectos do SA podemos listar (Elmohamed et al., 1998):

- Existem provas que garantem a convergência da solução, desde que o problema seja modelado por Cadeias de Markov;

- As soluções geradas são relativamente boas para muitos problemas de otimização combinatorial.

Em relação aos seus aspectos negativos, temos: 
- A redução gradativa da temperatura implica em um tempo maior para gerar uma solução;

- Existem muitos parâmetros para serem configurados que podem influenciar na qualidade da solução encontrada.

- Geralmente, é difícil definir um bom valor para o parâmetro de resfriamento.

\subsubsection{Algoritmos genéticos}

Os métodos de busca embutidos nesses algoritmos são baseados no processo natural da evolução das espécies (Holland, 1973; Goldberg, 1989; Reeves e Yamada, 1998). Indivíduos com maiores aptidões têm maiores chances de sobrevivência e de produzirem filhos cada vez mais aptos. Uma solução factível para o problema de otimização desejado representa um indivíduo e, consequentemente, uma população é um conjunto de soluções. O vetor de valores que representam uma solução corresponde ao cromossomo do individuo e cada elemento do vetor representa um gene do cromossomo. O pseudocódigo para um algoritmo genético (AG) está descrito no Algoritmo 7.

Algoritmo 7 Algoritmo Genético (Holland, 1973)

Entrada: IS I // Tamanho da população, ger ${ }_{\max } / /$ Número máximo de gerações.

Saida: $s^{*} / /$ Melhor solução gerada pelo algoritmo.

1: Gere $S=\left\{s_{1}, \ldots, s_{p}\right\} / /$ população inicial.

2: $\forall s_{i} \in S$ Calcule $f\left(s_{i}\right)$ // função de aptidão.

3: $s^{*} \leftarrow \operatorname{melhor}(S) / /$ seleciona indivíduo mais apto.

4: $\mathbf{P a r a}$ geracao $=1$ to ger $_{\max }$ Faça

5: $\quad$ Selecione $P \subset S / /$ seleciona os indivíduos pais.

6: $\quad F \leftarrow$ cruzamento $(P) / /$ pares de pais geram novos indivíduos (filhos).

7: $\quad$ mutacao (genes) // ocorre sob uma dada probabilidade (ex. 5\%).

8: $\quad \forall s_{i}^{\prime} \in F$ Calcule $f\left(s_{i}^{\prime}\right) / /$ valor de aptidão para os novos indivíduos.

9: $\quad$ Defina $S_{t+1} / /$ seleção da população sobrevivente.

10: $\quad s ' \leftarrow$ melhor $\left(S_{t+1}\right) / /$ indivíduo sobrevivente mais apto.

11: $\quad$ Se $f\left(s^{\prime}\right)<f\left(s^{*}\right)$ Então

12: $\quad s^{*} \leftarrow s$

13: fim-se

14: fim-para

15: Retorne $\left(s^{*}\right)$

Todos os indivíduos da população inicial são avaliados por uma função de aptidão e cada um tem um valor de fitness que indica a sua capacidade de sobrevivência. A evolução das espécies é feita a partir da seleção dos indivíduos mais aptos cujos genes são combinados para produção de novos indivíduos em uma etapa de reprodução. Dentre os principais métodos usados para a 
seleção de indivíduos estão a roleta e o torneio. Na roleta, a probabilidade de selecionar um indivíduo é proporcional ao seu valor de fitness, enquanto no torneio, dois ou mais indivíduos são sorteados e competem entre si, sendo vencedor aquele que tiver o maior fitness. O aspecto probabilístico inerente a esses processos de seleção garante a diversidade populacional, permitindo que uma boa solução seja obtida de maneira rápida. Os indivíduos selecionados geram outros novos por meio de operadores genéticos de cruzamento e/ou de mutação de seus genes. Algum critério deve ser usado para indicar os indivíduos sobreviventes, que devem ser submetidos ao mesmo processo evolutivo até atingir um número máximo de gerações (Goldberg, 1989).

Os principais aspectos positivos dos AGs são (Goldberg, 1989):

- Não há dependência da superfície do erro, podendo ser aplicado para resolver problemas multidimensionais e não contínuos;

- O entendimento do conceito é fácil;

- Múltiplas soluções podem ser fornecidas.

Em relação aos seus aspectos negativos, temos:

- Assim como as demais técnicas, não há garantias de que uma solução ótima global seja encontrada;

- Possui um comportamento complexo e imprevisível;

\subsubsection{Otimização baseada em colônia de formigas}

A técnica de otimização baseada em colônia de formigas (OCF) é inspirada no comportamento das formigas quando estão em busca de alimentos (Dorigo e Gambardella, 1997). As formigas se comunicam entre si por meio de uma substância denominada feromônio. Essa substância é depositada pelas formigas no caminho por onde passam para criar trilhos e orientar as outras formigas. Quanto maior o número de formigas passando pelo mesmo caminho, maior a quantidade de feromônio depositado. No entanto, o feromônio se evapora gradativamente ao longo do tempo.

No contexto do PCV, a probabilidade $p_{i j}^{k}$ da formiga $k$ ir da cidade $i$ para a cidade $j$ é calculada pela Equação 2.10.

$$
p_{i j}^{k}=\frac{\left(\tau_{i j}\right)^{\alpha}\left(\frac{1}{d_{i j}}\right)^{\beta}}{\sum_{v \in N_{i}^{k}}\left(\tau_{i v}\right)^{\alpha}\left(\frac{1}{d_{i j}}\right)^{\beta}}
$$

onde:

$\tau_{i j}$ é o feromônio contida na aresta $e_{i j}$; 
$\alpha$ e $\beta$ determinam a taxa de influência do feromônio e da informação heurística, respectivamente;

$N_{i}^{k}$ é o conjunto de cidades vizinhas à cidade $i$ para onde a formiga $k$ pode se deslocar;

$d_{i j}$ é a distância entre as cidades $i$ e $j$;

O Algoritmo 8 descreve o pseudocódigo do algoritmo OCF.

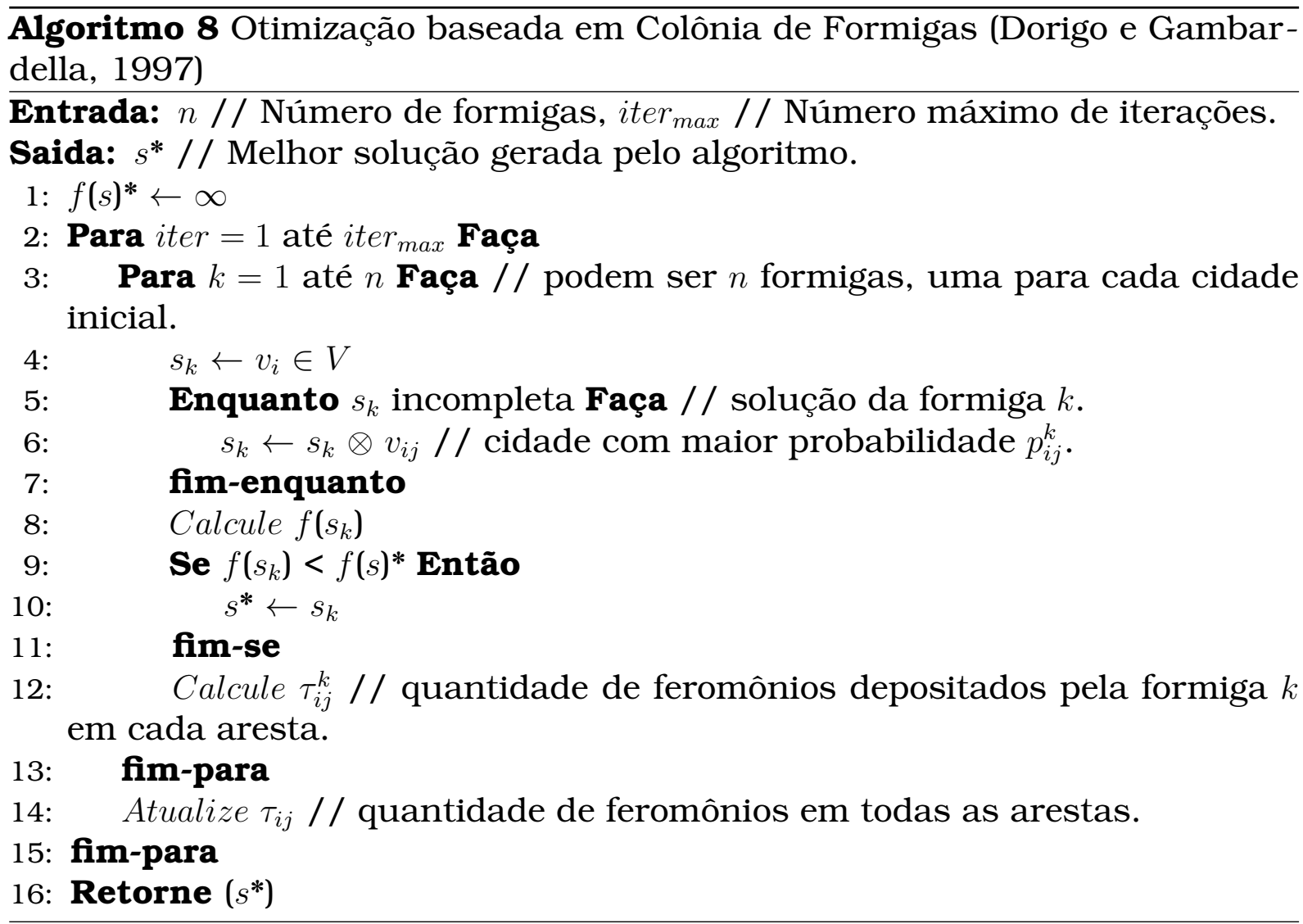

O algoritmo inicia com a distribuição de $n$ formigas em $n$ cidades distintas. O movimento de cada formiga de uma cidade para uma vizinha é realizada de modo probabilístico e basicamente depende de dois termos: a influência do feromônio e a influência da informação da heurística. O primeiro indica a intensidade do feromônio contido em uma dada aresta e o outro representa a atratividade da formiga usar essa aresta.

A quantidade de feromônio depositado por cada formiga em cada aresta pode ser calculada como sendo o custo da aresta dividido pelo custo total da rota realizada pela formiga. Por isso, essa quantidade é somente atualizada após a formiga completar o ciclo, quando é possivel obter o custo total da rota. O nível da atratividade de uma formiga usar uma determinada aresta é inversamente proporcional ao custo associado à essa aresta. Existem diferentes cálculos que podem ser usados para atualizar os feromônios. Neste trabalho, adotamos a atualização do feromônio em cada aresta $\tau_{i j}$ conforme a proposta feita em (Bullnheimer et al., 1999), que é calculada conforme a Equação 2.11. 


$$
\tau_{i j}=(1-\rho) \tau_{i j}+\sum_{\mu-1}^{\sigma-1}(\sigma-\mu) \Delta \tau_{i j}^{\mu}+\sigma \Delta \tau_{i j}^{*},
$$

onde:

$(1-\rho)$ é a taxa de evaporação;

$(\sigma-1)$ é o número de formigas que estão melhores ranqueadas;

$\mu$ é a posição da formiga no ranking;

$\Delta \tau_{i j}^{\mu}$ é igual a $(\sigma-\mu) / L_{\mu}$, se a aresta $e_{i j}$ pertence à rota da $\mu$-ésima melhor formiga e zero, caso contrário. $L_{\mu}$ é o custo da rota obtida por essa formiga.

$\Delta \tau_{i j}^{*}$ é igual a $1 / L^{*}$, se a aresta $e_{i j}$ pertence à melhor solução e zero, caso contrário.

O critério de parada adotado corresponde ao número máximo de rotas realizadas por cada formiga.

A OCF tem como principais aspectos positivos (Hung et al., 2007):

- Algoritmo pode ser adaptado para diversas situações, apenas alterando a maneira estocástica do movimento das formigas e da evaporação dos feromônios;

- Uso em problemas dinâmicos cujas características se alteram ao longo da execução do algoritmo.

Em relação a seus aspectos negativos, temos:

- Análise teórica é complicada devido às sequências de decisões aleatórias;

- Convergência prematura para ótimos locais de baixa qualidade. A convergência global é garantida, mas o tempo que isso acontece é incerto.

\subsection{Considerações finais}

Neste capítulo foi apresentada formalmente a definição do Problema do Caixeiro Viajante (PCV) por meio de sua representação matemática. Além disso, foram também descritas cinco meta-heurísticas (MHs) que, geralmente, fornecem boas soluções para diferentes instâncias desse problema.

Cada MH tem um viés que direciona o seu procedimento de busca para tentar encontrar a melhor solução possível para as instâncias de um problema. Desse modo, as MHs podem apresentar diferente desempenho de otimização para diferentes instâncias do problema.

Vale ressaltar que este trabalho não tem o objetivo de promover qualquer MH em particular, mas apenas usar um conjunto de MHs para selecionar, por meio de uma abordagem de meta-aprendizado, as mais promissoras para novas instâncias do PCV. 


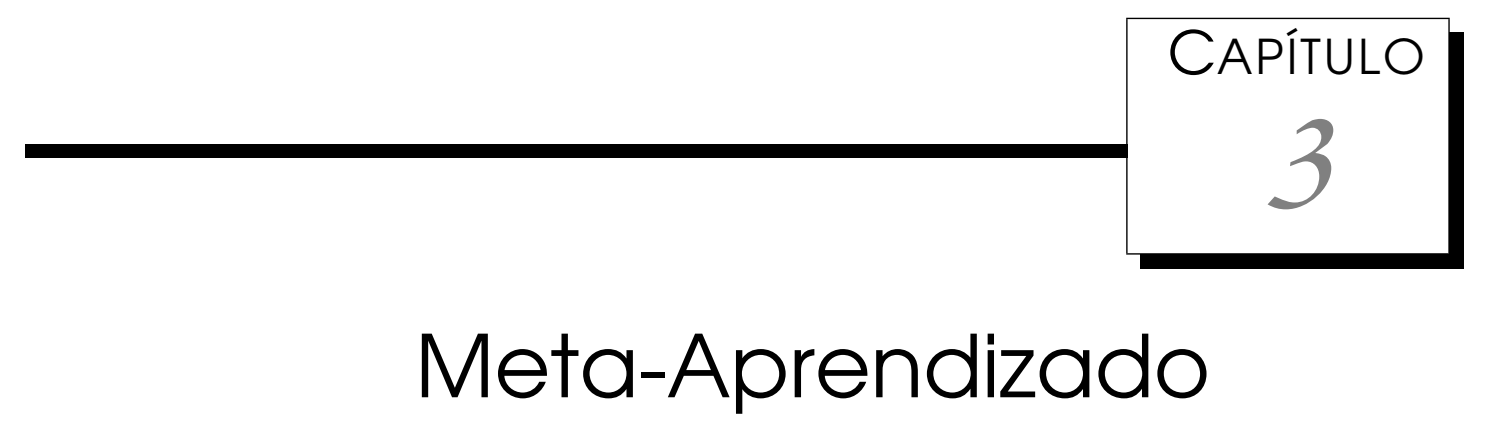

Dado um conjunto de diferentes MHs que podem ser aplicadas para uma dada instância de PCV, desejamos selecionar a mais promissora para essa instância. O problema de seleção das MHs é um típico problema de seleção de algoritmos, que foi originalmente descrito por Rice (Rice, 1976). A definição formal do problema de seleção de algoritmos é apresentada na Seção 3.1. Uma breve contextualização do uso de aprendizado de máquina para o problema de seleção de algoritmos é apresentada na Seção 3.2. Os principais elementos do meta-aprendizado são descritos na Seção 3.3.

\subsection{Definição do problema de seleção de algoritmos}

Para descrever o problema de seleção de algoritmos, Rice enunciou a seguinte questão: qual é o algoritmo que mais provavelmente tem o melhor desempenho para o meu problema? (Rice, 1976). Ele definiu formalmente o problema por meio do modelo ilustrado na Figura 3.1.

Os principais componentes desse modelo são:

- O espaço de problema $\mathcal{P}$, que representa o conjunto de instâncias de um problema.

- O espaço de algoritmo $\mathcal{A}$, que contém todos os algoritmos disponíveis para resolver o problema desejado. Esse espaço pode ser bastante extenso, porque existem milhares de algoritmos que podem fornecer soluções para um dado problema. Além disso, existem inúmeras combinações possíveis para os valores dos parâmetros de cada algoritmo e, adicionalmente, há ainda várias incertezas sobre a influência dos parâmetros de cada algoritmo em seu desempenho para um dado problema. 


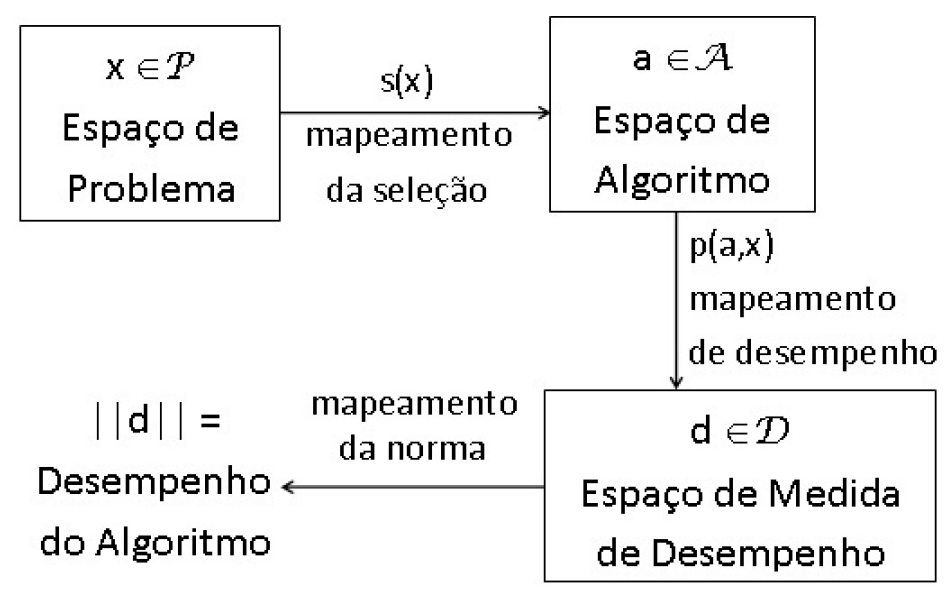

Figura 3.1: Modelo básico para o problema da seleção de algoritmos adaptado de (Rice, 1976).

- O espaço de medida de desempenho $\mathcal{D}$, que engloba todas as medidas usadas para mensurar o desempenho dos algoritmos para uma instância do problema (ex.: tempo de execução, qualidade da solução, etc.). Escolher critérios para definir medidas diferentes é um processo complexo, além de ser difícil realizar a comparação entre os resultados obtidos pelas diferentes medidas selecionadas.

A partir de um conjunto de instâncias do problema $\left\{p_{1}, \ldots, p_{p}\right\}$ e de um conjunto de algoritmos $\left\{a_{1}, \ldots, a_{q}\right\}$ disponíveis, o modelo proposto mostra que deve ser determinada uma função que mapeie cada par $\left\langle p_{i}, a_{j}\right\rangle$ para uma medida que avalie o desempenho $d$ obtido por $a_{j}$ quando aplicado em $p_{i}$. A partir da função mapeada que gera as informações $\left\langle p_{i}, a_{j}, d\right\rangle$, o desempenho dos algoritmos disponiveis pode ser predito para uma nova instância do problema, sendo que o algoritmo selecionado será aquele para o qual o modelo tenha predito o melhor desempenho.

Geralmente, uma amostra das instâncias do problema é usada para avaliar experimentalmente o desempenho de um conjunto de algoritmos. No entanto, se o número de instâncias usadas na amostra não é significativo, ou se as propriedades extraídas do problema não são adequadas para identificar de maneira única as instâncias, provavelmente, a função obtida a partir do mapeamento entre as propriedades do problema e o desempenho dos algoritmos pode não indicar, corretamente, o melhor algoritmo para uma nova instância do problema.

A fim de ressaltar o modo como as instâncias do problema devem ser descritas, Rice aprimorou o modelo original incluindo a extração de atributos como um passo necessário antes de realizar o mapeamento do problema para a seleção dos algoritmos (Rice, 1976). A Figura 3.2 ilustra o modelo de Rice para o problema de seleção de algoritmos baseado na extração de atributos do problema. 


\begin{tabular}{|c|c|c|c|c|}
\hline \multirow{3}{*}{$\begin{array}{c}\mathrm{x} \in \mathcal{P} \\
\text { Espaço de } \\
\text { Problema }\end{array}$} & \multirow{2}{*}{$\begin{array}{c}\text { extração de } \\
\text { atributos } \mathrm{F}\end{array}$} & \multirow{3}{*}{$\begin{array}{l}f(x) \in \mathcal{F} \\
\text { Espaço de } \\
\text { Atributo }\end{array}$} & \multirow{3}{*}{$\begin{array}{c}\mathrm{s}(\mathrm{f}(\mathrm{x})) \\
\text { mapeamento } \\
\text { da seleção }\end{array}$} & \multirow{3}{*}{$\begin{array}{c}a \in \mathcal{A} \\
\text { Espaço de } \\
\text { Algoritmo }\end{array}$} \\
\hline & & & & \\
\hline & & & & \\
\hline \multirow{3}{*}{$\begin{array}{l}\qquad|| d||= \\
\text { Desempenho } \\
\text { do Algoritmo }\end{array}$} & \multirow{3}{*}{$\begin{array}{c}\text { mapeamento } \\
\text { da norma }\end{array}$} & \multirow{3}{*}{\multicolumn{2}{|c|}{$\begin{array}{c}\mathrm{d} \in \mathcal{D} \\
\text { Espaço de Medida } \\
\text { de Desempenho }\end{array}$}} & $\begin{array}{c}p(a, x) \\
\text { mapeamento }\end{array}$ \\
\hline & & & & de desempenho \\
\hline & & & & \\
\hline
\end{tabular}

Figura 3.2: Modelo de Rice (1976) para a seleção de algoritmos com a identificação de atributos do problema.

O componente adicional no modelo de Rice é o Espaço de Atributos $\mathcal{F}$, que representa o conjunto de características independentes e mensuráveis. Esse conjunto é usado para descrever as instâncias do problema.

Com a atualização do modelo, o problema de seleção de algoritmos pode ser formalmente definido da seguinte maneira: Dado um exemplo $x \in \mathcal{P}$ descrito por um vetor de atributos $f(x) \in \mathcal{F}$, o problema consiste em encontrar o melhor mapeamento de seleção $S(f(x))$ para um conjunto de algoritmos $A$, tal que o algoritmo selecionado $a \in A$ maximize a medida de desempenho ||$d||$ para $y(a, x) \in \mathcal{D}$.

A partir do modelo atualizado de Rice, podemos notar que, para selecionar o algoritmo mais apropriado, é preciso definir as características do problema que estejam correlacionadas com o desempenho dos algoritmos. Todavia, é difícil saber antecipadamente quais as características que melhor mapeiam os problemas para o desempenho dos algoritmos nesses problemas. Desse modo, o problema de seleção de algoritmos se resume à seguinte questão: como escolher os melhores atributos de um problema que indiquem de maneira única o desempenho de cada um dos algoritmos para novas instâncias desse problema? Essa é uma indagação que ainda não tem - e nem sabemos se teremos no futuro - uma resposta irrefutável, mas que continua sendo amplamente investigada (Smith-Miles e Lopes, 2012).

Existem diversos trabalhos que propõem o uso de diferentes conjuntos de características para serem usados em um processo de seleção de algoritmos por meio da construção de modelos de AM. Alguns desses trabalhos estão brevemente descritos na próxima seção. 


\subsection{Aprendizado de máquina para o problema de seleção de algoritmos}

A fim de realizar a seleção de algoritmos de AM para problemas de classificação, Kalousis (2002) introduziu a ideia de histograma para caracterizar os diferentes conjuntos de dados. A ideia principal consiste em obter de maneira detalhada as distribuições de várias propriedades dos conjuntos de dados. Embora os atributos baseados em histograma tenham sistematicamente apresentados resultados melhores do que as outras caracterizações usadas, em quase todos os seus experimentos realizados, a diferença entre tais resultados não foi estatisticamente significativa. A abordagem SATzilla (Xu et al., 2008) seleciona algoritmos para resolver instâncias do problema de satisfatibilidde proposicional a partir de modelos de AM. Esses modelos são usados para predizer o tempo de execução de um algoritmo em uma instância particular descritas por propriedades similares a de instâncias previamente conhecidas.

Apesar do melhor conjunto de características depender muito do domínio do problema e dos algoritmos escolhidos, outros fatores também devem ser considerados durante o processo da escolha das características, tais como: as diversas complexidades inerentes às instâncias do problema; as propriedades estruturais do problema; e as vantagens e as limitações de diferentes técnicas de AM ao serem usadas com as características escolhidas. Um breve resumo sobre as técnicas de AM usadas nesta pesquisa está descrito no Apêndice A.

Para a comunidade de AM, o problema de seleção de algoritmos é, claramente, um problema de aprendizado (Aha, 1992; Michie et al., 1994). Existem trabalhos (Ali e Smith, 2006; Brazdil et al., 2003; Vilalta e Drissi, 2002), em que o problema de seleção consiste em obter o algoritmo de AM mais promissor para ser aplicado em um dado conjunto de dados. Esse processo de aprendizado sobre algoritmos de aprendizado deu origem ao termo meta-aprendizado.

No contexto de seleção de algoritmos, a definição mais apropriada de metaaprendizado é aquela que consta em (Brazdil et al., 1994): "Meta-aprendizado é um processo de geração de um conjunto de regras que sejam capazes de relacionar o desempenho dos algoritmos para as características dos conjuntos de dados". Desse modo, um dos objetivos do meta-aprendizado é entender a relação entre as características do problema e o desempenho de algoritmos para um conjunto de instâncias desse problema (Brazdil et al., 2009).

Uma abordagem apresentada em (Smith-Miles, 2009) discute a aplicação do conceito de meta-aprendizado em problemas de diferentes áreas como: ordenação, previsão, satisfação de restrição, otimização, bioinformática, criptografia, dentre outras. Particularmente em otimização, a autora mostra que existem relações entre essa área e a de AM, porém afirma que existem pou- 
cas pesquisas que exploram essas relações. O artigo sugere que ideias de meta-aprendizado sejam aplicadas nessa direção a fim de entender a relação entre o desempenho dos algoritmos e as características dos problemas. $\mathrm{O}$ aprendizado dessa relação pode ser atingido por meio do meta-aprendizado, a partir do qual diferentes áreas do conhecimento poderiam ser beneficiadas na tentativa de resolver o seu problema de seleção de algoritmos.

Conceitos de meta-aprendizado ainda têm sido pouco utilizados para seleção de algoritmos que resolvam problemas de otimização (Smith-Miles, 2008). Um dos poucos casos discutidos foi para o Problema Quadrático de Alocação (PQA) (Smith-Miles, 2009). Em seus experimentos relatados, foram usadas 28 instâncias de PQA, 3 MHs, 4 medidas de caracterização do problema e 4 medidas baseadas na execução da busca local iterativo. Além disso, o modelo preditivo foi induzido a partir uma rede neural para estimar o desvio percentual de cada $\mathrm{MH}$ em comparação à média conhecida das soluções obtidas a partir de 10 inicialização aleatórias dos respectivos algoritmos.

As instâncias no espaço de problemas e os atributos usados para caracterizar as instâncias formam um conjunto de meta-dados. Esse conjunto de meta-dados é usado para induzir um modelo preditivo. Sendo assim, é fundamental que o conjunto de meta-dados seja formado por um número suficiente de instâncias e, principalmente, por atributos apropriados. Uma metodologia para avaliar a adequação de um conjunto de meta-dados para o PCV é descrita em (Smith-Miles et al., 2010). A metodologia analisa a dificuldade dos algoritmos de otimização em encontrar a solução para instâncias do problema e a dificuldade de aprender a partir do desempenho desses algoritmos.

Outros artigos publicados que relacionam problemas de otimização, mais especificamente o PCV, com AM são aqueles nos quais relatam os principais resultados experimentais oriundos das pesquisas desenvolvidas nesta tese:

- Instâncias de PCV geradas artificialmente, rotuladas com a(s) MH(s) de melhor desempenho e classificadas por técnicas de classificação multirrótulo (Kanda et al., 2010);

- Extensão da pesquisa anterior por meio do uso de meta-exemplos gerados a partir de arquivos de PCV bem conhecidos (Kanda et al., 2011a);

- Experimentos com diferentes configurações de redes neurais artificiais para induzir modelos classificadores (Kanda et al., 2011b);

- Recomendação do ranking de MHs para instâncias de PCV em dois cenários diferentes de aplicação (Kanda et al., 2012).

Os principais conceitos de meta-aprendizado são apresentados na próxima seção, enquanto os experimentos realizados durante o desenvolvimento dessa pesquisa são descritos no Capítulo 5. 


\subsection{Elementos de meta-aprendizado}

Meta-aprendizado pode também ser definido como o estudo dos principais métodos que exploram o meta-conhecimento usado para induzir metamodelos com capacidade para gerar soluções eficientes para instâncias de um dado problema (Brazdil et al., 2009). Meta-conhecimento é o conhecimento adquirido a partir do mapeamento das propriedades de um conjunto de instâncias do problema para os valores das classes previamente conhecidas para essas instâncias. O uso de meta-aprendizado torna um sistema de recomendação de algoritmos mais eficiente quando consegue obter metaconhecimentos mais útil, ou seja, identificar a função de relacionamento entre as característica dos problema e o desempenho dos algoritmos candidatos (Brazdil et al., 2003). Um sistema de meta-aprendizado deve usar a experiência sobre o problema para melhorar o mapeamento principalmente quando diferentes vieses podem ser aplicados para um problema particular (Rendell et al., 1987). Viés é a preferência por escolher uma hipótese particular dentre outras igualmente prováveis que podem ser utilizadas para elucidar os dados, e hipótese é uma conjunção de restrições dos atributos de um conjunto de dados (Mitchell, 1997).

Um dos objetivos do meta-aprendizado é auxiliar na recomendação de algoritmos, ou combinação de algoritmos, para um determinado problema específico. Assim, um sistema de meta-aprendizado pode retornar um conjunto dos algoritmos mais promissores para esse problema. Em meta-aprendizado, a pesquisa por soluções tende a ser mais efetiva do que alternativas como tentativa e erro, pois as experiências anteriores do sistema tendem a aumentar a sua eficiência, melhorando a qualidade das soluções para cada novo problema apresentado (Brazdil et al., 2009).

Lembrando que técnicas de AM supervisionado induzem um modelo preditivo a partir de um conjunto de exemplos $X=\left\{x_{1}, x_{2}, \ldots, x_{e}\right\}$. Cada exemplo $x_{i}$ é descrito por um vetor de $m$ atributos preditivos, $x^{a}=\left[x_{a 1}, x_{a 2}, \ldots, x_{a m}\right]$. A classe do exemplo $x_{i}$ é identificada por um atributo alvo que pode assumir um dos $q$ rótulos do conjunto de classes $C=\left\{c_{1}, c_{2}, \ldots, c_{q}\right\}$. Em problemas de classificação multirrótulo, cada exemplo pode ser classificada simultaneamente em mais de uma classe. As informações dos atributos preditivos e alvo permitem induzir um modelo que seja capaz de determinar, com algum nível de acurácia, a classe para exemplos não vistos por esse modelo (Mitchell, 1997).

Em um processo de meta-aprendizado, os exemplos (denominados metaexemplos) representam um conjunto de instâncias do problema, enquanto os atributos preditivos (denominados meta-atributos preditivos) representam as propriedades inerentes a esses conjuntos. O desempenho de diferentes 
técnicas ou algoritmos para cada exemplo formam os atributos alvo. De agora em diante, nesta tese, salvo os casos para evitar a ambiguidade, os metaatributos preditivos serão denominados simplesmente por meta-atributos. Os meta-exemplos descritos por meta-atributos e meta-atributos alvo resultam em um conjunto de meta-dados.

\subsection{Meta-dados}

O desempenho preditivo de um sistema de meta-aprendizado depende da qualidade dos meta-dados usados em seu treinamento, os principais fatores que mais influenciam essa qualidade são: a quantidade de meta-exemplos e a escolha apropriada dos meta-atributos (Brazdil et al., 2009).

\section{Meta-exemplos}

Para serem usados em um processo de meta-aprendizado, os metaexemplos devem estar disponíveis em uma quantidade apropriada para que o meta-modelo possa ter um aprendizado tão diversificado quanto possível. Quando os exemplos disponíveis não são suficientes para serem usados em experimentos de meta-aprendizado, uma alternativa pode ser a geração de meta-dados artificiais. Isso pode ser feito desde que as propriedades relativas ao conjunto de dados reais sejam mantidas nos exemplos gerados (Brazdil et al., 2009). Abordagens para gerar aleatoriamente um conjunto de instâncias de PCV simétricos são mencionadas em (Gutin e Punnen, 2002). Durante a geração dos meta-dados podem ocorrer falhas no processamento dos metaatributos, deixando-os sem valor para algum meta-exemplo. Caso isto ocorra, pode ser aplicado, convenientemente, algum dos métodos utilizados para manipular conjunto de dados com valores ausentes, tais como: eliminação de instâncias, eliminação de atributos, modificação do algoritmo de aprendizado, ou estimativas de valores ausentes (Tan et al., 2006).

\section{Meta-atributos}

A geração dos meta-atributos é realizada a partir da identificação de características relevantes do problema. Os meta-atributos devem ser capazes de usar informações sobre o desempenho dos algoritmos candidatos para discriminar os meta-exemplos. O uso de meta-atributos apropriados é um dos fatores determinantes para o sucesso preditivo na tarefa de classificação de um meta-modelo. Em (Brazdil et al., 2009) são discutidos alguns aspectos que devem ser levados em consideração ao escolher os meta-atributos, como por exemplo: 
- Poder discriminatório. As informações dos meta-atributos devem ser suficientes para diferenciar os algoritmos candidatos em termos de seus desempenhos. Por esta razão, a seleção de cada meta-atributo deve ser criteriosa e a sua representação feita em uma forma adequada. Por exemplo, meta-atributos com informações sobre os valores absolutos das arestas de um PCV podem ser menos relevantes do que outros com informações sobre medidas de localização e de dispersão.

- Complexidade computacional. A geração dos meta-atributos não pode ter um custo computacional elevado, senão seria preferível executar todos os algoritmos candidatos a usar um meta-modelo para recomendar o uso dos mais promissores.

- Dimensionalidade. Se o número de meta-atributos é muito grande comparado à quantidade de meta-dados, pode ocorrer um overfitting, aumentando as chances de erros na predição da classe para exemplos não vistos (Mitchell, 1997).

Na seleção de algoritmos de AM, descrito em (Brazdil et al., 2009), foram propostas três abordagens para a geração de meta-atributos a partir da caracterização dos dados. A primeira é baseada em características obtidas a partir de medidas descritivas (ex. número de atributos), da teoria da informação (ex. entropia da classe) e de propriedades estatísticas (ex. média de atributos numéricos) que sumarizam os conjuntos de dados (Todorovski e Dzeroski, 1999). A segunda abordagem é baseada em informações extraídas do próprio modelo construído (ex. número de nós-folha de uma árvore de decisão) (Peng et al., 2002). Finalmente, a terceira é baseada em landmarkers, que caracterizam os dados por meio de estimativas rápidas de desempenhos obtidos a partir de classificadores simples, cujos resultados podem apontar diferenças significativas em seus mecanismos de aprendizado (Brazdil et al., 2003).

Não há uma quantidade mínima de meta-atributos que possa favorecer o aprendizado de um modelo classificador, por isso os meta-atributos poderiam ser gerados indefinidamente. A geração de muitos meta-atributos pode ser uma boa estratégia, já que posteriormente pode ser aplicado algum método de seleção de atributos com o objetivo de obter os mais relevantes. Segundo Tan et al. (2006), os principais métodos de seleção de atributos são: filtros, embarcado e wrapper. A aplicação desse último em conjuntos de meta-dados tem proporcionado melhor qualidade nos resultados, porém com maior custo computacional (Kalousis e Hilario, 2001). Um breve resumo sobre seleção de atributos está no Apêndice B.

Em um sistema de recomendação de algoritmos, cada meta-exemplo pode ser associado a um meta-atributo alvo, que identifica os melhores algorit- 
mos para a instância do problema representada no meta-exemplo. Os valores assumidos pelo meta-atributo alvo dependem da forma de recomendação. O usuário pode desejar apenas o algoritmo com a melhor recomendação ou um ranking dos melhores algoritmos. As principais formas de recomendação abordadas em (Brazdil et al., 2009) são descritas a seguir.

\subsubsection{Formas de recomendação}

Para efeito de ilustração, considere a apresentação de uma nova instância (meta-exemplo) do problema a um meta-modelo, que gera como saída um conjunto de valores reais: $\{0,39,0,03,0,01,0,22,0,22\}$, indicando a recomendação do meta-modelo para um conjunto de algoritmos $\left\{a_{1}, a_{2}, a_{3}, a_{4}, a_{5}\right\}$, respectivamente. Quanto menor o valor, melhor é a recomendação do algoritmo. A lista de valores gerados mostra o algoritmo $a_{3}$ como sendo o mais recomendável, mas o algoritmo $a_{2}$ também parece ser promissor, por não haver uma grande diferença para o algoritmo mais recomendado. Além disso, há um empate relativo entre os algoritmos $a_{4}$ e $a_{5}$. A partir das informações sobre o desempenho dos algoritmos, diversas formas de recomendação podem ser adotadas, tais como:

- Melhor algoritmo

O sistema de meta-aprendizado recomenda somente o algoritmo mais promissor $\left(a_{3}\right)$. Nesse caso, o problema se resume a uma tarefa de classificação. No entanto, a indicação de uma única opção pode ser uma desvantagem, pois não há garantias de que o algoritmo recomendado produzirá a melhor, ou até mesmo, uma boa solução. Essa incerteza decorre, principalmente, porque a maioria das MHs possuem vários componentes aleatórios, que podem ter uma configuração diferente para a instância desejada do PCV do aquela adotada para resolver as instâncias usadas na indução do meta-modelo.

- Subconjunto de algoritmos

Para que o usuário tenha outras opções de algoritmos, o sistema pode recomendar um conjunto dos mais promissores $\left\{a_{2}, a_{3}, a_{4}, a_{5}\right\}$. A inclusão ou não de um candidato nesse conjunto pode ser condicionada ao valor de desempenho predito para o mesmo, ou seja, se o valor está dentro de uma margem relativa em relação ao valor do algoritmo mais promissor. Duas formas para definir esta margem são mencionadas em (Brazdil et al., 2009). A primeira considera o seguinte intervalo:

$$
\left[e_{\min }, e_{\min }+k \sqrt{\frac{e_{\min }\left(1-e_{\min }\right)}{n}}\right)
$$


onde: $e_{\min }$ é o erro do melhor algoritmo, $n$ é o número de exemplos e $k$ é um parâmetro definido pelo usuário para determinar o tamanho da margem. Considerando o erro do melhor algoritmo igual a 0,01 em um conjunto com 500 meta-exemplos e atribuindo o valor 5 para o parâmetro $k$, todos os algoritmos com valores menores que 0,032 estarão no conjunto recomendado.

A outra maneira de obter a margem é usar testes de significância estatística para comparar a diferença entre os valores obtidos.

Apesar da vantagem de recomendar diferentes algoritmos para um único problema, os mesmos podem não estar dispostos em uma forma ordenada, de modo que o usuário terá dificuldade em selecionar um que, provavelmente, tenha o melhor desempenho.

- Ordenação de algoritmos

Uma lista recomendada pode dispor os algoritmos em uma ordem que já indique uma sugestão, em termos de preferência, para serem aplicados a um problema. Os principais tipos de ordenação são:

- Ordem linear e completa: a ordem é linear porque cada algoritmo da lista está em uma posição diferente, e completa porque todos os candidatos aparecem na lista recomendada $\left\{a_{3}, a_{2}, a_{4}, a_{5}, a_{1}\right\}$. Esse tipo de ordem não contém informações sobre possíveis empates entre os algoritmos.

- Ordem fraca e completa: a ordem fraca indica que não há uma ordem entre os algoritmos com desempenhos relativamente iguais. Os mesmos são identificados por uma linha contínua inserida sobre os rótulos de identificação, $\left\{a_{3}, a_{2}, \overline{a_{4}, a_{5}}, a_{1}\right\}$.

- Ordem linear e incompleta: a ausência de algum algoritmo na lista recomendada caracteriza a ordem incompleta, $\left\{a_{2}, a_{4}, a_{5}\right\}$. Alguns algoritmos podem não ser capazes de fornecer uma solução factível para a instância do problema após um intervalo de tempo de processamento. Nesse caso, é preferível não incluir esses algoritmos na lista recomendada.

- Ordem fraca e incompleta: a lista é recomendada considerando uma possivel igualdade no desempenho relativo de diferentes algoritmos e a possibilidade de não ser obtida a solução de algum dos algoritmos candidatos, de modo que o valor de seu desempenho para um dado metaexemplo não pode ser mensurado, $\left\{m_{3}, \overline{m_{4}, m_{5}}\right\}$.

Nos primeiros experimentos realizados neste projeto, o problema de recomendação de MHs para PCV foi visualizado como uma tarefa de classificação multirrótulo, para o qual um subconjunto de MHs é selecionado para uma dada instância. No entanto, como a recomendação de um subconjunto de 
MHs não indica qual delas deveria ser priorizada para ser aplicada a cada novo problema, os novos experimentos adotaram a recomendação de uma lista ordenada de MHs de acordo com o desempenho de otimização predito para cada $\mathrm{MH}$.

\subsection{Considerações Finais}

Este capítulo abordou o problema de seleção de algoritmos, um tema discutido há décadas. No entanto, somente em publicações recentes (Smith-Miles, 2009; Júnior, 2011; Smith-Miles e Lopes, 2012), foi proposto o uso de AM para o problema de seleção de algoritmos de otimização.

Uma alternativa para a seleção correta do algoritmo mais promissor é encontrar regras que mapeie as características do problema para o desempenho dos algoritmos disponíveis. Esse tipo de mapeamento é um dos objetivos de uma área de AM conhecida como meta-aprendizado.

Neste capítulo, também foram descritos alguns termos relacionados ao meta-aprendizado, entre os quais consta o meta-atributo. A escolha de metaatributos apropriados é fundamental para o sucesso de um meta-modelo preditivo. Os meta-atributos usados em nossos experimentos são detalhados no próximo capítulo. 


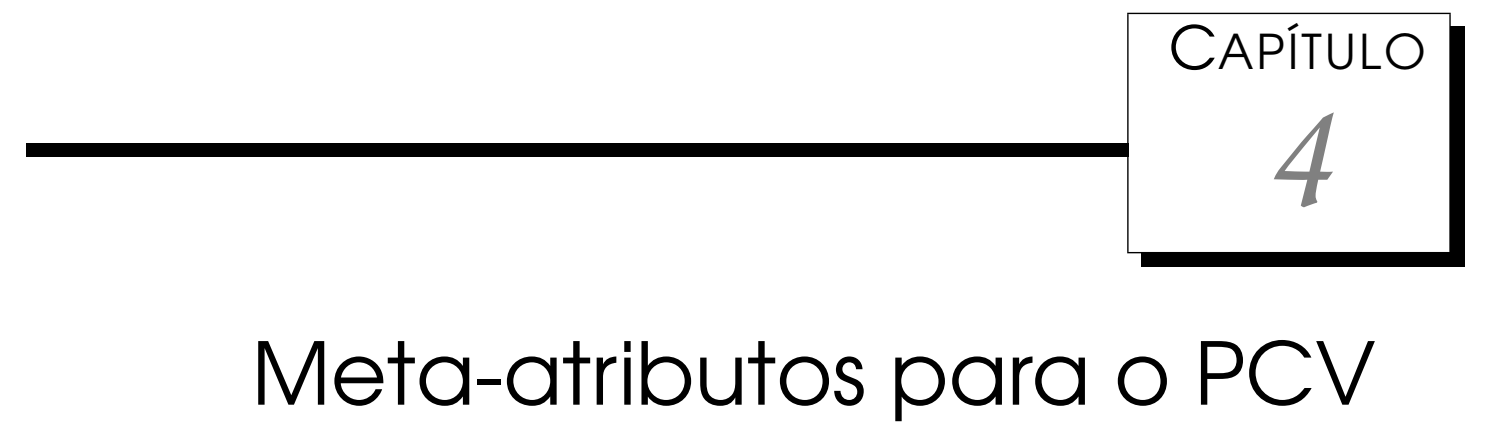

Em um conjunto de meta-dados, cada meta-exemplo é descrito por um conjunto de características do problema denominadas meta-atributos. Em problemas de classificação, um ou mais valores para classe(s) (meta-atributo(s) alvo) dos exemplos também deve ser conhecido(s) para que um meta-modelo seja induzido. O meta-modelo induzido deve ser capaz de predizer corretamente o valor do(s) meta-atributo(s) alvo para os exemplos não vistos durante o treinamento. Um dos fatores que influenciam o sucesso preditivo de um meta-modelo é a escolha de meta-atributos que devem ser apropriados para discriminar a verdadeira classe dos meta-exemplos (Brazdil et al., 2009). No trabalho descrito nesta tese, o número de MHs candidatas corresponde ao número de classes em nosso meta-dados e o desempenho de otimização das MHs é usado para indicar o valor dos meta-atributos alvo.

Aprender a relação entre as características de um conjunto de problemas e o desempenho dos algoritmos para esses problemas é um dos objetivos do meta-aprendizado. O melhor conjunto de meta-atributos para induzir um modelo preditivo é aquele que consegue diferenciar os algoritmos candidatos em termos de desempenho. O custo computacional para gerar os meta-atributos não deve ser maior do que o custo para executar todos os algoritmos disponíveis, já que a execução de todos os algoritmos garante a obtenção do algoritmo mais promissor (Brazdil et al., 2009). Nos experimentos realizados durante a pesquisa, diversas características de PCV foram extraídas para serem usadas como meta-atributos.

No restante deste capítulo estão descritos os conjuntos de meta-atributos para o PCV que foram avaliados em nossos modelos de meta-aprendizado. A Seção 4.1 descreve os meta-atributos que são baseados em medidas esta- 
tísticas dos custos de aresta e de vértice. Na Seção 4.2 estão descritos os meta-atributos que foram identificados a partir de algumas características específicas aos procedimentos de geração da solução fornecida pelas MHs. A Seção 4.3 detalha os meta-atributos correspondentes às medidas de desempenho dos landmarkers para as mesmas MHs. Os meta-atributos derivados da caracterização de redes complexas são apresentados na Seção 4.4. Finalmente, na Seção 4.5 são feitas algumas considerações sobre os diversos meta-atributos para o PCV.

\subsection{Meta-atributos baseados em custo de vértice e de aresta}

Formalmente, um exemplo do Problema do Caixeiro Viajante (PCV) pode ser definido por meio de um grafo $G=(V, E)$, onde $V=\left\{v_{1}, v_{2}, \ldots, v_{n}\right\}$ é um conjunto de vértices e $E=\left\{\left\langle v_{i}, v_{j}\right\rangle: v_{i}, v_{j} \in V\right\}$ é um conjunto de arestas. Cada vértice $v_{i} \in V$ representa uma cidade do problema e cada aresta $\left\langle v_{i}, v_{j}\right\rangle \in E$ indica a existência de uma conexão entre as cidades representadas por $v_{i}$ e $v_{j}$. Nesse caso, os vértices $v_{i}$ e $v_{j}$ são adjacentes. O custo $c_{i j}$ para viajar da cidade $v_{i}$ para a cidade $v_{j}$ é identificado por meio do valor de peso associado à aresta $\left\langle v_{i}, v_{j}\right\rangle$.

Meta-atributos baseados nos custos de vértices e arestas para descrever as instâncias de PCV foram propostos em (Kanda et al., 2011a). Enquanto o custo de aresta $\left(C^{E}\right)$ pode ser facilmente extraído a partir da identificação do valor de $c_{i j}$, o custo de vértice $\left(C^{V}\right)$ é obtido calculando a média aritmética dos custos das arestas conectadas ao vértice. O custo do vértice $v_{i}$ é calculado por meio da Equação 4.1.

$$
C_{i}^{V}=\frac{1}{n} \sum_{j=1}^{n} c_{i j}
$$

As MHs buscam por uma boa solução explorando diferentes regiões do espaço de busca, como a região de vizinhança da solução corrente. Em PCV, o número de vizinhos depende do número de cidades do problema. Por isso, medidas relacionadas aos vértices podem ser meta-atributos relevantes. As arestas com menores valores de pesos são as mais prováveis de estarem presentes nas soluções geradas pelas MHs. Por esse motivo, algumas propriedades referentes aos custos de arestas também são usadas para compor o conjunto de meta-atributos. Como por exemplo, o cálculo da soma dos $n$ menores custos de arestas, que será igual ao valor de uma solução gulosa se essas arestas compõem um ciclo hamiltoniano. Cálculos para os meta-atributos baseados nos custos de vértices e de arestas estão descritos na Tabela 4.1 
Tabela 4.1: Meta-atributos (MA) para PCV baseados em medidas de custo de vértice e de aresta.

\begin{tabular}{lll}
\hline MA & Notação Matemática & Descrição \\
\hline$V_{\text {number }}$ & length $(V)$ & número de vértices $(n)$ \\
$C_{\text {min }}^{V}$ & $\min \left(C_{1}^{V}, \ldots, C_{n}^{V}\right)$ & menor custo de vértice \\
$C_{\text {max }}^{V}$ & $\max \left(C_{1}^{V}, \ldots, C_{n}^{V}\right)$ & maior custo de vértice \\
$C_{\text {avg }}^{V}$ & $\frac{\sum_{i=1}^{n} C_{i}^{V}}{n}$ & média dos custos dos vértices \\
$C_{\text {sd }}^{V}$ & $\sqrt{\frac{1}{n-1} \sum_{i=1}^{n}\left(C_{i}^{V}-C_{\text {avg }}^{V}\right)^{2}}$ & desvio padrão dos custos dos vértices \\
$C_{\text {median }}^{V}$ & median $\left(C_{1}^{V}, \ldots, C_{n}^{V}\right)$ & mediana dos custos dos vértices \\
$C_{n n}^{V}$ & $\sum_{i=1}^{n} \min \left(c_{i 1}, \ldots, C_{i n}\right)$ & soma dos custos de viagem partindo de \\
& & cada cidade para a vizinha mais próxima \\
$E_{\text {number }}$ & $\operatorname{length}(E)$ & número de arestas ( $m$ ) \\
$C_{\text {min }}^{E}$ & $\min \left(C_{1}^{E}, \ldots, C_{m}^{E}\right)$ & menor custo de aresta \\
$C_{\text {max }}^{E}$ & $\max \left(C_{1}^{E}, \ldots, C_{m}^{E}\right)$ & maior custo de aresta \\
$C_{\text {avg }}^{E}$ & $\frac{\sum_{i=1}^{m} C_{i}^{E}}{m}$ & média dos custos das arestas \\
$C_{\text {sd }}^{E}$ & $\sqrt{\frac{1}{m-1} \sum_{i=1}^{m}\left(C_{i}^{E}-C_{\text {avg }}^{E}\right)^{2}}$ & desvio padrão dos custos das arestas \\
$C_{\text {median }}^{E}$ & $\operatorname{median}\left(C_{1}^{E}, \ldots, C_{m}^{E}\right)$ & mediana dos custos das arestas \\
$C_{\text {lowest }}^{E}$ & $\sum_{i=1}^{n} \operatorname{ord}\left(C_{i}^{E}\right)$ & soma dos $n$ menores custos de arestas \\
\hline
\end{tabular}

\subsection{Meta-atributos baseados em características das meta-heurísticas}

A solução provida por um algoritmo de otimização para uma instância de PCV depende do viés da MH utilizada. Por isso, a partir das principais propriedades das MHs usadas em nossos experimentos, estamos propondo um segundo conjunto de meta-atributos para o PCV. Antes de descrever esses meta-atributos, é necessário definir alguns elementos referentes às soluções clássicas para um PCV com $n$ cidades.

- $S_{i}=\left\{s_{i}^{1}, \ldots, s_{i}^{z}\right\}$ é o conjunto de soluções factíveis para a instância $i$ do PCV;

- $R_{i}=\left\{r_{i}^{1}, \ldots, r_{i}^{n}\right\}$ é o conjunto de $n$ soluções geradas aleatoriamente tal que $R_{i} \subset S_{i}$;

- $G_{i}=\left\{g_{i}^{1}, \ldots, g_{i}^{n}\right\}$ é o conjunto de $n$ soluções geradas pela heurística gulosa com diferentes cidades iniciais, tal que $G_{i} \subset S_{i}$;

- $N_{i}^{j}=\left\{n_{i}^{j 1}, \ldots, n_{i}^{j n}\right\}$ é o conjunto de soluções vizinhas a $s_{i}^{j}$. Neste trabalho, uma solução vizinha $n_{i}^{j k}$ é uma permutação entre as cidades adjacentes que pertencem à solução $s_{i}^{j}$. 
Toda solução factível $s_{i}^{j}$ está associada a um valor do custo da rota (ex. distância), que é obtido por uma função de custo da solução $c\left(s_{i}^{j}\right)$. O custo de uma solução corresponde à soma dos custos das arestas que compõem a rota indicada na solução. A melhor solução vizinha, identificada por $n_{i}^{j *}$, é aquela que possui o menor custo da rota dentre todas as soluções vizinhas, ou seja, $c\left(n_{i}^{j *}\right)=\min \left\{c\left(n_{i}^{j 1}\right), \ldots, c\left(n_{i}^{j n}\right)\right\}$.

Dadas essas definições, os meta-atributos baseados nas propriedades das MHs podem ser calculados usando as equações da Tabela 4.2 .

Tabela 4.2: Meta-atributos (MA) baseados em medidas que caracterizam as meta-heurísticas.

\begin{tabular}{|c|c|c|}
\hline MA & Notação Matemática & Descrição \\
\hline$I M V$ & $\frac{1}{n} \sum_{j=1}^{n} \operatorname{menor}\left(c\left(n_{i}^{j *}\right), c\left(r_{i}^{j}\right)\right)$ & $\begin{array}{l}\text { taxa da melhor solução vizi- } \\
\text { nha de uma solução aleatória } \\
\text { ser melhor do que a solução } \\
\text { aleatória }\end{array}$ \\
\hline$Q M V$ & $\frac{1}{n} \sum_{j=1}^{n} \frac{c\left(n_{i}^{j *}\right)}{c\left(r_{i}^{j}\right)}$ & $\begin{array}{l}\text { média das razões entre o va- } \\
\text { lor da melhor solução vizinha } \\
\text { de cada solução aleatória e o } \\
\text { valor da solução aleatória }\end{array}$ \\
\hline$Q S V$ & $\frac{1}{n^{2}} \sum_{j=1}^{n} \sum_{k=1}^{n} \operatorname{menor}\left(c\left(n_{i}^{j k}\right), c\left(r_{i}^{j}\right)\right)$ & $\begin{array}{l}\text { taxa das soluções vizinhas de } \\
\text { um conjunto de soluções alea- } \\
\text { tórias serem melhores do que } \\
\text { as soluções aleatórias }\end{array}$ \\
\hline IGS & $\frac{1}{n^{2}} \sum_{j=1}^{n} \sum_{k=1}^{n} \operatorname{menor}\left(c\left(g_{i}^{j}\right), c\left(r_{i}^{k}\right)\right)$ & $\begin{array}{l}\text { taxa das soluções gulosas se- } \\
\text { rem melhores do que as solu- } \\
\text { ções geradas aleatoriamente }\end{array}$ \\
\hline$R G A$ & $\sum_{j=1}^{n} \frac{c\left(g_{i}^{j}\right)}{c\left(r_{i}^{j}\right)}$ & $\begin{array}{l}\text { razão entre os valores das so- } \\
\text { luções gulosas e os valores } \\
\text { das soluções aleatórias }\end{array}$ \\
\hline$Q M F$ & $\frac{1}{p} \sum_{j=1}^{p} \sum_{k=1}^{2} \operatorname{menor}\left(\min \left\{\check{r}_{i k}^{j}\right\}, \min \left\{\hat{r}_{i k}^{j}\right\}\right)$ & $\begin{array}{l}\text { taxa da melhor solução-filho } \\
\text { ser melhor do que a melhor } \\
\text { solução-pai }\end{array}$ \\
\hline$R P F$ & $\frac{1}{p} \sum_{j=1}^{p} \frac{c\left(\min \left\{\check{r}_{i k}^{j}\right\}\right)}{c\left(\min \left\{\hat{r}_{i k}^{j}\right\}\right)}$ & $\begin{array}{l}\text { média das razões entre o va- } \\
\text { lor da melhor solução-filho e } \\
\text { o valor da melhor solução-pai } \\
\text { de todas as reproduções }\end{array}$ \\
\hline$Q R S$ & $\frac{1}{4 p} \sum_{j=1}^{p} \sum_{k=1}^{2} \sum_{l=1}^{2}$ menor $\left(c\left(\check{r}_{i k}^{j}\right), c\left(\hat{r}_{i l}^{j}\right)\right)$ & $\begin{array}{l}\text { taxa das soluções-filho serem } \\
\text { melhores que as soluções-pai }\end{array}$ \\
\hline$I A C$ & $\frac{1}{n(n-1)} \sum_{j=1}^{n-1} \sum_{k=j+1}^{n} \operatorname{tamanho}\left(E_{i}^{j} \cap E_{i}^{k}\right)$ & $\begin{array}{l}\text { taxa de arestas compartilha- } \\
\text { das por soluções gulosas }\end{array}$ \\
\hline$A M C$ & $\frac{1}{n} \sum_{j=1}^{n}$ pertence $\left(e_{m c}, g s_{i}^{j}\right)$ & $\begin{array}{l}\text { taxa de soluções que contêm a } \\
\text { aresta mais compartilhada }\end{array}$ \\
\hline
\end{tabular}


Os três primeiros meta-atributos ( $I M V, Q M V$ e $Q S V)$ mensuram a qualidade das soluções vizinhas. As MHs BT e SA exploram a região de vizinhança da solução corrente, podendo aceitar soluções vizinhas piores a fim de escapar de ótimos locais. Para calcular esses meta-atributos, cada uma das $n$ soluções geradas aleatoriamente é comparada com a sua melhor solução vizinha. O meta-atributo $I M V$ mensura a taxa relativa da melhor solução vizinha de uma solução aleatória ser melhor do que a própria solução aleatória. A função menor $(c(x), c(y))$ retorna 1 , se $c(x)$ é menor que $c(y)$ e 0 , caso contrário. O metaatributo $Q M V$ fornece a razão média entre o custo da rota da melhor solução vizinha de cada solução gerada aleatoriamente e o custo da rota dessa solução aleatória. O meta-atributo $Q S V$ informa a taxa relativa das soluções vizinhas de soluções geradas aleatoriamente serem melhores do que as soluções aleatórias.

Uma solução inicial fornecida por uma iteração do GRASP é construída com a inserção de uma nova cidade à rota. O critério para a seleção de uma cidade candidata depende do valor atribuído ao nível de gula e de aleatoriedade. Por isso, os próximos dois meta-atributos, IGS e $R G A$, comparam as soluções gulosas com as soluções aleatórias. O resultado do cálculo da taxa relativa de soluções gulosas serem melhores do que as soluções aleatórias é atribuído ao meta-atributo $I G S$, enquanto a soma das razões entre o custo de uma solução gulosa e o custo de uma solução aleatória é mostrada pelo meta-atributo $R G A$.

Os próximos três meta-atributos, $Q M F, R P F$ e $Q R S$, são específicos para capturar propriedades inerentes aos AGs. Do conjunto de soluções $R_{i}, p$ pares de soluções são selecionadas aleatoriamente para compor o conjunto de soluções-pai, $\hat{R}_{i}=\left\{\left(\hat{r}_{i 1}^{1}, \hat{r}_{i 2}^{1}\right), \ldots,\left(\hat{r}_{i 1}^{p}, \hat{r}_{i 2}^{p}\right)\right\}$. As soluções em cada par são combinadas por um operador de cruzamento - ex. operador PMX (do inglês, Partial Mapped Crossover) (Goldberg e Lingle, 1985) - para gerar duas novas soluções-filho, que são inseridas no conjunto $\check{R}_{i}=\left\{\left(\check{r}_{i 1}^{1}, \check{r}_{i 2}^{1}\right), \ldots,\left(\check{r}_{i 1}^{p}, \check{r}_{i 2}^{p}\right)\right\}$. O meta-atributo $Q M F$ mensura a taxa relativa da melhor solução-filho ter uma qualidade superior à melhor solução-pai. A função $\min \left\{\check{r}_{i 1}, \check{r}_{i 2}\right\}$ retorna $\check{r}_{i 1}$, se $\mathrm{c}\left(\check{r}_{i 1}\right)<\mathrm{c}\left(\check{r}_{i 2}\right)$ e $\check{r}_{i 2}$, caso contrário. A razão média entre os custos das melhores soluções-filho e os custos das melhores soluções-pai é capturada pelo meta-atributo RPF. Comparando todas as soluções-filho com as respectivas soluções-pai para todos os pares de soluções-pai selecionados, o metaatributo $Q R S$ mensura a taxa relativa das soluções reproduzidas serem melhores do que aquelas usadas para reproduzi-las.

A solução fornecida pela OCF identifica uma rota, provavelmente, percorrida por todas as formigas artificiais com rotas iniciais diferentes. A convergência das rotas ocorre porque as formigas mudam o trajeto ao longo do tempo, seguindo pelo caminho com o cheiro do feromônio mais forte. $\mathrm{O}$ fe- 
romônio é uma substância deixada pelas formigas por onde passam. Assim, uma solução da OCF é produzida quando todas as soluções (rotas das formigas) compartilham as mesmas arestas. Os dois últimos meta-atributos, $I A C$ e $A M C$, capturam informações sobre o compartilhamento de arestas entre várias soluções. Considere uma solução $s_{i}^{j}$ para um PCV como um conjunto das arestas $E_{i}^{j}=\left\{e_{i 1}^{j}, \ldots, e_{i n}^{j}\right\}$ que compõem a solução. O meta-atributo $I A C$ calcula a média relativa de arestas compartilhadas entre todos os pares de diferentes soluções geradas por uma heurística gulosa. A função tamanho(E) retorna o número de elementos do conjunto $E$ que, no nosso caso, é o número de arestas. Usando uma função de mapeamento $q: E \rightarrow \Re$ para identificar o número de soluções gulosas que usam cada aresta, podemos identificar a aresta mais compartilhada $e_{m c}$ por meio de $q\left(e_{m c}\right)=\max \left\{q\left(e_{1}\right), \ldots, q\left(e_{m}\right)\right\}$. Finalmente, o meta-atributo $A M C$ indica a frequência relativa da aresta $e_{m c}$ nas soluções gulosas. A função pertence $(a, X)$ retorna 1 , se $a$ pertence ao conjunto $X$ e 0 , caso contrário.

Para encontrar uma solução de otimização, SA explora diferentes regiões no espaço de soluções conforme a probabilidade de serem aceitas soluções vizinhas piores que a solução corrente. Inicialmente, o valor dessa probabilidade é elevado, sendo reduzido gradativamente. Como o processo de diversificação na busca por uma boa solução é também baseado na comparação da solução atual com as soluções vizinhas, não propusemos meta-atributos específicos para o SA. Pois, os meta-atributos que capturam as propriedades do BT também são baseados em características da região de vizinhança.

\subsection{Meta-atributos baseados em landmarkers}

Nesta tese, landmarkers são estimadores rápidos de desempenho das MHs para instâncias de PCV. Os estimadores podem ser obtidos por meio de execuções de versões simplificadas das MHs (ex.: algoritmo genético manipulando uma população com apenas quatro indivíduos). Uma alternativa para calcular os estimadores seria executar as MHs candidatas e obter o desempenho de cada uma em uma amostra das instâncias. Desse modo, os desempenhos obtidos representam as propriedades conhecidas como subsampling (Brazdil et al., 2009) (ex.: executar as MHs em subproblemas compostos por subconjunto de cinco cidades). Se o desempenho dos subsampling landmarkers tiver uma relação com o desempenho das MHs, espera-se que esta abordagem de geração de meta-atributos contribua para o aprendizado do meta-modelo.

Em nosso trabalho, usamos cinco MHs para investigar a capacidade preditiva dos meta-modelos. Em experimentos preliminares, essas MHs tiveram o mesmo desempenho de otimização para instâncias do PCV com poucas ci- 
dades. Por essa razão, as propriedades de subsampling usadas como metaatributos não foram investigadas nesta pesquisa. Assim, os meta-atributos apresentados nesta seção são aqueles baseados em landmarkers.

Seja $X=\left\{x_{1}, \ldots x_{t}\right\}$ o conjunto de instâncias do PCV usado para o treinamento dos modelos classificadores, em que cada $x_{i} \in X$ é submetida a uma versão simplificada das MHs disponíveis. As MHs usadas são estocásticas e diferentes soluções podem ser fornecidas após os respectivos algoritmos serem executados com diferentes inicializações. Por isso, cada instância foi submetida 30 vezes a cada algoritmo e o custo médio das rotas obtidas após as 30 execuções foi utilizado como desempenho da $\mathrm{MH}$ para essa instância. Os meta-atributos gerados a partir da caracterização de landmarkers, mostrados na Tabela 4.3, correspondem aos valores de solução das MHs, que podem ser usados para indicar um ranking de desempenho das MHs.

Tabela 4.3: Meta-atributos (MA) extraídos a partir da caracterização de landmarkers.

\begin{tabular}{lll}
\hline MA & Notação Matemática & Descrição \\
\hline$D B T$ & $\operatorname{tabu}(x)$ & valor da solução fornecida pela BT \\
$D G R$ & $\operatorname{grasp}(x)$ & valor da solução fornecida pelo GRASP \\
$D S A$ & $\operatorname{sa}(x)$ & valor da solução fornecido pelo SA \\
$D A G$ & genetico $(x)$ & valor da solução fornecido pelo AG \\
$D C F$ & formiga $(x)$ & valor da solução fornecido pela OCF \\
\hline
\end{tabular}

Para obter rapidamente uma solução, os parâmetros livres das MHs foram configurados conforme segue:

- BT: tamanho da lista tabu $=2$, número de vizinhos $=2$ e número de iterações sem melhoria da solução corrente $=1$;

- GRASP: número de iterações = 1 e nível de aleatoriedade e de gula = 0,5;

- SA: temperatura inicial $=1$, taxa de aumento da temperatura $=10 \%$, taxa de aceitação da solução vizinha $=90 \%$ e taxa de resfriamento $=1 \%$.

- AG: tamanho da população $=4$, seleção de pais por torneio com dois indivíduos, taxa de cruzamento $=100 \%$, operador de cruzamento $=$ PMX, taxa de mutação $=5 \%$ e seleção de um indivíduo para a nova população por elitismo.

- OCF: número de formigas $=2$, taxa de evaporação do feromônio $=50 \%$, taxa de influência do feromônio $=100 \%$, taxa de influência da informação da heurística $=100 \%$. 


\subsection{Meta-atributos baseados em características de redes complexas}

Redes complexas têm sido muito utilizadas, nos últimos anos, para a análise de grafos. Dentre as diversas variações de redes complexas, as mais comuns são aquelas que podem ser rapidamente modeladas por meios dos seguintes tipos de grafos:

- grafos bidirecionais ponderados;

- grafos unidirecionais ponderados;

- grafos bidirecionais não ponderados;

- grafos unidirecionais não ponderados.

Particularmente, no contexto do PCV, estamos interessados principalmente em grafos ponderados, por causa do valor de custo associado às arestas que conectam as cidades. Algumas características das redes não ponderadas também podem ser extraídas por conter informações relevantes sobre a estrutura do problema como, por exemplo, a distribuição de conexões entre as cidades. Grafos bidirecionais correspondem aos exemplos de TSP simétricos e os grafos unidirecionais representam os exemplos assimétricos. Diversas medidas para a caracterização de redes complexas foram descritas em (Costa et al., 2007). Algumas dessas medidas foram usadas para gerar o conjunto de metaatributos listados na Tabela 4.4.

Distância é uma das principais características de uma rede, que fornece informações essenciais sobre a sua estrutura geral. Em nosso caso, estamos considerando o custo de viagem entre duas cidades como sendo a menor distância entre elas. Os três primeiros meta-atributos são relativos às propriedades capturadas por meio de medidas de distância. A distância geodésica média, que corresponde a média das distâncias entre todos os pares de vértices conectados em uma rede, é calculada pelo meta-atributo $M D G$. A distância entre dois vértices $i$ e $j$ também pode ser usado para quantificar a eficiência da rede em enviar as informações entre esses vértices, conforme mostra a equação que calcula o valor do meta-atributo $E G R$. O valor inverso da eficiência global é o resultado da média harmônica da distância geodésica, que é capturado pelo meta-atributo $M H G$.

Os três próximos meta-atributos $(C A T, C A A$ e $A R P)$ são referentes a medidas de agrupamentos e de ciclos. O meta-atributo $C A T$ captura informação sobre a estrutura cíclica de uma rede, mensurada por meio da propriedade de transitividade. Para isso, os coeficientes de agrupamentos $N_{\Delta}$ e $N_{3}$, que 
Tabela 4.4: Meta-atributos (MA) baseados em medidas para caracterizar redes complexas.

\begin{tabular}{|c|c|c|}
\hline MA & Notação Matemática & Descrição \\
\hline$M D G$ & $\frac{1}{n(n-1)} \sum_{i \neq j} c_{i j}$ & distância geodésica média \\
\hline$E G R$ & $\frac{1}{n(n-1)} \sum_{i \neq j} \frac{1}{c_{i j}}$ & eficiência global da rede \\
\hline$M H G$ & $\frac{1}{M D G}$ & $\begin{array}{l}\text { média harmônica da distân- } \\
\text { cias geodésicas }\end{array}$ \\
\hline$C A T$ & $\frac{3 N_{\Delta}}{N_{3}}$ & $\begin{array}{l}\text { coeficiente de agrupamento } \\
\text { (transitividade) }\end{array}$ \\
\hline$C A A$ & $\frac{1}{n} \sum_{i=1}^{n} \frac{N_{\Delta}(i)}{N_{3}(i)}$ & $\begin{array}{l}\text { coeficiente de agrupamento } \\
\text { alternativo }\end{array}$ \\
\hline$A R P$ & $\frac{1}{n} \sum_{i=1}^{n} \frac{1}{s_{i}\left(k_{i}-1\right)} \sum_{j=1}^{n} \sum_{k=j+1}^{n} \frac{c_{i j}+c_{i k}}{2} a_{i j} a_{i k} a_{j k}$ & $\begin{array}{l}\text { coeficiente de agrupamento } \\
\text { para redes ponderados }\end{array}$ \\
\hline$C C R$ & $\frac{1}{n} \sum_{i=1}^{n} \frac{2}{k_{i}\left(k_{i}-1\right)} \sum_{j=1}^{n} \sum_{k=1}^{n} \frac{1}{3} a_{i j} a_{i k}$ & coeficiente cíclico da rede \\
\hline$G M V$ & $\max \left\{k_{1}, \ldots, k_{n}\right\}$ & grau máximo dos vértices \\
\hline$C G A$ & $\frac{(1 / m) \sum_{j>i} k_{i} k_{j} a_{i j}-\left[(1 / 2 m) \sum_{j>i}\left(k_{i}+k_{j}\right) a_{i j}\right]^{2}}{(1 / 2 m) \sum_{j>i}\left(k_{i}^{2}+k_{j}^{2}\right) a_{i j}-\left[(1 / 2 m) \sum_{j>i}\left(k_{i}+k_{j}\right) a_{i j}\right]^{2}}$ & $\begin{array}{l}\text { correlação entre os graus de } \\
\text { saída das arestas }\end{array}$ \\
\hline$V N C$ & $\max \left\{N V_{1}, \ldots, N V_{n}\right\} ; N V_{i}=\frac{E G R-E G R_{i}}{E G R}$ & vulnerabilidade da rede \\
\hline$E D G$ & $-\sum_{k=1}^{t} P(k) \log P(k)$ & $\begin{array}{l}\text { entropia da distribuição do } \\
\text { grau dos vértices }\end{array}$ \\
\hline$E V A$ & $-\frac{1}{n} \sum_{i=1}^{n} \sum_{j=1}^{n} a_{j i} c_{i j} \log _{2} c_{i j}$ & entropia do vértice alvo \\
\hline$C P V$ & $\frac{1}{n} \sum_{i=1}^{n} 1-\sum_{s=1}^{y}\left(\frac{q_{i s}}{k_{i}}\right)^{2}$ & $\begin{array}{l}\text { taxa de participação dos vér- } \\
\text { tices nas comunidades }\end{array}$ \\
\hline$G R A$ & $\frac{1}{m} \sum_{i=1}^{n} \sum_{j=1}^{n} a_{i j} a_{j i}$ & Reciprocidade de aresta \\
\hline$C M A$ & $\frac{\left.\sum_{i=1}^{n} \sum_{j=1}^{n}\left(a_{i j}-\overline{(a)}\right)\left(a_{j i}-\overline{(a}\right)\right)}{\sum_{i=1}^{n} \sum_{j=1}^{n}\left(a_{i j}-(a)\right)^{2}}$ & $\begin{array}{l}\text { coeficiente de correlação da } \\
\text { matriz de adjacência }\end{array}$ \\
\hline
\end{tabular}

identificam ciclos de ordem 3 , são calculados. $N_{\Delta}$ é o número de triângulos na rede calculado por meio da Equação 4.2. Um triângulo é um conjunto de três vértices com uma aresta para cada par de vértices.

$$
N_{\Delta}=\sum_{k>j>i} a_{i j} a_{i k} a_{j k}
$$

onde cada $a_{i j}$ é um elemento da matriz de adjacências que assume um valor binário, $a_{i j}=1$ se existe uma aresta entre os vértices $i$ e $j$, e $a_{i j}=0$ caso contrário. $N_{3}$ é o número de triplos conectados, que pode ser obtido por meio da Equação 4.3:

$$
N_{3}=\sum_{k>j>i}\left(a_{i j} a_{i k}+a_{j i} a_{j k}+a_{k i} a_{k j}\right)
$$


Um triplo conectado é um conjunto de três vértices em que cada vértice pode ser atingido por qualquer outro de maneira direta ou indireta. $\mathrm{O}$ fator de ponderação do número de triângulos é igual a 3 porque cada triângulo pode ser constituído por três modos diferentes de triplo conectado, nos quais cada vértice é usado como vértice central.

O coeficiente de agrupamento, mensurado pelo meta-atributo $C A A$, calcula a média das razões entre o número de triângulos e o número de triplos conectados de todos vértices da rede. Há coeficientes específicos para mensurar o agrupamento dos vértices em redes ponderadas, como aquele representado pelo meta-atributo $A R P$, em que: $s_{i}$ é a soma dos pesos das arestas conectadas ao vértice $i$; $k_{i}$ é a quantidade de arestas conectadas ao vértice $i$; $c_{i j}$ é o valor do peso da aresta que conecta os vértices $i$ e $j$; e $a_{i j}$ é o valor de um elemento da matriz de adjacências.

Para medir a propriedade cíclica de uma rede, usamos o meta-atributo $C C R$, que calcula a média do coeficiente cíclico de todos os vértices da rede.

Os dois meta-atributos seguintes, $G M V$ e $C G A$, estão relacionados às propriedades de distribuição e correlações dos graus dos vértices da rede. O grau de um vértice é o número de arestas que conectam esse vértice aos outros vértices da rede. O meta-atributo $G M V$ é uma característica bastante simples, pois indica o grau da rede, que é o grau do vértice que possui o maior número de arestas conectadas. Uma propriedade que também pode ser mensurada a partir dos graus dos vértices é o índice de correlação entre os graus de dois vértices adjacentes. Um modo para calcular essa correlação é aplicar o coeficiente de Pearson nos graus de saída para cada par de vértices adjacentes, conforme mostra o meta-atributo $C G A$, que tem as seguintes variáveis: $m$ é o número total de arestas; $k_{i}$ é o grau de saída do vértice $i$ e $a_{i j}$ é o valor de um elemento da matriz de adjacências.

Em uma rede, os vértices hubs são geralmente os mais críticos, porque possuem o maior grau de vértice. A desconexão de um vértice hub geralmente causa um impacto maior na rede do que a eliminação de outros vértices de menor grau. No entanto, existem redes, como a árvore binária, em que todos os vértices têm o mesmo grau e o mais crítico é aquele que está na raiz da árvore. Para identificar os vértices mais críticos de uma rede, podemos calcular a vulnerabilidade de todos os vértices da rede. O meta-atributo $V N C$ calcula a vulnerabilidade da rede a partir da identificação do vértice mais crítico, em que: $E G R$ é a eficiência global da rede original e $E G R_{i}$ é a eficiência global da rede após a remoção do vértice $i$ e de todas as suas arestas.

Entropia é uma propriedade, bem conhecida da área de Teoria da Informação, usada para mensurar a "desordem" das informações em um dado sistema. Em uma rede, essa medida também pode ser aplicada para quantificar 
algumas características, como aquelas calculadas pelos meta-atributos $E D G$ e $E V A$. A entropia da distribuição do grau dos vértices (meta-atributo $E D G$ ) indica o nível de heterogeneidade dos graus dos vértices de uma rede. Essa entropia atinge o valor máximo quando o grau de cada vértice da rede é diferente dos demais, enquanto o valor mínimo $\left(H_{\min }=0\right)$ é obtido se todos os vértices tem o mesmo grau. A entropia do grau do vértice alvo quantifica a previsibilidade do fluxo de mensagens em uma rede. O meta-atributo $E V A$ calcula essa entropia, assumindo que as mensagens seguem sempre pelo caminho mais curto e que todos os pares de vértices trocam o mesmo número de mensagens. O valor mínimo para essa entropia indica que o vértice para onde a próxima mensagem deve seguir pode ser facilmente previsto.

A identificação de comunidades em uma rede grande é, particularmente, útil porque os vértices pertencentes a uma mesma comunidade geralmente possuem propriedades similares. Em redes reais, geralmente, não há qualquer informação sobre o número de comunidades. Para identificar possíveis comunidades, subconjuntos de vértices são obtidos por meio de algum método divisivo ou aglomerativo e a qualidade da divisão em comunidades é mensurada por medidas apropriadas. Com as comunidades identificadas, podemos calcular o coeficiente de participação dos vértices, mensurando a conexão de cada um com os vértices pertencentes a outras comunidades, conforme mostra o meta-atributo $C P V$, em que $q_{i s}$ é o número de arestas do vértice $i$ para a comunidade $s$ e $k_{i}$ é o grau do vértice $i$.

Uma propriedade não menos importante em uma rede é a reciprocidade da aresta, que pode ser usada para avaliar a rede modelada com a rede real. Essa propriedade indica a quantidade de informações perdidas quando a direção das arestas não é considerada. O meta-atributo GRA calcula o valor dessa propriedade para uma rede com $n$ vértices e $m$ arestas. Finalmente, o metaatributo $C C A$ é usado para calcular a correlação de Pearson da matriz de adjacência, que representa uma alternativa para mensurar a reciprocidade das arestas.

\subsection{Considerações finais}

Neste capítulo foram propostos e descritos quatro conjuntos de metaatributos para o PCV, que têm sido usados em nossos experimentos para a indução de meta-modelos. Os meta-atributos do primeiro conjunto são baseados em medidas estatísticas para sumarizar os custos de arestas e de vértices, propostas em (Kanda et al., 2011a). O segundo conjunto é uma nova proposta baseada em características específicas das MHs a fim de obter um mapeamento entre tais características e o desempenho dessas MHs em instân- 
cias de PCV. O terceiro conjunto de meta-atributos é baseado em execuções rápidas dos algoritmos conhecidas como landmarkers (Brazdil et al., 2009). Finalmente, os meta-atributos do quarto conjunto correspondem a medidas utilizadas para análise de redes complexas, descritas em (Costa et al., 2007).

Outras medidas de caracterização para o PCV podem ser transformadas em meta-atributos, como aquelas propostas por (Smith-Miles et al., 2010). Basicamente, esses meta-atributos são usados para descrever instâncias de PCV em que cada cidade é identificada por meio de um par de valores que indica a sua localização no espaço bidimensional. Esse conjunto de meta-atributos não foi usado em nossas avaliações experimentais porque o nosso conjunto de dados contém instâncias de PCV descritas por matrizes de distância, sem informações específicas sobre a localização de cada cidade. 


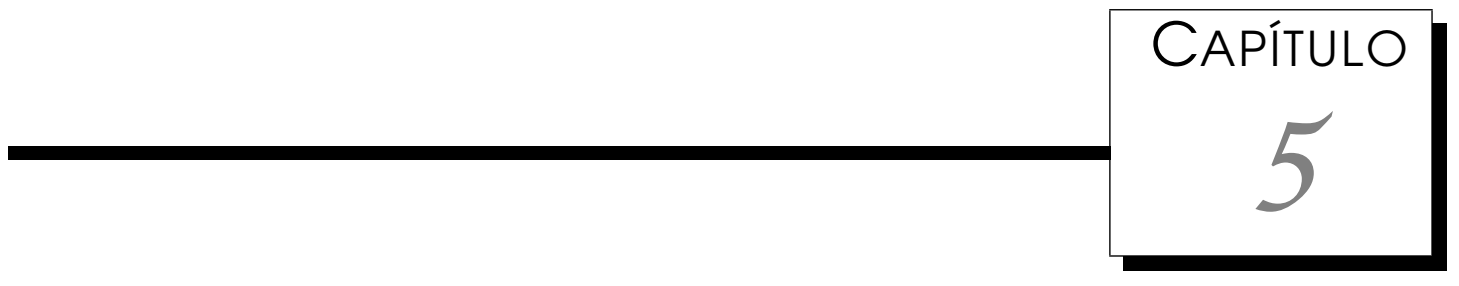

\section{Experimentos}

Neste capítulo estão descritos todos os experimentos realizados para avaliar a pesquisa desenvolvida nesta tese. Os experimentos preliminares consistiram na geração de um conjunto artificial de instâncias de PCV usadas para induzir meta-modelos. O problema de recomendação de MHs foi modelado como uma tarefa de classificação multirrótulo conforme descrito na Seção 5.1. Os principais resultados preliminares foram descritos em um artigo apresentado no 11o. Simpósio Brasileiro de Rede Neural Artificial (RNA) (Kanda et al., 2010). Uma extensão desse artigo, com resultados de experimentos complementares, foi publicada no periódico International Journal of Hybrid Intelligent Systems. Nesses experimentos, detalhados na Seção 5.2, os meta-exemplos de PCV foram gerados a partir de arquivos da biblioteca TSPLIB (Reinelt, 1991). Nos experimentos subsequentes, somente arquivos dessa biblioteca foram usados para gerar os meta-exemplos. A Seção 5.3 mostra os resultados da capacidade preditiva dos meta-modelos induzidos a partir de três diferentes abordagens de treinamento da RNA. A Seção 5.4 avalia os resultados experimentais de meta-modelos induzidos a partir de uma adaptação das RNAs, com a finalidade de recomendar um ranking de MHs para novas instâncias de PCV em dois cenários do mundo real. Finalmente, a Seção 5.5 relata os resultados experimentais, nos quais foram usados diferentes conjuntos de meta-atributos e diferentes algoritmos de AM adaptados para o ranking de rótulos.

Todas as seções deste capítulo são divididas em três subseções: a primeira descreve os procedimentos realizados para gerar o conjunto de metaexemplos; a segunda detalha a preparação dos meta-dados usados na indução dos meta-modelos; e a terceira analisa o desempenho preditivo dos metamodelos induzidos. 
É importante salientar que em nossos experimentos não houve a intenção de otimizar o desempenho das MHs e nem promover qualquer MH em particular, de modo que o objetivo foi apenas gerar meta-dados para o aprendizado do meta-modelo. Os parâmetros das MHs foram configurados após a realização de experimentos preliminares com diferentes valores a fim de que cada MH pudesse obter uma boa solução para o conjunto de instâncias. A fim de não favorecer qualquer $\mathrm{MH}$, todos algoritmos candidatos tiveram um mesmo tempo de processamento para fornecer a sua solução para cada uma das instâncias do PCV.

\subsection{Classificação multirrótulo em exemplos sintéticos de PCV}

Nos experimentos preliminares, os exemplos de PCV foram gerados empiricamente. A quantidade de vértices e arestas, assim como, os valores dos custos foram escolhidos arbitrariamente, com a única finalidade de obter uma diversidade de meta-exemplos com características diferentes e variações para os valores da classe. Cada meta-exemplo foi classificado de acordo com a $\mathrm{MH}$ que obteve o melhor desempenho de otimização. Como o melhor desempenho pode ser obtido por mais de uma $\mathrm{MH}$, técnicas de classificação multirrótulo foram utilizadas. Diferentes técnicas de AM foram usadas para a indução dos meta-modelos cujo desempenho preditivo foi avaliado por meio da acurácia e da área sob a curva ROC (AUC).

\subsubsection{Geração de meta-exemplos}

O primeiro conjunto de dados foi empiricamente criado a partir de 535 exemplos de PCV distribuídos em 12 grupos. Cada grupo foi identificado por uma das possíveis combinações de valores de três características extraídas do PCV: simetria, conectividade e laço. Um exemplo de PCV pode ser simétrico ou assimétrico; fortemente ou fracamente conectado; e com custo do laço (aresta de auto-conexão) podendo assumir valores: positivo, negativo ou nulo. A quantidade de exemplos em cada grupo foi definida por uma distribuição uniforme no intervalo [30, 70]. O número de vértices em cada exemplo foi escolhido aleatoriamente dentre os valores do intervalo [6, 50]. O valor do peso (custo) de cada aresta foi escolhido aleatoriamente dentre os valores do intervalo [50, 1000]. Para os exemplos de PCV fracamente conectados, foi adotada uma probabilidade igual a 0.84 para a inserção de cada aresta. Para os exemplos caracterizados por laços positivos, foi gerado um valor aleatório no intervalo $[50,200]$ para indicar o peso da aresta de auto-conexão, enquanto os 
valores de recompensa indicados nos laços negativos foram escolhidos de maneira aleatória no intervalo $[-40,-5]$. A distribuição quantitativa dos exemplos gerados por grupo é mostrada na Tabela 5.1.

Tabela 5.1: Quantidade de instâncias geradas de PCV por grupo de características: simetria, grau de conectividade e sinal do laço.

\begin{tabular}{clccc}
\hline Grupo & Simetria & Conectividade & Sinal do Laço & Instâncias \\
\hline 1 & Simétrico & Forte & Nulo & 30 \\
2 & Assimétrico & Forte & Nulo & 50 \\
3 & Simétrico & Fraco & Nulo & 56 \\
4 & Assimétrico & Fraco & Nulo & 49 \\
5 & Simétrico & Forte & Positivo & 58 \\
6 & Assimétrico & Forte & Positivo & 32 \\
7 & Simétrico & Fraco & Positivo & 55 \\
8 & Assimétrico & Fraco & Positivo & 41 \\
9 & Simétrico & Forte & Negativo & 47 \\
10 & Assimétrico & Forte & Negativo & 43 \\
11 & Simétrico & Fraco & Negativo & 37 \\
12 & Assimétrico & Fraco & Negativo & 37 \\
\hline
\end{tabular}

A fim de gerar a informação sobre o desempenho de otimização das diferentes MHs, todos os 535 exemplos de PCV foram processados por quatro $\mathrm{MHs}$ cujos algoritmos foram implementados na Linguagem de Programação C. Os parâmetros das MHs foram configurados com os seguintes valores:

- BT: tamanho da lista tabu $=2$, número de iterações sem melhoria da solução corrente $=2$;

- GRASP: número de iterações $=50$ e nível de gula e de aleatoriedade $(\alpha)=$ 0,1 ;

- SA: taxa de aceitação da solução vizinha $(\beta)=0,95$, temperatura inicial $=$ 1 e taxa de resfriamento $(\alpha)=0,01$;

- AG: tamanho da população $=128$, seleção de pais por torneio com dois indivíduos, taxa de cruzamento $=1$, edge recombination crossover $(\mathrm{ERX})$ (Whitley et al., 1991) como operador de cruzamento, taxa de mutação = $5 \%$, e seleção de um indivíduo para a nova população por elitismo.

Como as MHs adotadas são estocásticas, todos os algoritmos de otimização foram executados 50 vezes para cada instância de PCV, obtendo-se 50 soluções. $\mathrm{O}$ valor médio das 50 soluções obtidas por cada $\mathrm{MH}$ foi utilizado como valor de seu desempenho para essa instância. A Tabela 5.2 mostra a quantidade de exemplos em que cada $\mathrm{MH}$ teve o melhor desempenho para cada grupo de características. O valor da última coluna dessa tabela indica a soma dos valores 
mostrados nas quatro colunas anteriores. Esse valor é maior que o número de instâncias de PCV geradas no respectivo grupo devido ao mesmo desempenho de otimização obtido por diferentes MHs para algumas dessas instâncias. Em particular, BT obteve o melhor desempenho de otimização em 39,25\% das instâncias, seguido por GRASP (33,08\%), SA (31,59\%) e AG (20,37\%). Esses valores percentuais podem ser usados como referências para mensurar a qualidade da capacidade preditiva dos classificadores induzidos. Por exemplo, um classificador simples que indique somente a classe majoritária para todas as instâncias terá uma acurácia preditiva igual a 39,25\% para esse conjunto de dados. Desse modo, para usar a abordagem de meta-aprendizado, espera-se que a capacidade preditiva do meta-modelo induzido seja superior a 39,25\%.

Tabela 5.2: Número de instâncias de PCV geradas empiricamente em que as MHs obtiveram o melhor desempenho de otimização em cada grupo de características do problema.

\begin{tabular}{cccccc}
\hline Grupo & BT & GRASP & SA & AG & Total \\
\hline 1 & 7 & 9 & 5 & 19 & 40 \\
2 & 11 & 42 & 5 & 0 & 58 \\
3 & 35 & 4 & 23 & 6 & 68 \\
4 & 23 & 3 & 31 & 1 & 58 \\
5 & 13 & 24 & 9 & 29 & 75 \\
6 & 11 & 23 & 4 & 1 & 39 \\
7 & 35 & 7 & 20 & 13 & 75 \\
8 & 19 & 4 & 26 & 0 & 49 \\
9 & 7 & 20 & 4 & 30 & 61 \\
10 & 10 & 35 & 5 & 1 & 51 \\
11 & 21 & 5 & 13 & 9 & 48 \\
12 & 18 & 1 & 24 & 0 & 43 \\
\hline Total & 210 & 177 & 169 & 109 & 665 \\
\hline
\end{tabular}

Após a geração do conjunto de dados de PCV e a obtenção do desempenho de otimização das MHs, o conjunto de meta-dados foi gerado. Cada metaexemplo no conjunto de meta-dados corresponde a uma instância de PCV descrita por um conjunto de características (meta-atributos) do problema. Os meta-atributos usados nos experimentos preliminares são aqueles descritos na Tabela 5.3. Cada meta-exemplo foi classificado com o nome da(s) $\mathrm{MH}(\mathrm{s})$ de melhor desempenho para a instância de PCV correspondente.

\subsubsection{Indução dos meta-modelos}

Antes de escolher uma técnica de AM para induzir um meta-modelo a partir do conjunto de meta-dados, foi realizado o procedimento de préprocessamento que converte os valores simbólicos em valores numéricos (Tan 
Tabela 5.3: Meta-atributos de PCV usados para induzir meta-modelos classificadores de $\mathrm{MHs}$ - experimentos preliminares.

\begin{tabular}{lll}
\hline Meta-atributo & Descrição & Tipo \\
\hline Num_Vertice & quantidade de vértices & numérico \\
Num_Aresta & quantidade de arestas & numérico \\
Max_Aresta & número máximo de arestas & numérico \\
Menor_Aresta & menor custo entre duas cidades & numérico \\
Maior_Aresta & maior custo entre duas cidades & numérico \\
Media_Custo & média dos custos entre duas cidades & numérico \\
Desvio_Padrao & desvio padrão dos custos entre duas cidades & numérico \\
Mediana_Custo & mediana dos custos entre duas cidades & numérico \\
Freq_Moda & frequência do custo mais repetitivo & numérico \\
Qtde_Moda & quantidade de custos com maior frequência & numérico \\
Media_Moda & média dos custos mais frequentes & numérico \\
Menores_Media & quantidade de arestas com custo menor que & numérico \\
& a media dos custos & \\
Soma_Menores & soma dos Num_Vertice menores custos entre & numérico \\
Simetria & duas cidades & \\
indica se o PCV é simétrico ou assimétrico & simbólico \\
Sinal_Laco & informa se o PCV é fortemente ou fracamente & simbólico \\
& conectado & \\
& sinal do valor de auto-conexão: nulo, positivo & simbólico
\end{tabular}

et al., 2006). Para exemplificar, todos os valores "sim" e "nao" do meta-atributo "Simetria" foram transformados em " 1 " e " 0 ", respectivamente. Outro procedimento de pré-processamento realizado foi a transformação das classes multirrótulos em classe de rótulo único. Essa tarefa foi feita a partir da aplicação de três abordagens de conversão de classes: transformação baseada em rótulos (Tsoumakas e Katakis, 2007), decomposição de rótulos (Boutell et al., 2004) e eliminação de exemplos multirrótulos (De Carvalho e Freitas, 2009).

A fim de analisar comparativamente as três abordagens adotadas, Os 535 meta-exemplos foram utilizados em cada uma das abordagens, de modo que três cenários diferentes foram obtidos. O cenário 1 corresponde ao uso da abordagem da decomposição de rótulos, o cenário 2 ao uso da abordagem da eliminação de exemplos multirrótulos e o cenário 3 ao uso da abordagem de transformação baseada em rótulos.

Em cada cenário, o conjunto de meta-dados resultante da transformação foi usado por quatro algoritmos de AM do Software Weka 3.6 (Bouckaert et al., 2008): K-Vizinhos-Mais-Próximos (K-NN), algoritmo de indução de Árvore de Decisão (AD), Máquina de Vetor de Suporte (SVM) e Nä̈ve Bayes (NB). Para o treinamento dos meta-modelos, a metodologia de validação cruzada em 10 pastas foi adotada, sendo parametrizada com os valores sugeridos pelo refe- 
rido software. A avaliação da capacidade preditiva dos meta-modelos treinados foi estimada por meio das medidas de acurácia e AUC. Os desempenhos preditivos calculados a partir dessas medidas estão descritos na próxima seção.

\section{1.3 Resultados experimentais}

Os valores de acurácia e AUC mostrados na Tabela 5.4 indicam o desempenho preditivo dos meta-modelos para o cenário 1 . Os valores obtidos para cada medida sugerem uma similaridade na capacidade preditiva dos meta-modelos induzidos por diferentes técnicas de AM. Apesar dos valores de acurácia terem sido superiores a 50\%, o desempenho dos meta-modelos foi influenciado pelas instâncias replicadas. A replicação resultou em instâncias diferentes com valor igual para um dado meta-atributo e valor diferente para o metaatributo alvo. Desse modo, as instâncias replicadas dificultam o aprendizado do modelo classificador.

Tabela 5.4: Acurácia e AUC dos classificadores para a abordagem de decomposição de instâncias multirrótulo — instâncias de PCV geradas empiricamente.

\begin{tabular}{lcccc}
\hline Medidas & K-NN & AD & SVM & NB \\
\hline Acurácia & $0.52 \pm 0.06$ & $0.54 \pm 0.08$ & $0.53 \pm 0.06$ & $0.53 \pm 0.03$ \\
AUC & $0.79 \pm 0.08$ & $0.77 \pm 0.07$ & $0.75 \pm 0.07$ & $0.74 \pm 0.08$ \\
\hline
\end{tabular}

No cenário 2, os classificadores induzidos tiveram um desempenho melhor do que no cenário anterior, conforme pode ser observado os resultados na Tabela 5.5. Esse resultado já era esperado, pois todos os meta-exemplos multirrótulos foram eliminados e, consequentemente, não houve inconsistência no conjunto de meta-dados. No entanto, a abordagem aplicada para esse cenário é somente recomendável quando a quantidade de instâncias multirrótulos não é significativa, ou seja, as instâncias remanescentes do problema continuam sendo representativas e apropriadas para a indução do meta-modelo.

Tabela 5.5: Acurácia e AUC dos classificadores para a abordagem de eliminação de instâncias multirrótulo — instâncias de PCV geradas empiricamente.

\begin{tabular}{lcccc}
\hline Medidas & K-NN & AD & SVM & NB \\
\hline Acurácia & $0.63 \pm 0.07$ & $0.64 \pm 0.05$ & $0.63 \pm 0.07$ & $0.63 \pm 0.04$ \\
AUC & $0.88 \pm 0.06$ & $0.81 \pm 0.07$ & $0.84 \pm 0.07$ & $0.84 \pm 0.09$ \\
\hline
\end{tabular}

Os resultados obtidos para o cenário 3 podem ser visualizados na Tabela 5.6. O uso de quatro MHs candidatas implicou na replicação de quatro con- 
juntos de meta-dados para classificação binária. Para cada conjunto de metadados, uma das MHs foi considerada como a classe positiva e as demais como a classe negativa. Os classificadores tiveram desempenhos similares para as diferentes classes, sendo que alguns foram melhores para uma das classes, como, por exemplo: a técnica NB, que foi melhor para predizer a classe AG, enquanto a técnica $\mathrm{AD}$ foi a melhor para predizer a classe GRASP. Os resultados preditivos mensurados pela AUC podem ser considerados muito bons em termos práticos, levando em conta à complexidade do problema investigado.

Tabela 5.6: Acurácia e AUC dos classificadores para a abordagem de transformação baseada em rótulos — instâncias de PCV geradas empiricamente.

\begin{tabular}{lcccc}
\hline Medidas & K-NN & AD & SVM & NB \\
\hline Acurácia - Classe TB & 0.80 & 0.88 & 0.81 & 0.77 \\
AUC - Classe TB & 0.90 & 0.93 & 0.79 & 0.81 \\
Acurácia - Classe GRASP & 0.86 & 0.95 & 0.82 & 0.71 \\
AUC - Classe GRASP & 0.93 & 0.98 & 0.80 & 0.81 \\
Acurácia - Classe SA & 0.79 & 0.85 & 0.82 & 0.72 \\
AUC - Classe SA & 0.89 & 0.93 & 0.78 & 0.78 \\
Acurácia - Classe AG & 0.87 & 0.92 & 0.86 & 0.84 \\
AUC - Classe AG & 0.92 & 0.94 & 0.79 & 0.88 \\
\hline
\end{tabular}

Ainda no cenário 3, a medida "HammingLoss" (De Carvalho e Freitas, 2009) foi também usada para mensurar a qualidade preditiva dos meta-modelos. Essa medida é apropriada para problemas de classificação multirrótulo porque calcula a diferença de simetria entre o conjunto de classes preditas e o conjunto de classes verdadeiras para cada instância. Quanto menor o valor obtido para essa medida, melhor é o desempenho do classificador. A Tabela 5.7 mostra o desempenho dos classificadores obtidos a partir da medida "HammingLoss" para o cenário 3. Particularmente para este cenário, o cálculo da acurácia foi realizado conforme proposto em (Tsoumakas e Katakis, 2007) e a AUC foi calculada a partir dos valores obtidos por classe. Como a metodologia usada para calcular o desempenho preditivo dos meta-modelos no terceiro cenário é diferente daquela que foi usada nos dois primeiros, não é possivel fazer uma comparação entre cenários.

Comparando o desempenho preditivo dos diferentes classificadores induzidos por cada cenário, a Figura 5.1 mostra uma similaridade no desempenho dos classificadores tanto para o cenário 1 quanto para o cenário 2 . No terceiro cenário, houve uma divergência maior entre o desempenho preditivo dos meta-modelos. A principal razão para essa diferença está na técnica de classificação multirrótulo adotada para esse cenário. A indução de múltiplos modelos e a avaliação preditiva condicionada para cada meta-exemplo podem favorecer o viés de uma determinada técnica de AM. Outro aspecto relevante 
Tabela 5.7: Resultado de medidas especificas para a classificação multirrótulo baseada em rótulos — instâncias de PCV geradas empiricamente.

\begin{tabular}{lcccc}
\hline Medidas & $\mathrm{K}-\mathrm{NN}$ & $\mathrm{AD}$ & $\mathrm{SVM}$ & $\mathrm{NB}$ \\
\hline Acurácia & $0.62 \pm 0.07$ & $0.73 \pm 0.07$ & $0.56 \pm 0.07$ & $0.30 \pm 0.11$ \\
AUC & $0.91 \pm 0.02$ & $0.95 \pm 0.02$ & $0.79 \pm 0.01$ & $0.82 \pm 0.04$ \\
HammingLoss & $0.17 \pm 0.03$ & $0.10 \pm 0.03$ & $0.18 \pm 0.03$ & $0.24 \pm 0.03$ \\
\hline
\end{tabular}

nesse cenário é o elevado custo computacional, pois um meta-modelo deve ser induzido separadamente para cada conjunto de meta-dados resultante, de modo que a classificação multirrótulo para um meta-exemplo é a combinação das classes indicadas por todos os meta-modelos. Em todos os cenários, o desempenho preditivo foi superior a $50 \%$, mostrando o potencial da abordagem de meta-aprendizado na recomendação de MHs para novas instâncias de PCV.

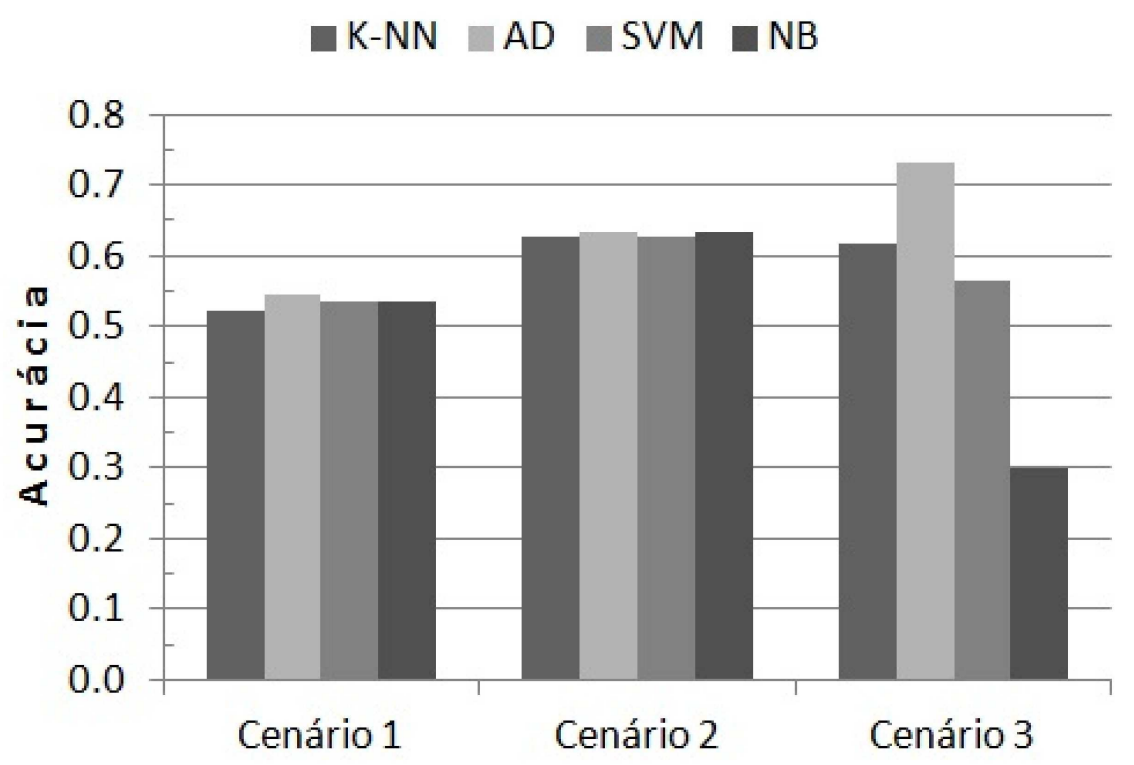

Figura 5.1: Acurácia dos modelos de classificação nos conjuntos de PCV sintéticos resultantes da aplicação de três técnicas de classificação multirrótulo.

A fim de verificar a existência de diferenças significativas no desempenho dos meta-modelos induzidos por diferentes técnicas de AM, testes estatísticos foram realizados. Para esses experimentos, seguimos o estudo de Demsar (Demšar, 2006), que essencialmente aplica o Teste de Friedman e, quando a hipótese nula (algoritmos apresentaram o mesmo desempenho) foi rejeitada para um determinado valor de alfa (nível de significância), o Teste de Nemenyi foi aplicado para comparar o desempenho de dois algoritmos diferentes. O Teste de Nemenyi avalia as diferenças entre as posições médias referentes à ordem de desempenho de diferentes algoritmos aplicados a diferentes conjuntos de dados. 
As tabelas 5.8 e 5.9 mostram o ranking de desempenho dos classificadores mensurado pela acurácia e AUC, respectivamente, para os diferentes conjuntos de meta-dados. O menor valor em cada linha das tabelas indica que o classificador identificado na coluna teve o melhor desempenho preditivo naquele conjunto de meta-dados. A última linha informa a posição média de cada classificador no ranking de desempenho.

Tabela 5.8: Ranking dos classificadores de acordo com o desempenho preditivo medido pela acurácia - instâncias de PCV geradas empiricamente.

\begin{tabular}{lcccc}
\hline Conjunto de Dados & K-NN & AD & SVM & NB \\
\hline Cenário 1 & 4 & 1 & 2,5 & 2,5 \\
Cenário 2 & 4 & 1 & 3 & 2 \\
Cenário 3 - Classe TS & 3 & 1 & 2 & 4 \\
Cenário 3 - Classe GRASP & 2 & 1 & 3 & 4 \\
Cenário 3 - Classe SA & 3 & 1 & 2 & 4 \\
Cenário 3 - Classe GA & 2 & 1 & 3 & 4 \\
\hline Posição média no ranking & 3,0 & 1,0 & 2,6 & 3,4 \\
\hline
\end{tabular}

Considerando os valores de acurácia obtidos e aplicando o Teste de Friedman a fim detectar diferenças significativas entre o desempenho dos algoritmos de classificação, um valor de probabilidade $p=0,0066$ foi obtido. Esse valor indica, grosseiramente, a probabilidade de obter resultados tão extremos quanto os que foram obtidos, assumindo que os algoritmos apresentaram o mesmo desempenho. Como o valor de $p$ foi menor que 5\% (nível de significância adotado), a hipótese nula foi rejeitada, de modo que o Teste de Nemenyi foi aplicado. Os resultados obtidos pelo Teste de Nemenyi indicaram, que ao nível de significância de 5\%, existem diferenças significativas quando os seguintes pares de algoritmos de classificação foram comparados: (K-NN, $\mathrm{AD})$ e (NB, AD). Aplicando os mesmos testes aos valores de AUC, um valor de $p$ igual a 0,0186 foi obtido para o Teste de Friedman e a hipótese nula foi rejeitada para o mesmo nível de significância. No entanto, usando o Teste de Nemenyi, não foi possível identificar evidências estatísticas que comprovem diferenças entre o desempenho dos diferentes classificadores para esse conjunto de experimentos. Isso significa que, dentre as técnicas de AM adotadas, o desempenho preditivo dos classificadores deve ser similar e que outros fatores, como o tempo computacional para induzir o meta-modelo, podem ser determinantes para a escolha da técnica de AM. 
Tabela 5.9: Ranking dos classificadores de acordo com o desempenho preditivo medido pela AUC - instâncias de PCV geradas empiricamente.

\begin{tabular}{lcccc}
\hline Conjunto de Dados & K-NN & AD & SVM & NB \\
\hline Cenário 1 & 1 & 2 & 3 & 4 \\
Cenário 2 & 1 & 4 & 2 & 3 \\
Cenário 3 - Classe TS & 2 & 1 & 4 & 3 \\
Cenário 3 - Classe GRASP & 2 & 1 & 4 & 3 \\
Cenário 3 - Classe SA & 2 & 1 & 3 & 4 \\
Cenário 3 - Classe GA & 2 & 1 & 4 & 3 \\
\hline Posição média no ranking & 1,7 & 1,7 & 3,3 & 3,3 \\
\hline
\end{tabular}

\subsection{Classificação multirrótulo em exemplos de PCV gerados a partir de arquivos da biblioteca TSPLIB}

A fim de usar outros conjuntos de dados para avaliar os mesmos experimentos descritos na seção anterior, vários subproblemas foram gerados a partir de arquivos de PCV. Os principais resultados foram reportados em um artigo (Kanda et al., 201 1a) publicado no peródico International Journal of Hybrid Intelligent Systems.

\subsubsection{Geração de meta-exemplos}

Os exemplos de PCV usados na geração dos subproblemas foram extraídos dos seguintes arquivos contidos na biblioteca TSPLIB: $d 1291$, fl1400, nrw1379, pcb1173 e pr 1002. Cada arquivo é uma instância de PCV descrita por uma matriz de distância. O nome do arquivo identifica o número de cidades do problema, por exemplo, a instância dada em $d 1291$ contém 1291 cidades. A fim de reduzir o custo computacional para a obtenção do conjunto de meta-dados, um limite máximo de 100 cidades foi arbitrariamente estabelecido para os subproblemas gerados. Como as instâncias de PCV geradas hipoteticamente tinham no máximo 50 cidades, o tamanho dos subproblemas gerados a partir de dados reais variou de 60 a 100 cidades. Particularmente, 100 subproblemas foram gerados para cada um dos cinco tamanhos: 60, 70, 80, 90 e 100 cidades selecionadas aleatoriamente. Desse modo, o novo conjunto de meta-dados foi composto por 2500 instâncias de PCV (5 arquivos de PCV $\times 5$ tamanhos diferentes do problema $\times 100$ subproblemas gerados aleatoriamente).

As mesmas MHs descritas na seção anterior, com suas respectivas configurações de parâmetros, foram adotadas nesses experimentos. A quantidade relativa de instâncias para as quais cada $\mathrm{MH}$ obteve a melhor solução média é mostrada na Tabela 5.10. 
Tabela 5.10: Desempenho das MHs mensurado pelo número relativo de instâncias em que a melhor solução foi obtida para instâncias de PCV geradas a partir de arquivos da biblioteca TSPLIB.

\begin{tabular}{cc}
\hline Meta-heurística & Desempenho \\
\hline GRASP & $59,00 \%$ \\
AG & $26,56 \%$ \\
SA & $26,40 \%$ \\
TS & $15,48 \%$ \\
\hline
\end{tabular}

O melhor desempenho (59\%) indicado na tabela será posteriormente usado como valor de referência (baseline) para avaliar a capacidade preditiva dos meta-modelos. A Figura 5.2 ilustra o número de melhores soluções obtidas por cada MH no conjunto de 2500 instâncias. As áreas de interseção na figura representam as instâncias para as quais mais de uma $\mathrm{MH}$ obteve o melhor desempenho. Conforme mencionado, o problema de recomendação de $\mathrm{MH}$ foi modelado como uma tarefa de classificação multirrótulo. Os três cenários de classificação multirrótulo já descritos foram novamente considerados para avaliar o desempenho preditivo dos meta-modelos.

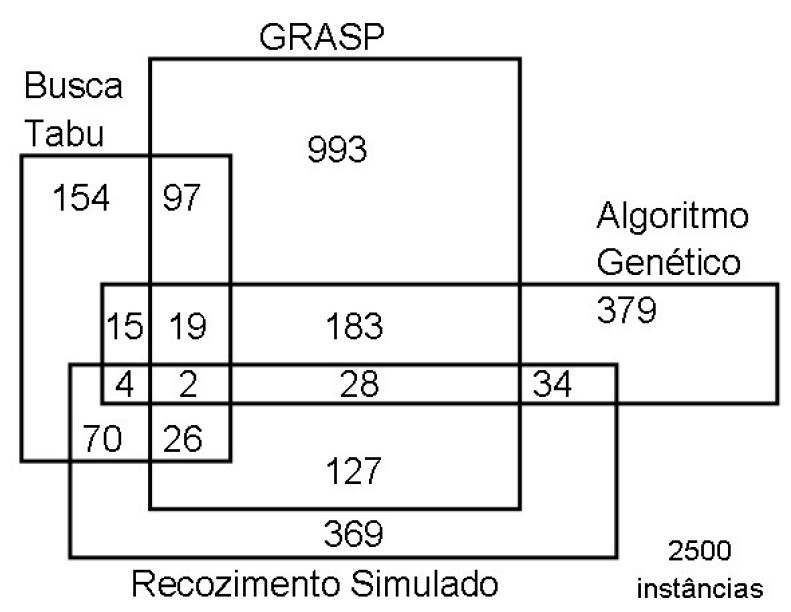

Figura 5.2: Número de instâncias de PCV geradas a partir de arquivos da bibllioteca TSPLIB em que cada meta-heurística (MH) obteve o melhor desempenho de otimização.

\subsubsection{Indução dos meta-modelos}

A fim de padronizar os experimentos usando os dois conjuntos de metadados de PCV (dados empíricos e dados de arquivos reais), os mesmos algoritmos de classificação e suas respectivas configurações foram adotados nesses experimentos. Os resultados experimentais para o conjunto de meta-dados construído a partir de arquivos da bibilioteca TSPLIB são apresentados na próxima seção. 


\subsubsection{Resultados experimentais}

As tabelas 5.11, 5.12 e 5.13 mostram os resultados mensurados por acurácia e AUC para os cenários 1, 2 e 3, respectivamente. Para o cenário 1, a acurácia preditiva dos meta-modelos mostra que o desempenho preditivo foi baixo, já que todos foram inferiores ao valor do baseline. Esse fraco desempenho se deve a inconsistência do conjunto de meta-dados após a replicação das instâncias multirrótulos. Os meta-modelos conseguiram um bom desempenho preditivo no conjunto de meta-dados do cenário 2 , mas que pode ser inferior se o conjunto original contiver muitos exemplos multirrótulos, que devem ser excluídos para a indução do meta-modelo. A combinação dos resultados de classificação dos meta-modelos induzidos no cenário 3 propiciou novamente um bom resultado preditivo.

Tabela 5.11: Acurácia e AUC dos classificadores para a decomposição de instâncias multirrótulo - instâncias de PCV geradas a partir de arquivos do TSPLIB.

\begin{tabular}{lcccc}
\hline Medidas & K-NN & AD & SVM & NB \\
\hline Acurácia & $0.50 \pm 0.02$ & $0.50 \pm 0.02$ & $0.53 \pm 0.02$ & $0.39 \pm 0.03$ \\
AUC & $0.66 \pm 0.08$ & $0.63 \pm 0.06$ & $0.66 \pm 0.07$ & $0.67 \pm 0.06$ \\
\hline
\end{tabular}

Tabela 5.12: Acurácia e AUC dos classificadores para a eliminação de instâncias multirrótulo - instâncias de PCV geradas a partir de arquivos do TSPLIB.

\begin{tabular}{lcccc}
\hline Medidas & K-NN & AD & SVM & NB \\
\hline Acurácia & $0.63 \pm 0.01$ & $0.61 \pm 0.03$ & $0.64 \pm 0.01$ & $0.45 \pm 0.03$ \\
AUC & $0.75 \pm 0.12$ & $0.70 \pm 0.10$ & $0.72 \pm 0.08$ & $0.73 \pm 0.08$ \\
\hline
\end{tabular}

Tabela 5.13: Acurácia e AUC dos classificadores para a transformação baseada em rótulos - instâncias de PCV geradas a partir de arquivos do TSPLIB.

\begin{tabular}{lcccc}
\hline Medidas & K-NN & AD & SVM & NB \\
\hline Acurácia & $0.77 \pm 0.02$ & $0.77 \pm 0.02$ & $0.76 \pm 0.02$ & $0.60 \pm 0.04$ \\
AUC & $0.72 \pm 0.08$ & $0.66 \pm 0.12$ & $0.60 \pm 0.09$ & $0.71 \pm 0.06$ \\
\hline
\end{tabular}

A partir desses resultados, podemos inferir que, dentre os métodos de classificação multirrótulo investigados, aquele que foi usado no cenário 3 parece ser o mais promissor para ser aplicado na classificação de instâncias de PCV. Além disso, a similaridade entre o valor de acurácia obtido por três classificadores (K-NN, AD e SVM) em cada cenário sugere que o custo computacional 
para o processo de aprendizado pode ser reduzido. Essa redução pode ser atingida escolhendo apenas um dos três classificadores para ser aplicado em um conjunto de dados semelhante àquele usado no cenário 3. Provavelmente, o menor desempenho do classificador NB pode ter sido causado pela violação da hipótese sobre a interdependência dos atributos.

Comparando os valores da AUC obtidos para os diferentes cenários, podemos ver que o melhor resultado ocorreu para o cenário 2. A expectativa era que o aprendizado decorrente do conjunto de meta-dados do cenário 3 produzisse melhores resultados, por causa do maior número de exemplos usados para o treinamento dos meta-modelos. No entanto, o desempenho desses meta-modelos foi fortemente influenciado pelo balanceamento das classes. Enquanto no conjunto de meta-dados produzido no cenário 2 houve 46\% dos meta-exemplos na classe majoritária, no cenário 3 a classe majoritária foi composta por $73 \%$ dos meta-exemplos.

Para avaliar se existe diferença significativa entre o desempenho dos metamodelos induzidos a partir de diferentes algoritmos de classificação, o Teste de Friedman foi novamente aplicado e seguido, quando necessário, do Teste de Nemenyi. O ranking de desempenho dos algoritmos de classificação avaliados por medidas de acurácia e AUC nos diferentes conjuntos de dados gerados a partir de arquivos reais estão mostrados nas tabelas 5.14 e 5.15, respectivamente. Considerando os valores de acurácia, um valor $p$ igual a 0,0083 foi obtido a partir do Teste de Friedman, rejeitando a hipótese nula para $\alpha=5 \%$. Aplicando o Teste de Nemenyi para o mesmo nível de significância, foi observada a existência de uma diferença significativa entre o desempenho preditivo obtido pelos seguintes pares de técnicas de AM: (NB, KNN) e (NB, SVM). Aplicando o Teste de Friedman com o mesmo nível de significância nos valores de AUC, um valor $p$ igual a 0,0169 foi obtido. Em seguida, usando o Teste de Nemenyi, não foi possível detectar qualquer diferença significativa entre os pares de algoritmos de AM. A partir dos resultados dos testes estatísticos, uma conclusão mais conservadora indica a necessidade de realizar mais pesquisas para afirmar que um classificador particular é mais apropriado do que outro para esse tipo de problema.

\subsection{Recomendação de ranking de $\mathrm{MHs}$}

A recomendação da $\mathrm{MH}$ mais promissora para uma instância de PCV por um classificador resulta na indicação de um único algoritmo de otimização ou um conjunto de algoritmos para a classificação multirrótulo. Essa forma de recomendação não contém informações sobre a ordem dos algoritmos classificados. Para suprir essa necessidade, uma lista ordenada (ranking) das MHs 
Tabela 5.14: Ranking dos classificadores de acordo com o desempenho preditivo medido pela acurácia - instâncias de PCV geradas a partir de arquivos do TSPLIB.

\begin{tabular}{lcccc}
\hline Conjunto de Dados & K-NN & AD & SVM & NB \\
\hline Cenário 1 & 2,5 & 2,5 & 1 & 4 \\
Cenário 2 & 2 & 3 & 1 & 4 \\
Cenário 3 - Classe TS & 3 & 1,5 & 1,5 & 4 \\
Cenário 3 - Classe GRASP & 1 & 2 & 3 & 4 \\
Cenário 3 - Classe SA & 1,5 & 1,5 & 3 & 4 \\
Cenário 3 - Classe GA & 1 & 3 & 2 & 4 \\
\hline Posição média no ranking & 1,8 & 2,3 & 1,9 & 4,0 \\
\hline
\end{tabular}

Tabela 5.15: Ranking dos classificadores de acordo com o desempenho preditivo medido pela AUC - instâncias de PCV geradas a partir de arquivos do TSPLIB.

\begin{tabular}{lcccc}
\hline Conjunto de Dados & K-NN & AD & SVM & NB \\
\hline Cenário 1 & 3 & 4 & 2 & 1 \\
Cenário 2 & 1 & 4 & 3 & 2 \\
Cenário 3 - Classe TS & 2 & 4 & 3 & 1 \\
Cenário 3 - Classe GRASP & 1 & 2 & 4 & 3 \\
Cenário 3 - Classe SA & 1 & 3 & 4 & 2 \\
Cenário 3 - Classe GA & 1 & 3 & 4 & 2 \\
\hline Posição média no ranking & 1,5 & 3,3 & 3,3 & 1,8 \\
\hline
\end{tabular}

pode ser sugerida, de acordo com seu potencial para uma nova instância. A fim de induzir os meta-modelos com capacidade para sugerir corretamente um ranking de $\mathrm{MHs}$, foram realizados experimentos usando a abordagem baseada em ranking de rótulos (label ranking) (Dekel et al., 2003).

\subsubsection{Geração de meta-exemplos}

Para esse conjunto de experimentos, 2000 subproblemas de PCV simétricos e fortemente conectados foram gerados a partir de 10 arquivos (d1655, fl1400, nrw1379, pcb3038, pr2392, rl1889, u1817, vm1748, fnl4461 e rat783) extraídos da biblioteca TSPLIB. De cada arquivo, 200 subproblemas diferentes foram gerados a partir de 100 cidades escolhidas aleatoriamente. Os custos de viagem entre as cidades dos problemas originais foram mantidos nos respectivos subproblemas.

Todas as 2000 instâncias de PCV foram submetidas as quatro MHs descritas nas seções anteriores. Um ranking de MHs obtido a partir do desempenho de otimização das MHs para cada instância foi utilizado como classe do metaexemplo correspondente. Com a finalidade de obter uma diversificação maior 
na distribuição das classes para o conjunto de meta-dados, os parâmetros das MHs foram configurados conforme segue:

- BT: tamanho da lista tabu $=3$ e número de iterações sem melhora na solução corrente $=2$;

- GRASP: número de iterações = 50 e $\alpha=0.6$;

- SA: temperatura inicial $=1, \beta=0.9$ e $\alpha=0.01$;

- AG: tamanho da população $=128$, seleção de pais por torneio com dois indivíduos, taxa de cruzamento $=100 \%$, operador de cruzamento $=$ PMX, taxa de mutação = 5\% e seleção de um indivíduo para a nova população por elitismo.

Para cada instância de PCV, o desempenho de cada $\mathrm{MH}$ foi assinalado como sendo a média de 50 soluções obtidas a partir de 50 execuções com diferentes sementes de inicialização. Desse modo, os desempenhos das MHs foram ordenados para compor o ranking de MHs para essa instância. A distribuição dos rankings de MHs para o conjunto de meta-dados está listada na Tabela 5.16, sendo omitidos aqueles que tiveram frequência nula. A frequência do ranking majoritário $(38,5 \%)$ corresponde à acurácia preditiva de um classificador simples que recomende somente esse ranking para todos os meta-exemplos.

Tabela 5.16: Frequência relativa dos rankings de desempenho das MHs para instâncias de PCV geradas a partir de arquivos do TSPLIB.

\begin{tabular}{llllc}
\hline la. pos. & 2a. pos. & 3a. pos. & 4a pos. & Frequência(\%) \\
\hline AG & SA & GRASP & BT & 38,50 \\
AG & SA & BT & GRASP & 19,95 \\
AG & GRASP & SA & BT & 10,50 \\
SA & AG & GRASP & BT & 9,90 \\
GRASP & AG & SA & BT & 7,10 \\
SA & AG & BT & GRASP & 5,50 \\
AG & BT & SA & GRASP & 3,65 \\
GRASP & SA & AG & BT & 1,60 \\
AG & BT & GRASP & SA & 1,15 \\
BT & AG & SA & GRASP & 0,55 \\
AG & GRASP & BT & SA & 0,55 \\
GRASP & AG & BT & SA & 0,50 \\
SA & GRASP & AG & BT & 0,20 \\
BT & SA & AG & GRASP & 0,10 \\
GRASP & BT & AG & SA & 0,10 \\
BT & GRASP & SA & AG & 0,05 \\
BT & AG & GRASP & SA & 0,05 \\
SA & BT & AG & GRASP & 0,05 \\
\hline
\end{tabular}


Tabela 5.17: Meta-atributos (MA) usados para a indução do modelo de metaaprendizado para ranquear rótulos.

\begin{tabular}{lll}
\hline MA & Notação matemática & Descrição \\
\hline$V_{\text {number }}$ & length $(V)$ & número de vértices $(n)$ \\
$C_{\text {min }}^{V}$ & $\min \left(C_{1}^{V}, \ldots, C_{n}^{V}\right)$ & menor custo de vértice \\
$C_{\text {max }}^{V}$ & $\max \left(C_{1}^{V}, \ldots, C_{n}^{V}\right)$ & maior custo de vértice \\
$C_{\text {avg }}^{V}$ & $\frac{\sum_{i=1}^{n} C_{i}^{V}}{n}$ & média dos custos de vértice \\
$C_{\text {sd }}^{V}$ & $\sqrt{\frac{1}{n-1} \sum_{i=1}^{n}\left(C_{i}^{V}-C_{\text {avg }}^{V}\right)^{2}}$ & desvio padrão dos custos de vértice \\
$C_{\text {median }}^{V}$ & $\operatorname{median}\left(C_{1}^{V}, \ldots, C_{n}^{V}\right)$ & mediana dos custos de vértice \\
$C_{\text {nn }}^{V}$ & $\sum_{i=1}^{n} \min \left(c_{i 1}, \ldots, C_{i n}\right)$ & soma dos custos dos vértices para o mais \\
& & próximo \\
$E_{\text {number }}$ & $\operatorname{length}(E)$ & número de arestas (m) \\
$C_{\text {min }}^{E}$ & $\min \left(C_{1}^{E}, \ldots, C_{m}^{E}\right)$ & menor custo de aresta \\
$C_{\text {max }}^{E}$ & $\max \left(C_{1}^{E}, \ldots, C_{m}^{E}\right)$ & maior custo de aresta \\
$C_{\text {avg }}^{E}$ & $\frac{\sum_{i=1}^{m} C_{i}^{E}}{m}$ & média dos custos de aresta \\
$C_{\text {sd }}^{E}$ & $\sqrt{\frac{1}{m-1} \sum_{i=1}^{m}\left(C_{i}^{E}-C_{\text {avg }}^{E}\right)^{2}}$ & desvio padrão dos custos de aresta \\
$C_{\text {median }}^{E}$ & $\operatorname{median}\left(C_{1}^{E}, \ldots, C_{m}^{E}\right)$ & mediana dos custos de aresta \\
$C_{\text {lowest }}^{E}$ & $\sum_{i=1}^{n}$ ord $\left(C_{i}^{E}\right)$ & soma dos $n$ menores custos de aresta \\
\hline
\end{tabular}

Houve pequenas alterações nos meta-atributos em relação aos que foram usados nos experimentos anteriores, pois o foco da pesquisa foi maior nas instâncias de PCV simétricos e fortemente conectados. Os novos meta-atributos foram baseados em propriedades extraídas dos grafos que representam as instâncias do PCV. Essas propriedades, propostas em (Kanda et al., 2011a), são medidas usadas para calcular os custos de arestas e os custos de vértices. O custo de aresta $\left(C^{E}\right)$ pode ser facilmente extraído a partir dos valores associados às arestas em um grafo ponderado, enquanto o custo de um vértice $\left(C^{V}\right)$ foi definido como sendo a média dos custos das arestas conectadas ao vértice. Geralmente, as MHs usam diferentes mecanismos de diversificação no processo de busca por uma boa solução, explorando diferentes regiões do espaço de busca, como as regiões vizinhas da solução corrente. Em um PCV, o número de vizinhos depende do número de cidades envolvidas no problema, por isso as propriedades inerentes ao custo dos vértices podem representar meta-atributos relevantes. Além disso, as MHs sempre buscam a melhor solução tentando usar as arestas de menor custo, por isso algumas medidas calculadas a partir dos custos de arestas também fazem parte do conjunto de meta-atributos. A Tabela 5.17 mostra o conjunto de meta-atributos, baseados em propriedades de vértices e de arestas, usados para induzir o meta-modelo. 


\subsubsection{Indução dos meta-modelos}

Meta-modelos foram induzidos a partir das três diferentes abordagens de redes neurais ilustradas na Figura 5.3. Para todos os meta-modelos, cada neurônio de entrada da RNA correspondeu a um meta-atributo baseado nos custos de arestas e de vértices. A principal diferença entre as abordagens diz respeito a configuração de saída do meta-modelo induzido a partir da RNA. A abordagem 1 usou uma RNA (Figura 5.3a), na qual a camada de saída continha $q$ neurônios que armazenaram o valor da solução obtida pelas $q$ MHs para um meta-exemplo submetido à entrada do meta-modelo. A abordagem 2 usou uma RNA (Figura 5.3b) que também continha $q$ neurônios de saída, porém estes neurônios indicaram a posição de cada $\mathrm{MH}$ em um ranking de desempenho das $q$ MHs. A MH mais promissora foi aquela que estava na primeira posição do ranking sugerido. Finalmente, a abordagem 3 usou $q$ modelos de RNA (Figura 5.3c) com um neurônio de saída, indicando a posição no ranking para uma das $q$ MHs. Essa abordagem foi baseada na estratégia de predição de ranking para classificadores (Bensusan e Kalousis, 2001). A predição da posição do ranking de cada $\mathrm{MH}$ foi feita por meio de uma função de regressão não-linear, que é uma maneira de estimar a expectativa condicional da variável dependente, mantendo fixas as variáveis independentes (Seber e Wild, 1989).

Como a configuração da camada escondida que maximiza o desempenho de uma RNA depende do conjunto de dados (Smith, 1993), investigamos o uso de 2 a 36 neurônios nessa camada. Os meta-modelos foram implementados usando a linguagem de programação $\mathrm{R}$ e o pacote neuralnet sem alteração dos valores sugeridos para os parâmetros. A validação cruzada em 10 pastas (Haykin, 2009) foi utilizada para a indução dos meta-modelos.

\subsubsection{Resultados experimentais}

Para cada abordagem, o meta-modelo induzido a partir da RNA foi aquele que obteve o menor erro quadrático médio (EQM) no conjunto de validação. A Tabela 5.18 mostra que a abordagem 1 teve o menor EQM, provavelmente, por causa do tipo de informação fornecida pela rede (valor da solução das MHs). Devido a magnitude dos valores de saída, os valores normalizados das soluções das MHs ficaram muito mais próximos entre si do que os valores normalizados das posições do ranking das MHs.

A RNA que obteve o melhor desempenho preditivo no conjunto de validação foi usada para predizer o ranking de MHs para os meta-exemplos do conjunto de teste. A capacidade preditiva dos meta-modelos no conjunto de teste foi mensurada por meio de duas medidas de correlação: Coeficiente de Spe- 


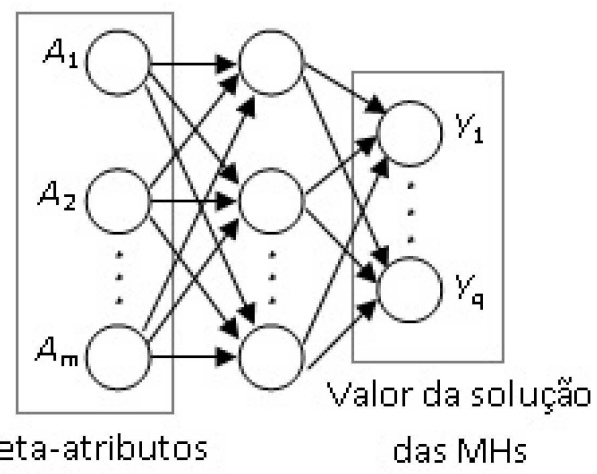

a - Os neurônios de saida indicam o valor da soluçăo das q meta-heuristicas para um meta-exemplo de $\mathrm{PO}$.

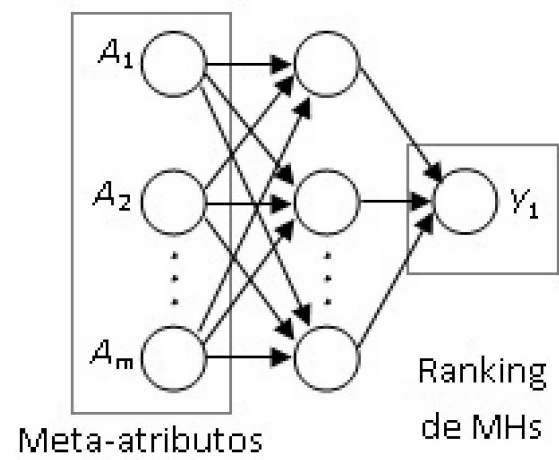

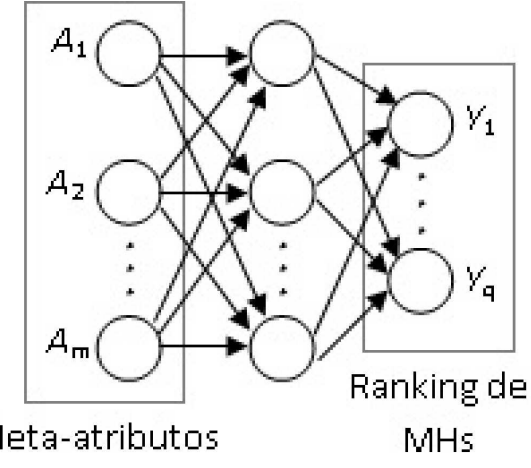

b - Os neurônios de saída indicam as posiợes das meta-heuristicas no ranking de soluçốes para um meta-exemplo de $\mathrm{PCV}$.

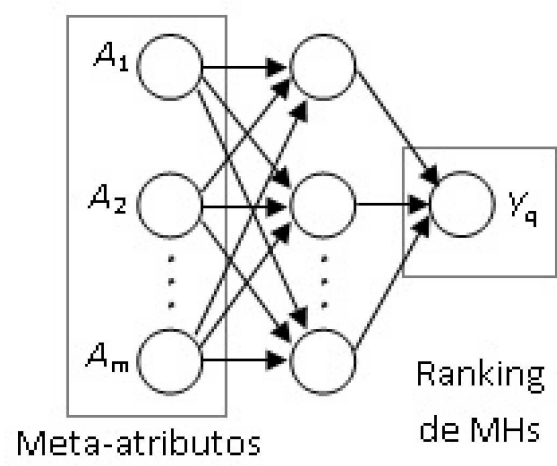

c-Cada neurônio de saida dos q model os de RivA indica a posiçăo de uma meta-heuristica diferente no ranking de soluçōes para um meta-exemplo.

Figura 5.3: Três abordagens de rede neural artificial para recomendar ranking de MHs.

Tabela 5.18: Configuração da RNA que obteve o menor erro quadrático médio para os meta-exemplos de validação em três abordagens diferentes.

\begin{tabular}{ccc}
\hline Abordagem & EQM & Número de neurônios na camada escondida \\
\hline 1 & $8,562 \times 10^{-5}$ & 3 \\
2 & $6,414 \times 10^{-3}$ & 19 \\
3 & $7,307 \times 10^{-3}$ & 25 \\
\hline
\end{tabular}

arman (CS) (Spearman, 1904) e Coeficiente de Goodman-Kruskal Ponderado (GKP) (Campello e Hruschka, 2009). A primeira medida basicamente calcula a média normalizada dos erros quadráticos das posições das MHs no ranking recomendado em relação ao ranking verdadeiro. A segunda medida foi adotada como um complemento da primeira porque calcula a correlação entre 
duas sequências de valores considerando a magnitude dos valores contidos em cada sequência. Não somente a tendência dos valores é avaliada, mas também a taxa de variação desses valores. Para as duas medidas, o valor +1 indica uma perfeita correlação entre as sequências comparadas e o valor - 1 significa que as sequências são completamente discordantes.

O desempenho preditivo das RNAs medido pelo CS e GKP nas três abordagens de aprendizado é apresentado nas tabelas 5.19 e 5.20, respectivamente. A fim de avaliar a qualidade do desempenho preditivo dos meta-modelos, as tabelas também mostram um valor de referência para a medida de correlação adotada. O valor de referência adotado é a média da taxa de correlação obtida a partir da comparação entre cada ranking previamente conhecido e o ranking majoritário mencionado na Seção 5.3.1. A informação contida no meta-atributo alvo da abordagem 1 é diferente das outras abordagens, por isso a magnitude dos valores no ranking desejado é diferente para a primeira abordagem. Por consequência, o valor de referência para GKP é diferente para essa abordagem. A quarta coluna das duas tabelas mostra o índice de superioridade dos modelos de meta-aprendizado em relação ao valor de referência. O maior valor calculado para esse índice indica que o melhor desempenho preditivo foi obtido pelo meta-modelo induzido por uma RNA com 4 saídas (abordagem 2). A necessidade de ordenar os valores preditos antes de recomendar o ranking de MHs é uma desvantagem da abordagem 1. Um aspecto negativo da abordagem 3 é o custo computacional para a implementação de várias RNAs cuja quantidade depende do número de MHs candidatas.

Tabela 5.19: Desempenho preditivo dos meta-modelos no conjunto de teste mensurado por Coeficiente de Spearman.

\begin{tabular}{cccc}
\hline Abordagem & CS & Valor de referência (R) & (CS-R)/R \\
\hline 1 & 0,8210 & 0,7895 & 0,040 \\
2 & 0,8330 & 0,7895 & 0,055 \\
3 & 0,8255 & 0,7895 & 0,046 \\
\hline
\end{tabular}

Tabela 5.20: Desempenho preditivo dos meta-modelos no conjunto de teste mensurado por Coeficiente de Goodman-Kruskal Ponderado.

\begin{tabular}{cccc}
\hline Abordagem & GKP & Valor de referência (R) & (GKP-R)/R \\
\hline 1 & 0,8106 & 0,7518 & 0,078 \\
2 & 0,8346 & 0,6478 & 0,288 \\
3 & 0,7599 & 0,6478 & 0,173 \\
\hline
\end{tabular}




\subsection{Classificação por ranking de MHs para diferentes cenários de PCV}

Em publicações recentes (Smith-Miles et al., 2010; Kanda et al., 2011a), apenas um cenário de PCV foi considerado, aquele em que MHs são recomendadas para instâncias de PCV em que a interseção dos conjuntos de cidades é um conjunto não vazio. Do ponto de vista prático, esse cenário representa o planejamento da rota para revisitar um subconjunto de clientes antigos. Nos experimentos descritos nesta seção, foi considerado um cenário adicional, em que a abordagem de meta-aprendizado é usada para recomendar MHs para instâncias com novas cidades. Para ilustrar, considere uma empresa que visita seus clientes em cidades diferentes e, por simplicidade, existe apenas um cliente em cada cidade. Desse modo, os cenários de recomendação de $\mathrm{MHs}$ para o PCV que foram investigados estão descritos a seguir:

Cenário revisitando clientes. Os clientes que devem ser visitados em uma nova rota são um subconjunto de clientes visitados anteriormente. Dadas as instâncias relacionadas aos subconjuntos diferentes do conjunto de cidades (ex.: \{São Paulo, São Carlos, Campinas, Ribeirão Preto\}), nós desejamos saber a ordem das MHs mais promissoras a fim de definir uma rota para visitar um outro subconjunto dessas cidades (ex.: \{São Paulo, Jundiaí, Campinas\}). A interseção entre os conjuntos de cidades que representam as diferentes instâncias de PCV é não vazia.

Cenário prospectando novos clientes. Todos os clientes em uma nova rota nunca foram visitados em rotas anteriores. Dadas as instâncias relacionadas aos subconjuntos diferentes do conjunto de cidades (ex.: \{São Paulo, São Carlos, Campinas, Ribeirão Preto\}), nós desejamos saber a ordem das $\mathrm{MHs}$ mais promissoras a fim de definir uma rota para visitar um conjunto diferente de cidades (ex.: \{Rio de Janeiro, Belo Horizonte, Curitiba e Florianópolis\}). A interseção entre os conjuntos de cidades que representam uma nova e uma antiga instância de PCV é vazia.

\subsubsection{Geração de meta-exemplos}

Para o cenário revisitando clientes, 1000 subproblemas foram gerados a partir de 10 arquivos de PCV extraídos da biblioteca TSPLIB: d1655, fl1400, fnl4461, nrw1379, pcb3038, pr2392, rat783, rl1889, u1817 e vm1748. De cada arquivo, 100 subproblemas foram gerados, sendo 10 para cada um dos 10 diferentes tamanhos do problema $(10,20, \ldots, 100)$ cidades.

Para o cenário prospectando novos clientes, 300 subproblemas foram gerados a partir de 30 arquivos de PCV: a280, berlin52, bier127, ch130, d1655, d15112, 
eil101, fl417, fl3795, fnl4461, kroA200, kroB100, kroC100, kroD100, kroE100, linhp318, lin318, nrw1379, p654, pcb3038, pr2392, rat783, rd400, rl1889, rl11849, ts225, tsp225, u1817, usa13509 e vm1748. As cidades de cada arquivo foram distribuídas aleatoriamente em 10 conjuntos com o mesmo número de cidades. Cada conjunto de cidades foi usado para gerar um novo subproblema. Sendo assim, 10 subproblemas com cidades totalmente diferentes foram gerados a partir de cada arquivo.

As MHs usadas foram aquelas citadas nos experimentos anteriores, além da $\mathrm{MH}$ conhecida como Otimização por Colônia de Formigas (OCF) (Dorigo e Gambardella, 1997). Os parâmetros da OCF foram configurados conforme segue: número de formigas $=5$, taxa de evaporação do feromônio $=0.5$, taxa de influência do feromônio $=1$ e taxa de influência da informação da heurística $=1$. As configurações dos parâmetros das outras MHs foram as mesmas descritas na Seção 5.3.1.

Todas as MHs, implementadas na linguagem de programação R, foram executadas 30 vezes para cada instância de PCV, produzindo 30 soluções. A média dos custos das rotas correspondente às 30 soluções obtidas por cada $\mathrm{MH}$ foi utilizada como valor de desempenho da $\mathrm{MH}$ para essa instância. Para cada instância, a lista ordenada dos valores de desempenho das MHs foi usada para compor o ranking das MHs. Esse ranking foi associado ao valor da classe do meta-exemplo correspondente. Os meta-atributos usados nesses experimentos são os mesmos adotados nos experimentos descritos na seção anterior e que estão listados na Tabela 5.17.

\subsubsection{Indução dos meta-modelos}

Nos experimentos anteriores, em que diferentes abordagens de RNA foram usadas, o melhor resultado preditivo foi obtido pela RNA para a qual o valor de cada neurônio de saída correspondia a posição de uma $\mathrm{MH}$ no ranking de desempenho. Por essa razão, o meta-modelo induzido a partir dessa RNA também foi aplicado nos conjuntos de meta-exemplos gerados para os dois diferentes cenários de PCV.

Para reduzir o tempo computacional com a realização de vários experimentos com diferentes configurações na camada escondida, adotamos o número de neurônios sugerido em (Hall et al., 2009). Esse número é a média aritmética do número de atributos de entrada e do número de neurônios da camada de saída. 


\subsubsection{Resultados experimentais}

A fim de comparar os rankings de MHs recomendados pelo meta-modelo com aqueles previamente conhecidos, a correlação para cada par de ranking $\langle$ recomendado, conhecido $\rangle$ do conjunto de teste foi calculada a partir do coeficiente de Spearman $\left(r_{S}\right)$, que é uma maneira de estimar a acurácia de ranking. Para avaliar a qualidade da capacidade preditiva do meta-modelo, a média $\overline{r_{S}}$ foi comparada com o valor de um baseline. No caso particular, o baseline é o valor de $\overline{r_{S}}$ calculado para mensurar a capacidade preditiva de um modelo que recomende somente o ranking médio para todos os meta-exemplos do conjunto de teste.

O meta-modelo obteve um desempenho médio $\overline{r_{S}}=0,96$ e $\overline{r_{S}}=0,93$ para os cenários revisitando clientes e prospectando novos clientes, respectivamente. O valor do baseline para os respectivos cenários foi: $\overline{r_{S}}=0,89$ e $\overline{r_{S}}=0,83$.

$\mathrm{O}$ valor de $\overline{r_{S}}$ para cada ranking observado nos cenários revisitando clientes e prospectando novos clientes está ilustrado nas figuras 5.4 e 5.5, respectivamente. Os rankings estão listados no eixo vertical, juntamente com o valor de sua frequência observado em cada conjunto de meta-dados. O eixo horizontal indica o valor do $\overline{r_{S}}$ calculado tanto para o meta-modelo quanto para o baseline. Os rankings mais frequentes, aqueles que estão na parte inferior da figura, são os mais parecidos com o ranking médio. Pois, quanto maior é a frequência do ranking majoritário, maior é a sua influência no cálculo das médias dos rankings. Por isso, é muito difícil para um meta-modelo ter uma acurácia preditiva maior que o baseline ao recomendar os rankings mais comuns. O maior ganho de uma abordagem de meta-aprendizado está na sua capacidade em predizer, com elevada acurácia, os rankings menos frequentes. No cenário revisitando clientes, o meta-modelo foi melhor que o baseline em seis dos sete rankings que teve somente uma frequência (Figura 5.4). No cenário prospectando novos clientes, o meta-modelo teve um desempenho $\overline{r_{S}} \geq 0.6$ para todos os diferentes rankings, enquanto o baseline atingiu esse desempenho em apenas $43 \%$ desses rankings (Figura 5.5).

Para avaliar se existe diferença significativa entre o desempenho preditivo do meta-modelo e o baseline, o teste $t$ foi aplicado. Esse teste estatístico foi escolhido a partir do estudo reportado por Demsar em (Demšar, 2006). Os resultados do teste $\mathrm{t}$, para $\alpha=5 \%$, indicaram os valores de probabilidade $7,15 \times 10^{-42}$ e $2,61 \times 10^{-12}$ para os cenários revisitando clientes e prospectando novos clientes, respectivamente. Essas probabilidades informam que, para um nível de confiança de 95\%, os meta-modelos induzidos a partir da abordagem de meta-aprendizado para ranquear rótulos tiveram um desempenho preditivo significativamente melhor que os respectivos baselines nos dois cenários investigados. 


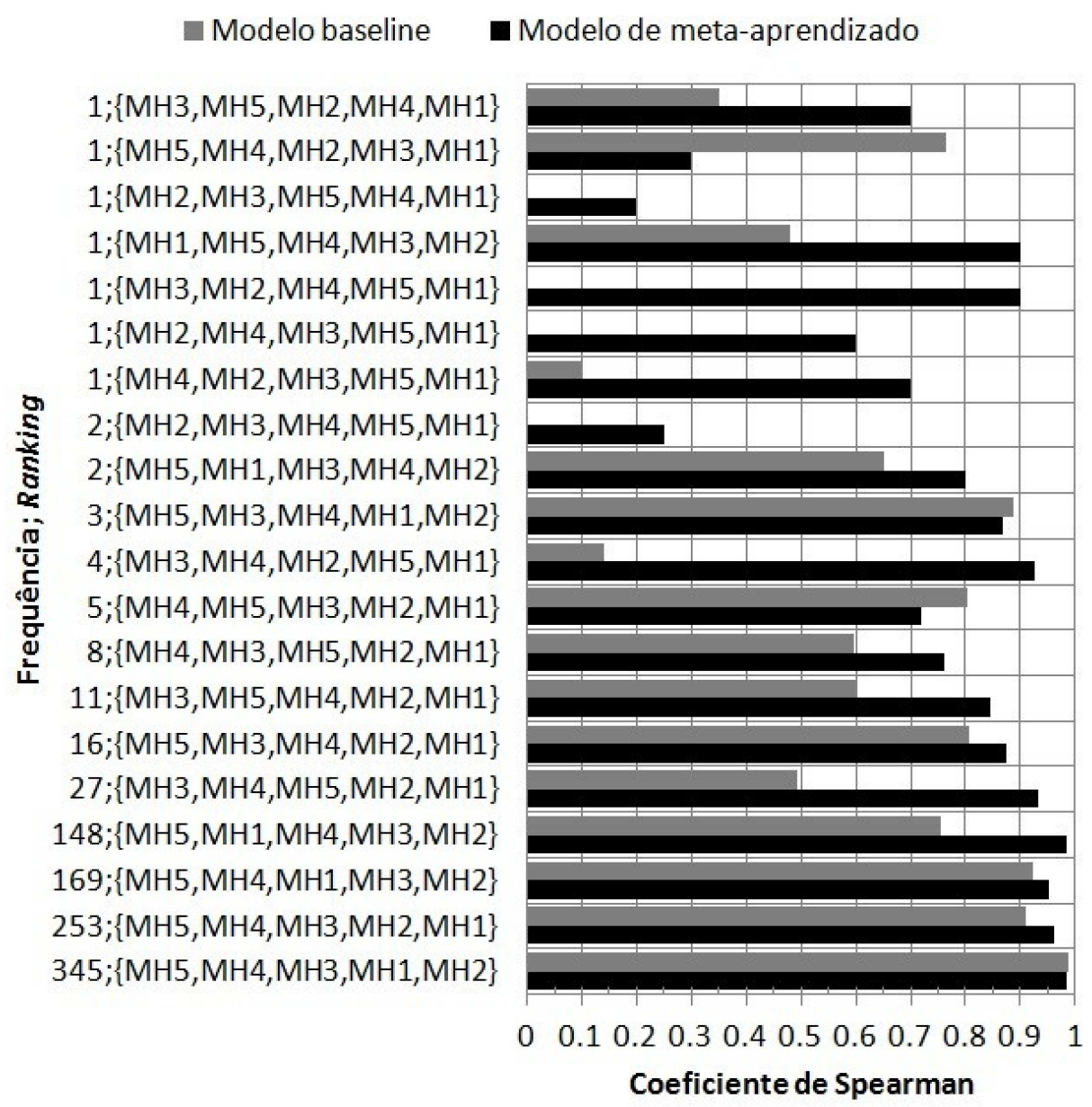

Figura 5.4: Média do desempenho preditivo do meta-modelo mensurado pelo coeficiente de Spearman para os rankings de MHs - cenário revisitando clientes.

Comparamos também o desempenho preditivo do meta-modelo baseado em rankings com o desempenho obtido por um meta-modelo baseado em classificação multirrótulo. Para a classificação multirrótulo foi adotada a abordagem de transformação baseada em rótulos, pois essa abordagem obteve os melhores resultados nos experimentos reportados nas seções 5.1 e 5.2. Para realizar apropriadamente essa comparação, usamos a estratégia Top $-N$ (Brazdil et al., 2003). Essa estratégia avalia um ranking de algoritmos levando em conta a qualidade da solução obtida pelos algoritmos e o custo computacional para obtê-la. Em nosso caso, os algoritmos são as MHs, a qualidade da solução é o valor da solução (ex. custo da rota), e o custo computacional é o tempo de execução para as MHs encontrarem a solução. A qualidade das soluções das MHs $T o p-N$ é mensurada pelo valor da melhor solução processada pelas $N$ MHs. O custo computacional para executar todas as MHs Top - $N$ corresponde a soma dos tempos de execução para as $N$ MHs encontrarem as suas soluções. 


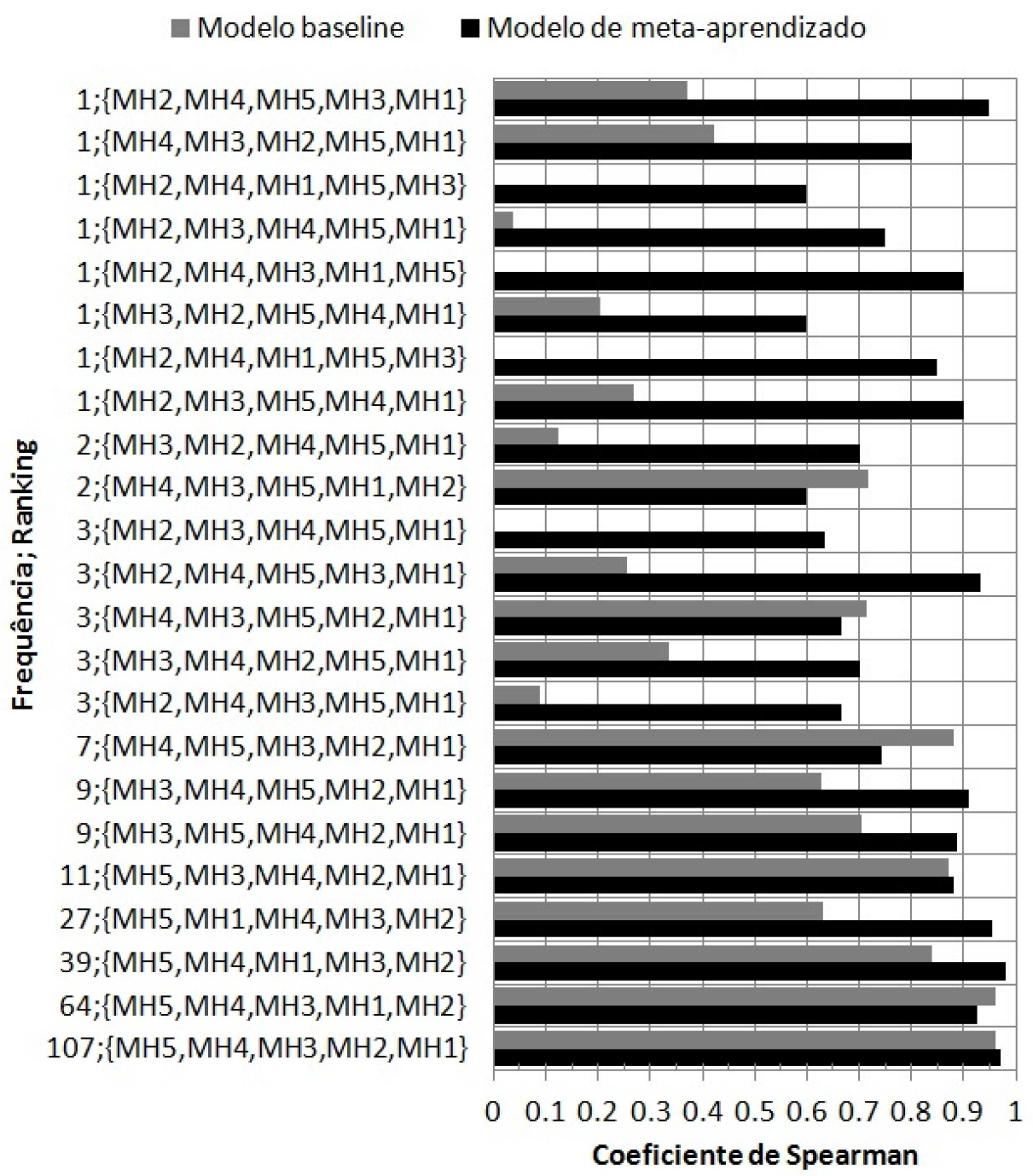

Figura 5.5: Média do desempenho preditivo do meta-modelo mensurado pelo coeficiente de Spearman para os rankings de MHs - cenário prospectando novos clientes.

Uma vez que diferentes instâncias de PCV podem ter custos de viagens entre as cidades com magnitudes significativamente diferentes, o valor da solução $S_{j}^{i}$ obtida pela $\mathrm{MH}_{j}$ para uma instância $i$ foi normalizada usando a Equação 5.1.

$$
S_{j}^{i^{\prime}}=\frac{S_{j}^{i}-S_{\text {min }}^{i}}{S_{\text {max }}^{i}-S_{\text {min }}^{i}},
$$

onde $S_{\min }^{i}$ e $S_{\text {max }}^{i}$ representam, respectivamente, o menor e o maior valor da solução para a instância $i$.

Os resultados obtidos a partir da estratégia $T o p-N$ são mostrados nas figuras 5.6 e 5.7 para os cenários revisitando clientes e prospectando novos clientes, respectivamente. Nos dois cenários, a MH Top - 1 recomendada pelo meta-modelo foi capaz de prover uma solução melhor do que a MH Top - 
1 sugerida pelo baseline. Os resultados para o cenário revisitando clientes (Figura 5.6) mostram que é necessário executar as MHs Top -2 indicadas pelo baseline para obter uma solução tão boa quanto aquela provida pela $\mathrm{MH}$ Top - 1 recomendada pelo meta-modelo.

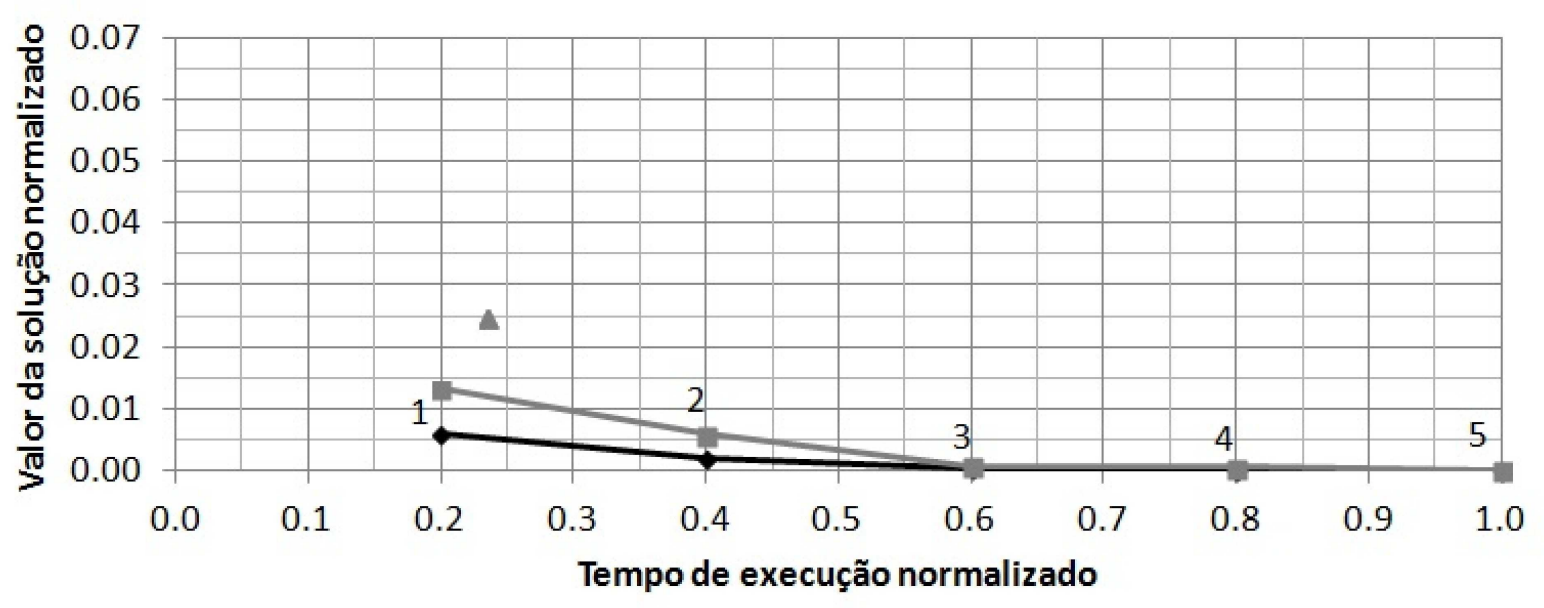

$\rightarrow$ Classificação por ranking de rótulo - -Modelo baseline $\rightarrow$ Classificação multirrótulo

Figura 5.6: Valor normalizado da solução média para PCV versus tempo médio normalizado para encontrar a solução usando a estratégia que executa as MHs Top $-N$ - cenário revisitando clientes.

A principal vantagem do meta-modelo é o tempo necessário para obter a solução da $\mathrm{MH}$ mais promissora para uma nova instância do PCV. O tempo de execução de uma $\mathrm{MH}$ (a Top - 1 recomendada pelo meta-aprendizado) é 50\% menor que o tempo para executar as MHs nas duas primeiras posições do ranking baseline. A solução média das MHs recomendadas pelo meta-modelo multirrótulo é pior do que a solução média gerada pela $\mathrm{MH}$ Top-1 sugerida tanto pelo meta-modelo quanto pelo baseline. Essa constatação decorre do fato de que as MHs indicadas na classificação multirrótulo para algumas instâncias não são aquelas que geram as melhores soluções de otimização.

Para o cenário prospectando novos clientes, a estratégia de executar a $\mathrm{MH}$ Top - 1 recomendada pelo meta-modelo propicia uma solução melhor ao ser comparada com aquela obtida após o processamento das MHs Top - 4 indicadas no ranking baseline (Figura 5.7). A solução média das MHs ranqueadas pelo modelo baseline é pior para esse cenário em relação ao cenário anterior devido ao aumento no número de diferentes rankings observados no conjunto de meta-dados.

A classificação multirrótulo recomendou MHs cujas soluções são tão boas quanto àquelas providas pela $\mathrm{MH}$ Top -1 sugerida pela abordagem ranking de rótulos. No entanto, todas as MHs recomendadas pela classificação multirrótulo devem ser executadas para obter a melhor solução para uma instância de 
PCV, demandando um tempo maior de processamento.

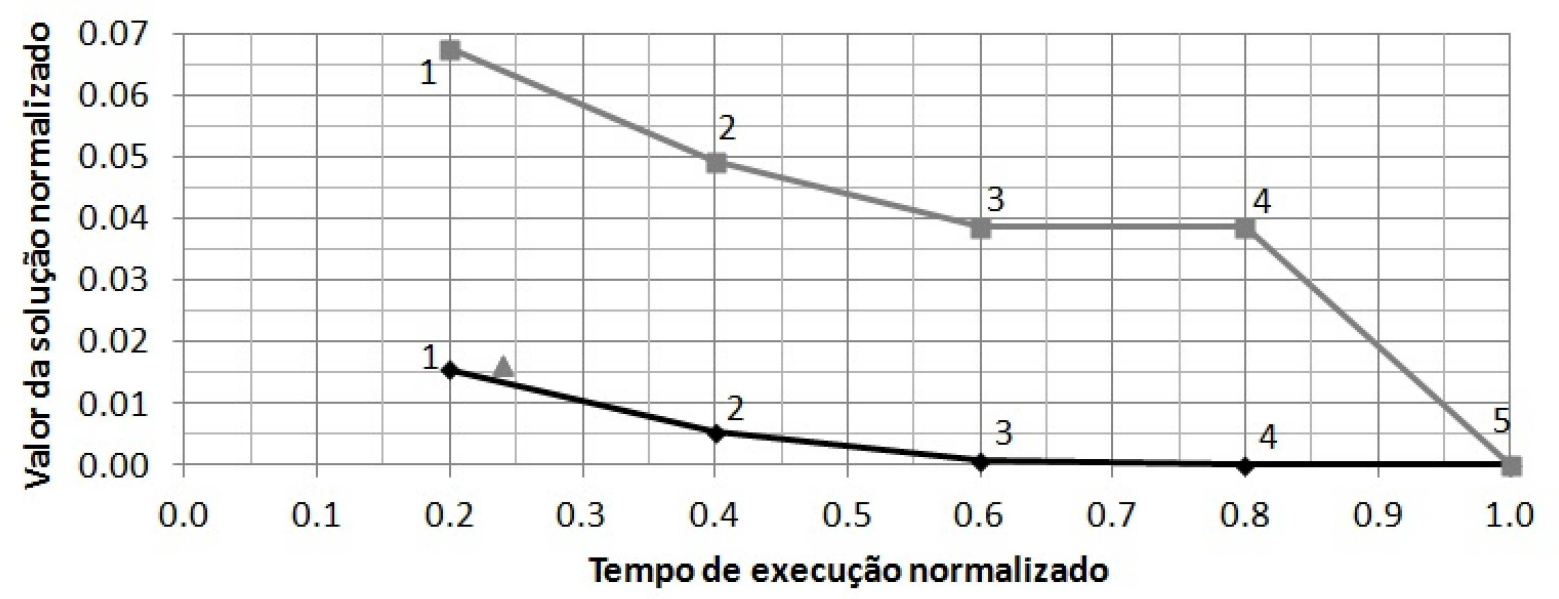

$\rightarrow$ Classificação por ranking de rótulo $\rightarrow$-Classificação multirrótulo $\rightarrow$-Modelo baseline

Figura 5.7: Valor normalizado da solução média para PCV versus tempo médio normalizado para encontrar a solução usando a estratégia que executa as MHs Top $-N$ - cenário prospectando novos clientes.

O meta-modelo baseado em ranking de rótulos permite ao usuário obter uma boa solução executando somente da MH Top - 1. Em situações práticas, quando o usuário tiver um tempo maior para executar as outras MHs ranqueadas pelo modelo classificador, soluções com melhor qualidade podem ser obtidas.

Os resultados desse conjunto de experimentos mostraram que é importante considerar diferentes cenários do mundo real que podem ser modelados pelo PCV. Nos cenários simulados, os resultados da recomendação do ranking de MHs por meio do aprendizado de ranking de rótulos foram promissores.

\subsection{Investigação de diferentes meta-atributos}

Considerando que o desempenho preditivo de um meta-modelo pode ser maximizado com o uso de meta-atributos apropriados, esta seção detalha os resultados experimentais obtidos a partir dos conjuntos de meta-atributos para o PCV propostos nesta tese e descritos no capítulo anterior.

- Conjunto de medidas de vértice e aresta (MVA);

- Conjunto de propriedades das meta-heurísticas (PMH);

- Conjunto de características extraídas a partir de landmarkers (CLM);

- Conjunto de medidas para caracterizar redes complexas (MRC). 
Nos experimentos realizados, cada conjunto de meta-atributo foi usado para descrever as instâncias de PCV dos seguintes conjuntos:

- Simétrico e fortemente conectado;

- Assimétrico e fortemente conectado;

- Simétrico e fracamente conectado;

- Assimétrico e fracamente conectado.

\subsubsection{Geração de meta-exemplos}

Um conjunto de 600 subproblemas foi gerado para cada uma das quatro variações do PCV, sendo 150 subproblemas diferentes para cada um dos seguintes tamanhos: 10, 25, 50 e 100 cidades. Os subproblemas de mesmo tamanho foram gerados a partir de um mesmo arquivo extraído da biblioteca TSPLIB. Os subproblemas simétricos de diferentes tamanhos foram gerados a partir dos arquivos: eil76, ch150, $\operatorname{lin} 318$ e $u 724$, respectivamente. E a geração dos subproblemas assimétricos para os tamanhos especificados ocorreu a partir dos arquivos $p 43, k r o 124 p$, ftv170 e rbg443, respectivamente.

Todos os subproblemas fracamente conectados, simétricos e assimétricos, foram gerados a partir dos subproblemas fortemente conectados. O modelo conhecido como mundo-pequeno (Watts, 1999) foi adotado para identificar quais arestas deveriam ser eliminadas de cada subproblema fortemente conectado para criar um fracamente conectado. O modelo mundo-pequeno tem como principal característica a certeza de que a maioria dos vértices do grafo pode ser atingida a partir dos demais vértices por meio de um pequeno número de arestas.

Em nossos experimentos, o modelo mundo-pequeno foi construído a partir da conexão de cada vértice com os seus $k$-vizinhos mais próximos, com $k=$ $60 \%$ do número de cidades contidas na instância do problema. Em seguida, cada aresta foi aleatoriamente reconectada com uma probabilidade $p=0,1$. Se $p=0$, a rede é caracterizada por uma estrutura ordenada com um grande número de ciclos de tamanho três. Por outro lado, se $p=1$, a rede é um grafo totalmente aleatório com distâncias pequenas entre os vértices e poucos ciclos. Os valores de $k$ e $p$ foram escolhidos de acordo com as sugestões feitas em (Costa et al., 2007).

Em relação à configuração das cinco MHs, os parâmetros livres de cada uma foram configurados com os mesmos valores adotados no conjunto de experimentos descritos na seção anterior. 


\subsubsection{Indução dos meta-modelos}

Para induzir os meta-modelos recomendadores de ranking de MHs, foram usadas as seguintes técnicas de AM: rede perceptron multicamadas (MLP), $\mathrm{k}$-vizinhos mais próximos (K-NN) e algoritmos de árvore de decisão (AD). As adaptações dessas técnicas para ranquear rótulos estão descritas em: (Kanda et al., 2011a), (Brazdil et al., 2009) e (Vens et al., 2008), respectivamente. Os algoritmos usados foram implementados na linguagem de programação $\mathrm{R}$ usando os pacotes: nnet, FNN and Clus, respectivamente. Não houve qualquer alteração no valor padrão dos parâmetros livres desses pacotes.

Para avaliar a capacidade preditiva dos meta-modelos, os resultados foram comparados com um baseline. Nesse caso, o baseline é um vetor de MHs indicando a posição média de cada uma no ranking de desempenho dessas MHs para as instâncias de PCV contidas no conjunto de meta-dados. Esse vetor pode ser usado por um modelo classificador simples para recomendar o ranking de MHs para todos os meta-exemplos. Para cada meta-exemplo do conjunto de teste, o ranking recomendado pelo meta-modelo e o ranking baseline foram comparados com o ranking verdadeiro por meio da correlação do Coeficiente de Spearman $\left(r_{S}\right)$. O teste $\mathrm{t}$ foi adotado para indicar se existe diferença signficativa entre os valores de $\overline{r_{S}}$ obtidos pelo meta-modelo e pelo baseline.

\subsubsection{Resultados experimentais}

A média da acurácia preditiva $\left(\bar{r}_{S}\right)$ dos meta-modelos induzidos a partir de diferentes técnicas de AM e diferentes conjuntos de meta-atributos foi maior que a do baseline para todos os cenários de PCV investigados. A análise comparativa do desempenho preditivo entre cada meta-modelo e o baseline é feita a seguir, de modo separado, para cada cenário do PCV.

\section{Cenário simétrico e fortemente conectado}

A Figura 5.8 mostra que os meta-modelos tiveram uma acurácia média preditiva $(0,94)$ superior à media do baseline $(0,90)$, que está representada pela reta contínua paralela ao eixo horizontal. Usando o teste t para comparar o desempenho preditivo do meta-modelo - MLP com meta-atributos PMH que teve a menor acurácia $(0,943)$ com o desempenho do baseline $(0,894)$, obtivemos, para $\alpha=5 \%$, um valor de probabilidade $p=1,33 \times 10^{-} 12$. Esse resultado indica que, para o nível de confiança adotado, existe uma diferença significativa entre o desempenho preditivo desse meta-modelo e o baseline. Comparando os demais meta-modelos com o baseline por meio do teste $\mathrm{t}$, os resultados também indicaram que todos os meta-modelos tiveram um desem- 
penho preditivo superiores a do classificador baseline que recomenda somente o ranking médio.

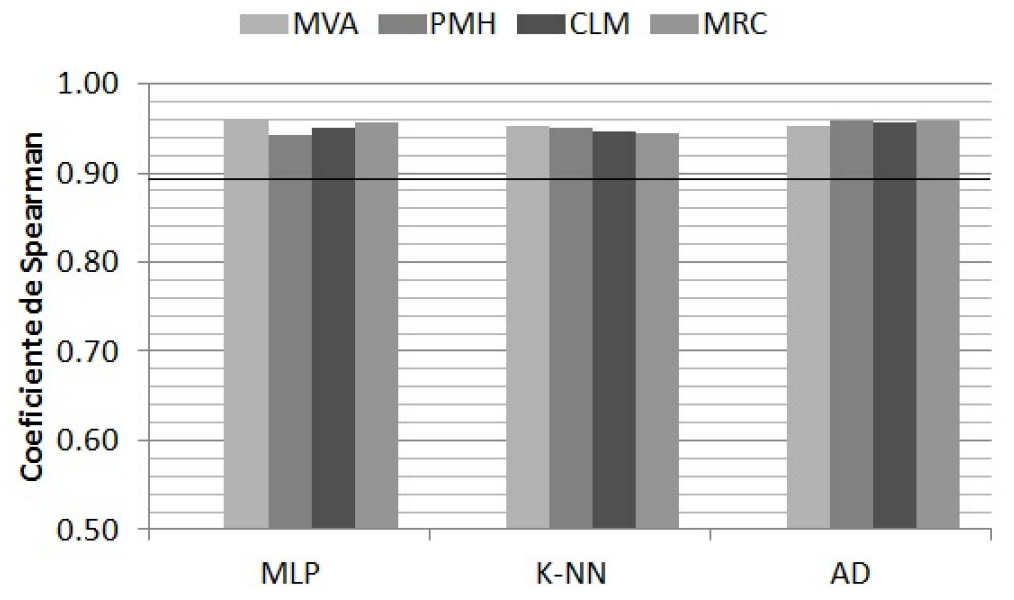

Figura 5.8: Média do coeficiente de Spearman que mensura o desempenho preditivo dos meta-modelos induzidos a partir de diferentes conjuntos de meta-atributos - Cenário simétrico e fortemente conectado.

A Tabela 5.21 mostra os valores obtidos pelo teste t, para $\alpha=5 \%$, ao comparar o desempenho preditivo dos meta-modelos induzidos a partir dos diferentes conjuntos de meta-atributos. Os valores em negrito indicam que a hipótese nula - desempenhos preditivos iguais - foi rejeitada pelo teste para um nível de confiança $=95 \%$. Na maioria das comparações, o teste $t$ não foi capaz de detectar qualquer diferença significativa no desempenho dos metamodelos. Somente os meta-modelos induzidos a partir da MLP apresentaram desempenhos preditivos diferentes para os seguintes pares de meta-atributos: (MVA, PMH), (MVA, CLM) e (MRC, PMH). A MLP teve um melhor desempenho preditivo quando o conjunto de meta-atributos MVA foi usado, porque esses meta-atributos tem uma correlação maior do que os meta-atributos dos outros conjuntos devido às propriedades extraídas serem basicamente constituídas de medidas estatísticas.

Tabela 5.21: Resultados do teste $t$ para comparar o desempenho preditivo de meta-modelos usando diferentes conjuntos de meta-atributos - Cenário simétrico e fortemente conectado.

\begin{tabular}{lccc}
\hline Conjuntos de meta-atributos & MLP & K-NN & AD \\
\hline (MVA, PMH) & $\mathbf{0 . 0 0 0 5}$ & 0.5810 & 0.2279 \\
(MVA, CLM) & $\mathbf{0 . 0 2 5 8}$ & 0.1476 & 0.4904 \\
(MVA, MRC) & 0.3114 & 0.0734 & 0.2612 \\
(PMH, CLM) & 0.1441 & 0.3471 & 0.5618 \\
(PMH, MRC) & $\mathbf{0 . 0 1 3 8}$ & 0.2000 & 0.9326 \\
(CLM, MRC) & 0.2556 & 0.7531 & 0.6233 \\
\hline
\end{tabular}


Cenário assimétrico e fortemente conectado

Figura 5.9 ilustra a acurácia preditiva média $\left(\overline{r_{S}}\right)$ obtida pelos meta-modelos para este cenário de PCV. Os meta-modelos mantiveram um alto desempenho preditivo, enquanto houve um decréscimo no valor do baseline. O valor de referência sofreu uma redução por causa do aumento no número de rankings diferentes observados no conjunto de meta-dados. Além disso, a redução no valor do baseline também foi influenciada pela menor frequência relativa do ranking majoritário.

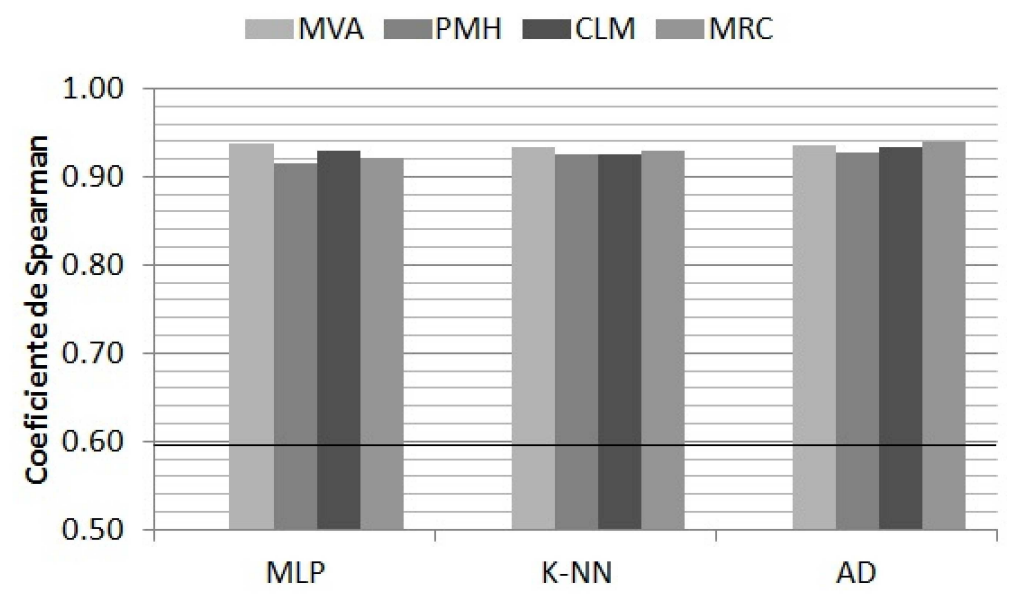

Figura 5.9: Média do coeficiente de Spearman que mensura o desempenho preditivo dos meta-modelos induzidos a partir de diferentes conjuntos de meta-atributos - Cenário assimétrico e fortemente conectado.

Visualmente podemos ver que, para esse cenário, a diferença do desempenho preditivo entre cada meta-modelo e o baseline foi maior do que no cenário anterior. Os valores obtidos a partir do cálculo do teste $t$ indicaram que, para $\alpha=5 \%$, todos os meta-modelos tiveram um desempenho significativamente melhor do que o baseline.

Esse teste estatístico, com mesmo valor para $\alpha$, foi também usado para comparar o desempenho preditivo dos meta-modelos com diferentes conjuntos de meta-atributos. Os valores de probabilidades que foram obtidos estão mostrados na Tabela 5.22. A única diferença significativa detectada pelo teste $\mathrm{t}$ foi entre os conjuntos de meta-atributos MVA e PMH usados pela MLP. Esses resultados apontam que, para os exemplos de PCV simétrico, qualquer conjunto de meta-atributos pode ser usado para induzir um meta-modelo. Por essa razão, a escolha do conjunto mais apropriado vai depender de outras variáveis, como o tempo de processamento, conforme veremos mais adiante. 
Tabela 5.22: Resultados do teste $t$ para comparar o desempenho preditivo de meta-modelos usando diferentes conjuntos de meta-atributos - Cenário assimétrico e fortemente conectado.

\begin{tabular}{lccc}
\hline Conjuntos de meta-atributos & MLP & K-NN & AD \\
\hline (MVA, PMH) & $\mathbf{0 . 0 0 9 0}$ & 0.2162 & 0.2512 \\
(MVA, CLM) & 0.3458 & 0.2769 & 0.8713 \\
(MVA, MRC) & 0.0535 & 0.5622 & 0.6102 \\
(PMH, CLM) & 0.0934 & 0.9504 & 0.3567 \\
(PMH, MRC) & 0.5314 & 0.5449 & 0.1010 \\
(CLM, MRC) & 0.3081 & 0.6122 & 0.5229 \\
\hline
\end{tabular}

\section{Cenário simétrico e fracamente conectado}

A acurácia de ranking registrada para medir o desempenho preditivo dos meta-modelos está ilustrada na Figura 5.10. Assim como ocorreu nos cenários anteriores, a capacidade dos meta-modelos em recomendar rankings de MHs foi significativamente melhor do que o baseline. Os resultados obtidos a partir do teste $\mathrm{t}$ comprovaram essa superioridade, para um nível de confiança igual a $95 \%$.

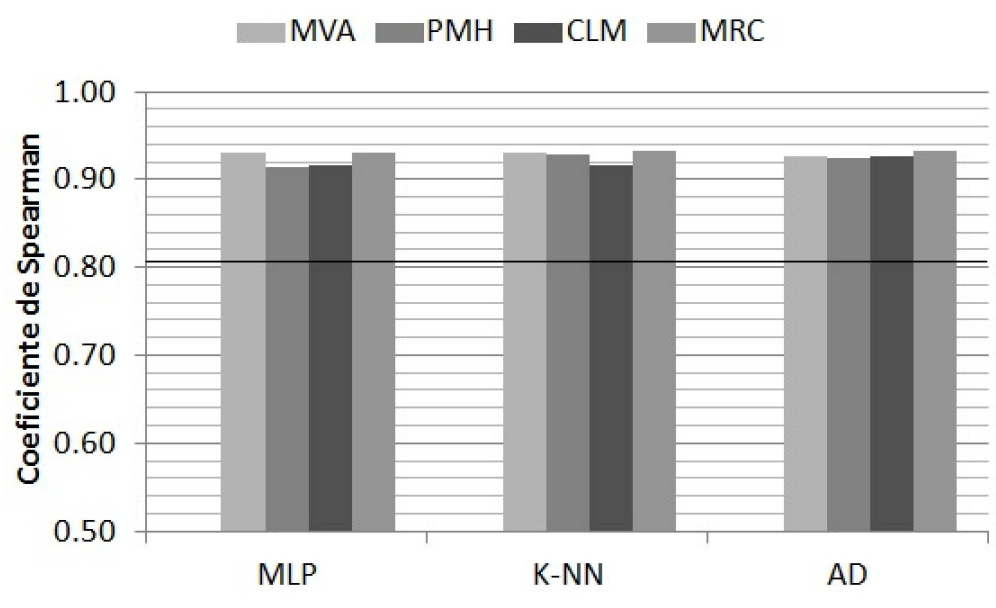

Figura 5.10: Média do coeficiente de Spearman que mensura o desempenho preditivo dos meta-modelos induzidos a partir de diferentes conjuntos de meta-atributos - Cenário simétrico e fracamente conectado.

O teste $\mathrm{t}$ foi também usado para avaliar se houve diferença significativa entre os desempenhos preditivos dos meta-modelos induzidos pelo mesmo algoritmo de AM, mas usando diferentes conjuntos de meta-atributos. Os valores de probabilidade obtidos pelo teste t, para $\alpha=5 \%$, estão mostrados na Tabela 5.23. Os resultados indicam que o teste não foi capaz de detectar qualquer diferença significativa no desempenho preditivo do meta-modelo para os diferentes pares de conjuntos de meta-atributos. 
Tabela 5.23: Resultados do teste $t$ para comparar o desempenho preditivo de meta-modelos usando diferentes conjuntos de meta-atributos - Cenário simétrico e fracamente conectado.

\begin{tabular}{lccc}
\hline Conjuntos de meta-atributos & MLP & K-NN & AD \\
\hline (MVA, PMH) & 0.0861 & 0.7740 & 0.8166 \\
(MVA, CLM) & 0.1117 & 0.1135 & 0.9379 \\
(MVA, MRC) & 0.9514 & 0.7608 & 0.3940 \\
(PMH, CLM) & 0.9728 & 0.1847 & 0.8783 \\
(PMH, MRC) & 0.0927 & 0.5525 & 0.2804 \\
(CLM, MRC) & 0.1200 & 0.0620 & 0.3548 \\
\hline
\end{tabular}

\section{Cenário assimétrico e fracamente conectado}

Os valores da acurácia de ranking registrados para medir a capacidade preditiva dos meta-modelos estão ilustrados na Figura 5.11. Para esse cenário, o desempenho preditivo médio $\left(\overline{r_{S}}<0,9\right)$ não foi tão bom quanto aqueles obtidos para os outros cenários. As instâncias de PCV fracamente conectadas são caracterizadas pela ausência de arestas, e isso pode influenciar diretamente a qualidade das soluções obtidas pelas MHs. Essa qualidade pode ter uma grande variação para diferentes subproblemas gerados a partir do mesmo exemplo real, principalmente para instâncias menores, devido a enorme dificuldade para encontrar uma solução factível quando determinadas arestas não existem.

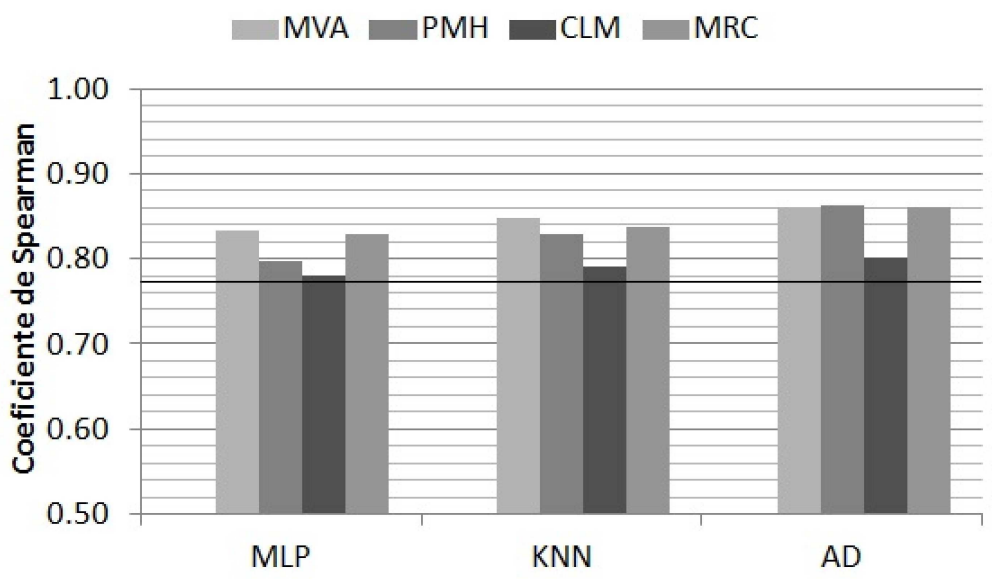

Figura 5.11: Média do coeficiente de Spearman que mensura o desempenho preditivo dos meta-modelos induzidos a partir de diferentes conjuntos de meta-atributos - Cenário assimétrico e fracamente conectado.

A fim de analisar a diferença de desempenho preditivo entre cada metamodelo e o baseline, o teste $\mathrm{t}$ foi calculado para $\alpha=5 \%$. Os resultados indicaram que não houve diferença significativa entre o valor do baseline e 
os seguintes meta-modelos: MLP com meta-atributos PMH; MLP com metaatributos CLM; e K-NN com meta-atributos CLM.

Os meta-atributos CLM não foram muito apropriados para induzir os metamodelos para este cenário, porque geralmente não é possível obter as soluções por meio de execuções rápidas das MHs para muitas instâncias fracamente conectadas. Em relação aos meta-atributos PMH, algumas delas dependem dos resultados das soluções aleatórias e suas respectivas soluções vizinhas. Dessas soluções, muitas não são factíveis e, por isso, a MLP teve dificuldades para mapear esses meta-atributos para o desempenho das MHs.

Quanto à comparação do desempenho preditivo dos meta-modelos usando diferentes conjuntos de meta-atributos, a Tabela 5.24 mostra os resultados do teste $\mathrm{t}$ para $\alpha=5 \%$. Os resultados sugerem que os meta-modelos tiveram um desempenho pior quando o conjunto de meta-atributos CLM foi usado. Esses meta-atributos foram calculados a partir das execuções rápidas das MHs e, muito provavelmente, as MHs estocásticas não conseguiram encontrar soluções factíveis em algumas das execuções para os exemplos de PCV fracamente conectados. Por isso, as soluções de otimização obtidas a partir de execuções rápidas podem não representar apropriadamente o desempenho das MHs para as instâncias de PCV usadas neste cenário.

Tabela 5.24: Resultados do teste $t$ para comparar o desempenho preditivo de meta-modelos usando diferentes conjuntos de meta-atributos - Cenário assimétrico e fracamente conectado.

\begin{tabular}{lccc}
\hline Conjuntos de meta-atributos & MLP & K-NN & AD \\
\hline (MVA, PMH) & $\mathbf{0 . 0 2 9 5}$ & 0.2113 & 0.8850 \\
(MVA, CLM) & $\mathbf{0 . 0 0 0 5}$ & $\mathbf{0 . 0 0 0 2}$ & $\mathbf{0 . 0 0 0 0}$ \\
(MVA, MRC) & 0.7816 & 0.5027 & 0.9838 \\
(PMH, CLM) & 0.3289 & $\mathbf{0 . 0 1 6 2}$ & $\mathbf{0 . 0 0 0 0}$ \\
(PMH, MRC) & 0.0629 & 0.5460 & 0.8993 \\
(CLM, MRC) & $\mathbf{0 . 0 0 2 0}$ & $\mathbf{0 . 0 0 1 8}$ & $\mathbf{0 . 0 0 0 0}$ \\
\hline
\end{tabular}

\section{Análise do tempo de geração dos meta-atributos}

Em todos os cenários de PCV discutidos nesta seção, os meta-modelos baseados em ranqueamento de classes tiveram um bom desempenho preditivo, independente do conjunto de meta-atributos usado. No entanto, para selecionar apropriadamente um dos conjuntos de meta-atributos é importante investigar o tempo computacional necessário para gerá-los. Se o tempo para calcular os meta-atributos para uma dada instância de PCV é maior que o tempo para executar todas as MHs disponiveis, não há vantagem em usar o meta-modelo para conhecer as MHs mais promissoras para essa instância. 
Para investigar essa relação de tempo, primeiramente, identificamos para cada instância de PCV o tempo de processamento para cada MH fornecer a sua solução. Em seguida, somamos o tempo de processamento de todas as MHs para essa instância e usamos o tempo total como valor de referência na comparação com o tempo de geração dos diferentes conjuntos de metaatributos.

Para ilustrar essa comparação, considere que o tempo computacional para executar todas as MHs é igual a 2 segundos e o tempo para gerar todos os meta-atributos é igual 0,4 segundos. Nesse caso, o tempo economizado por gerar os meta-atributos é de $80 \%$. No entanto, se a geração dos meta-atributos demora 5 segundos, o tempo economizado é de $-150 \%$. O valor negativo indica que, ao invés de economia, houve um prejuízo no tempo computacional. Para esse último caso, o uso de meta-aprendizado não proporciona vantagens significativas.

As tabelas 5.25, 5.26, 5.27 e 5.28 indicam o tempo economizado na geração dos conjuntos de meta-atributos em relação à execução de todas as MHs para os quatro cenários de PCV: simétrico fortemente conectado, assimétrico fortemente conectado, simétrico fracamente conectado e assimétrico fracamente conectado, respectivamente. Os resultados mostrados nessas quatro tabelas informam que somente os conjuntos de meta-atributos MVA e CLM foram gerados mais rapidamente do que a execução de todas as MHs, principalmente, para as grandes instâncias de PCV.

Tabela 5.25: Taxa do tempo economizado ao gerar meta-atributos ao invés de executar todas as MHs candidatas - Cenário simétrico e fortemente conectado.

\begin{tabular}{ccccc}
\hline Tamanho do PCV & MVA & PMH & CLM & MRC \\
\hline 10 cidades & $93 \%$ & $81 \%$ & $0 \%$ & $77 \%$ \\
25 cidades & $93 \%$ & $44 \%$ & $12 \%$ & $59 \%$ \\
50 cidades & $92 \%$ & $-31 \%$ & $26 \%$ & $23 \%$ \\
100 cidades & $82 \%$ & $-469 \%$ & $19 \%$ & $-226 \%$ \\
\hline
\end{tabular}

A geração dos meta-atributos MVA foi bastante rápido no cenário simétrico e fortemente conectado, conforme mostra a Tabela 5.25. O tempo computacional requerido para gerar esses meta-atributos não foi além de $20 \%$ do tempo para executar todas as MHs disponiveis. Para o conjunto de meta-atributos CLM, não houve um ganho significativo de tempo para pequenas instâncias do problema, porque boas soluções foram rapidamente encontradas pelas versões originais e simplificadas das MHs. Para as instâncias maiores (100 cidades), a economia de tempo na geração dos meta-atributos CLM foi sendo reduzida, já que as versões original e simplificada das MHs construtivas (ex.: 
GRASP) precisaram praticamente do mesmo tempo para construir uma solução. O tempo para gerar o conjunto de meta-atributos PMH cresceu com o aumento do número de cidades do problema, devido às $n^{2}$ comparações necessárias para a geração de alguns meta-atributos, tornando muito custoso o uso desses meta-atributos para grandes instâncias de PCV. Custo computacional quadrático também foi observado na geração de alguns meta-atributos do conjunto CLM.

Para o cenário assimétrico e fortemente conectado (Tabela 5.26), os resultados do tempo economizado indicaram que a relação entre o tempo para gerar os meta-atributos e o tempo para executar as MHs foi semelhante a que foi registrada para o cenário anterior.

Tabela 5.26: Taxa do tempo economizado ao gerar meta-atributos ao invés de executar todas as MHs candidatas - Cenário assimétrico e fortemente conectado.

\begin{tabular}{ccccc}
\hline Tamanho do PCV & MVA & PMH & CLM & MRC \\
\hline 10 cidades & $93 \%$ & $85 \%$ & $0 \%$ & $77 \%$ \\
25 cidades & $92 \%$ & $47 \%$ & $15 \%$ & $51 \%$ \\
50 cidades & $92 \%$ & $3 \%$ & $26 \%$ & $20 \%$ \\
100 cidades & $80 \%$ & $-394 \%$ & $22 \%$ & $-274 \%$ \\
\hline
\end{tabular}

Os resultados do tempo economizado por gerar os meta-atributos para os cenários simétrico fracamente conectado e assimétrico fracamente conectado estão mostrados nas tabelas 5.27 e 5.28. Os valores positivos do tempo economizado foram similares nos dois cenários para o mesmo conjunto de metaatributos e mesmo tamanho de PCV. É importante destacar que o conjunto de meta-atributos MVA, que teve o melhor resultado nos cenários anteriores, melhorou ainda mais o desempenho dos modelos preditivos nesses dois últimos cenários (tempo economizado > 90\%). Essa melhora foi decorrente da ausência de arestas nas instâncias de PCV. Com isso, poucos valores foram usados para calcular as medidas baseadas nos custos de aresta e vértice.

Tabela 5.27: Taxa do tempo economizado ao gerar meta-atributos ao invés de executar todas as MHs candidatas - Cenário simétrico e fracamente conectado.

\begin{tabular}{ccccc}
\hline Tamanho do PCV & MVA & PMH & CLM & MRC \\
\hline 10 cidades & $97 \%$ & $90 \%$ & $11 \%$ & $88 \%$ \\
25 cidades & $97 \%$ & $66 \%$ & $14 \%$ & $75 \%$ \\
50 cidades & $96 \%$ & $20 \%$ & $28 \%$ & $52 \%$ \\
100 cidades & $91 \%$ & $-277 \%$ & $20 \%$ & $-109 \%$ \\
\hline
\end{tabular}


Tabela 5.28: Taxa do tempo economizado ao gerar meta-atributos ao invés de executar todas as MHs candidatas - Cenário assimétrico e fracamente conectado.

\begin{tabular}{ccccc}
\hline Tamanho do PCV & MVA & PMH & CLM & MRC \\
\hline 10 cidades & $97 \%$ & $90 \%$ & $12 \%$ & $89 \%$ \\
25 cidades & $96 \%$ & $66 \%$ & $14 \%$ & $77 \%$ \\
50 cidades & $97 \%$ & $28 \%$ & $23 \%$ & $59 \%$ \\
100 cidades & $92 \%$ & $-228 \%$ & $18 \%$ & $-83 \%$ \\
\hline
\end{tabular}

\section{Seleção de meta-atributos}

A fim de analisar a relevância dos meta-atributos de todos conjuntos, eles foram inseridos em um único conjunto e uma técnica de seleção de atributos foi aplicada. A técnica escolhida neste trabalho discrimina os atributos mais relevantes como sendo os que possuem valores maiores para a soma quadrática entre os exemplos de classes diferentes e valores menores para os exemplos de mesma classe (Dudoit et al., 2002).

A técnica de seleção foi configurada para fornecer o melhor subconjunto com 10 meta-atributos. Conforme as análises anteriores, as técnicas de AM não tiveram forte influência no desempenho do meta-modelo, por isso usamos somente a árvore de decisão para induzir os meta-modelos a partir dos metaatributos selecionados.

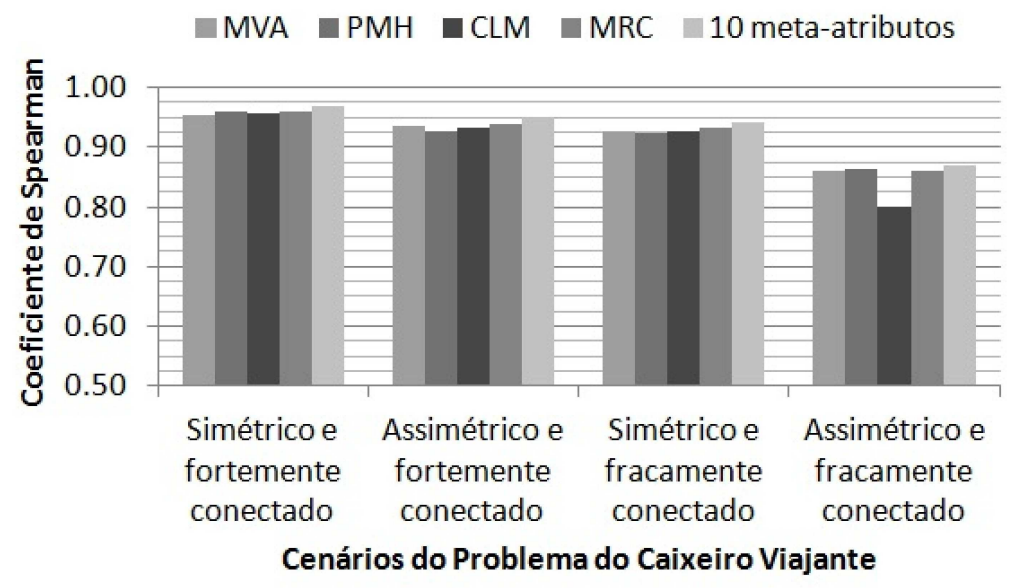

Figura 5.12: Média do coeficiente de Spearman que mensura o desempenho preditivo dos meta-modelos induzidos a partir de uma árvore de decisão e meta-atributos selecionados em quatro cenários de PCV.

Os resultados experimentais mensurados pela média da acurácia preditiva dos meta-modelos para cada um dos cenários de PCV estão mostrados na Figura 5.12. O desempenho preditivo do meta-modelo com o subconjunto de meta-atributos selecionados é comparado com os resultados obtidos separa- 
damente por cada conjuntos de meta-atributos. Visualmente, podemos notar que em todos os cenários houve um ligeiro aumento na capacidade preditiva do meta-modelo que usou os meta-atributos selecionados.

Os meta-atributos selecionados para cada cenário de PCV estão destacados na Tabela 5.29. A primeira coluna da tabela identifica o subconjunto que contém o meta-atributo selecionado e as colunas restantes indicam para quais cenários de PCV o meta-atributo foi usado na indução do meta-modelo. Os subconjuntos MVA e MRC foram os que tiveram maior quantidade de metaatributos selecionados, sugerindo que os mesmos podem ser relevantes para o processo de aprendizado do meta-modelo.

Tabela 5.29: Meta-atributos selecionados para os diferentes cenários de PCV.

\begin{tabular}{|c|c|c|c|c|c|}
\hline Conjunto & MA & $\begin{array}{l}\text { Simétrico e } \\
\text { fortemente } \\
\text { conectado }\end{array}$ & $\begin{array}{l}\text { Assimétrico e } \\
\text { fortemente } \\
\text { conectado }\end{array}$ & $\begin{array}{c}\text { Simétrico } \\
\text { fracamente } \\
\text { conectado }\end{array}$ & $\begin{array}{c}\text { Assimétrico } \\
\text { fracamente } \\
\text { conectado }\end{array}$ \\
\hline MVA & $V_{\text {number }}$ & & $X$ & & \\
\hline MVA & $C_{\min }^{V}$ & $X$ & & & $X$ \\
\hline MVA & $C_{\max }^{V}$ & $\mathrm{X}$ & & & \\
\hline MVA & $C_{a v g}^{V}$ & $X$ & & & \\
\hline MVA & $C_{\text {median }}^{V}$ & $X$ & & & $X$ \\
\hline MVA & $C_{n n}^{V}$ & & & $X$ & \\
\hline MVA & $A_{\text {number }}$ & & $X$ & & \\
\hline MVA & $C_{\max }^{A}$ & $\mathrm{X}$ & & & \\
\hline MVA & $C_{a v g}^{A}$ & $X$ & & & $X$ \\
\hline MVA & $C_{s d}^{A}$ & $X$ & & & \\
\hline MVA & $C_{\text {median }}^{A}$ & $\mathrm{X}$ & & & $X$ \\
\hline MVA & $C_{\text {lowest }}^{A}$ & & & $X$ & $X$ \\
\hline $\mathrm{PMH}$ & $Q M V$ & & & $X$ & $X$ \\
\hline PMH & $I A C$ & & $X$ & $X$ & $X$ \\
\hline CLM & $D S A$ & & & $X$ & \\
\hline MRC & $M D G$ & $X$ & $X$ & & $X$ \\
\hline MRC & $E G R$ & & & $X$ & \\
\hline MRC & $M H G$ & $X$ & & & $X$ \\
\hline MRC & $V N C$ & & & $X$ & \\
\hline MRC & $G M V$ & & $X$ & & \\
\hline MRC & $E D G$ & & $X$ & $X$ & \\
\hline MRC & $E V A$ & & $X$ & $X$ & $\mathrm{X}$ \\
\hline MRC & $C P V$ & & $X$ & $X$ & \\
\hline MRC & $G R A$ & & $X$ & & \\
\hline MRC & $C M A$ & & $X$ & & \\
\hline
\end{tabular}


Tabela 5.30 mostra o tempo economizado por gerar o melhor subconjunto de 10 meta-atributos para cada cenário de PCV ao invés de executar todas as MHs disponíveis. Para todos os cenários, a geração dos meta-atributos selecionados proporcionou uma economia de tempo maior devido ao menor número de meta-atributos que foram calculados para induzir o meta-modelo.

Tabela 5.30: Taxa do tempo economizado para quatro cenários de PCV ao gerar a seleção de 10 meta-atributos ao invés de executar todas as metaheurísticas candidatas.

\begin{tabular}{ccccc}
\hline $\begin{array}{c}\text { Tamanho } \\
\text { do }\end{array}$ & $\begin{array}{c}\text { Simétrico e } \\
\text { fortemente } \\
\text { conectado }\end{array}$ & $\begin{array}{c}\text { Assimétrico e } \\
\text { fortemente } \\
\text { conectado }\end{array}$ & $\begin{array}{c}\text { Simétrico } \\
\text { fracamente } \\
\text { conectado }\end{array}$ & $\begin{array}{c}\text { Assimétrico } \\
\text { fracamente } \\
\text { conectado }\end{array}$ \\
\hline 10 cidades & $76 \%$ & $69 \%$ & $62 \%$ & $41 \%$ \\
25 cidades & $94 \%$ & $91 \%$ & $84 \%$ & $78 \%$ \\
50 cidades & $98 \%$ & $96 \%$ & $86 \%$ & $86 \%$ \\
100 cidades & $97 \%$ & $93 \%$ & $61 \%$ & $66 \%$ \\
\hline
\end{tabular}

A maior vantagem em usar a seleção de atributos ocorre principalmente quando o sistema de meta-aprendizado é usado na recomendação de $\mathrm{MHs}$ para grandes instâncias de PCV fortemente conectadas. Para esses casos, a economia de tempo é bastante significativa, aproximando-se de 100\%.

Apesar da economia de tempo ter sido maior ao gerar os meta-atributos MVA, não se pode garantir que haverá uma economia maior ao usar um conjunto de meta-atributos selecionados composto em sua maioria pelos metaatributos MVA. Esse aspecto pode ser analisado a partir dos valores contidos na Tabela 5.31. Essa tabela mostra, para os diferentes cenários de PCV, a taxa de tempo economizado ao processar a seleção de meta-atributos e calcular os valores desses meta-aributos ao invés de calcular somente os meta-atributos do conjunto MVA. Os valores positivos da tabela confirmam a vantagem da seleção de atributos para as grandes instâncias fortemente conectadas.

Tabela 5.31: Taxa do tempo economizado para quatro cenários de PCV ao gerar a seleção de 10 meta-atributos ao invés de processar todos os metaatributos MVA.

\begin{tabular}{ccccc}
\hline $\begin{array}{c}\text { Tamanho } \\
\text { do }\end{array}$ & $\begin{array}{c}\text { Simétrico e } \\
\text { fortemente } \\
\text { conectado }\end{array}$ & $\begin{array}{c}\text { Assimétrico e } \\
\text { fortemente } \\
\text { conectado }\end{array}$ & $\begin{array}{c}\text { Simétrico } \\
\text { fracamente } \\
\text { conectado }\end{array}$ & $\begin{array}{c}\text { Assimétrico } \\
\text { fracamente } \\
\text { conectado }\end{array}$ \\
\hline 10 cidades & $-236 \%$ & $-348 \%$ & $-1106 \%$ & $-1718 \%$ \\
25 cidades & $19 \%$ & $-6 \%$ & $-367 \%$ & $-501 \%$ \\
50 cidades & $69 \%$ & $54 \%$ & $-274 \%$ & $-309 \%$ \\
100 cidades & $83 \%$ & $63 \%$ & $-344 \%$ & $-347 \%$ \\
\hline
\end{tabular}


Para os cenários assimétricos, é preferivel usar o conjunto de metaatributos MVA, pois a geração de alguns meta-atributos selecionados teve um alto custo computacional, enquanto todos os meta-atributos MVA tiveram um custo menor, conforme mostra a Figura 5.13. Essa figura ilustra o tempo médio para gerar os meta-atributos para o cenário de PCV simétrico e fortemente conectado.

Todos os meta-atributos do conjunto MVA (Figura 5.13a) foram gerados rapidamente, enquanto que alguns meta-atributos dos demais conjuntos demandaram um tempo maior de processamento, principalmente, para as grandes instâncias de PCV. O tempo de processamento para a geração dos metaatributos dos demais cenários de PCV investigados durante os experimentos não está sendo mostrado aqui porque o tempo foi bastante semelhante entre os diferentes cenários.
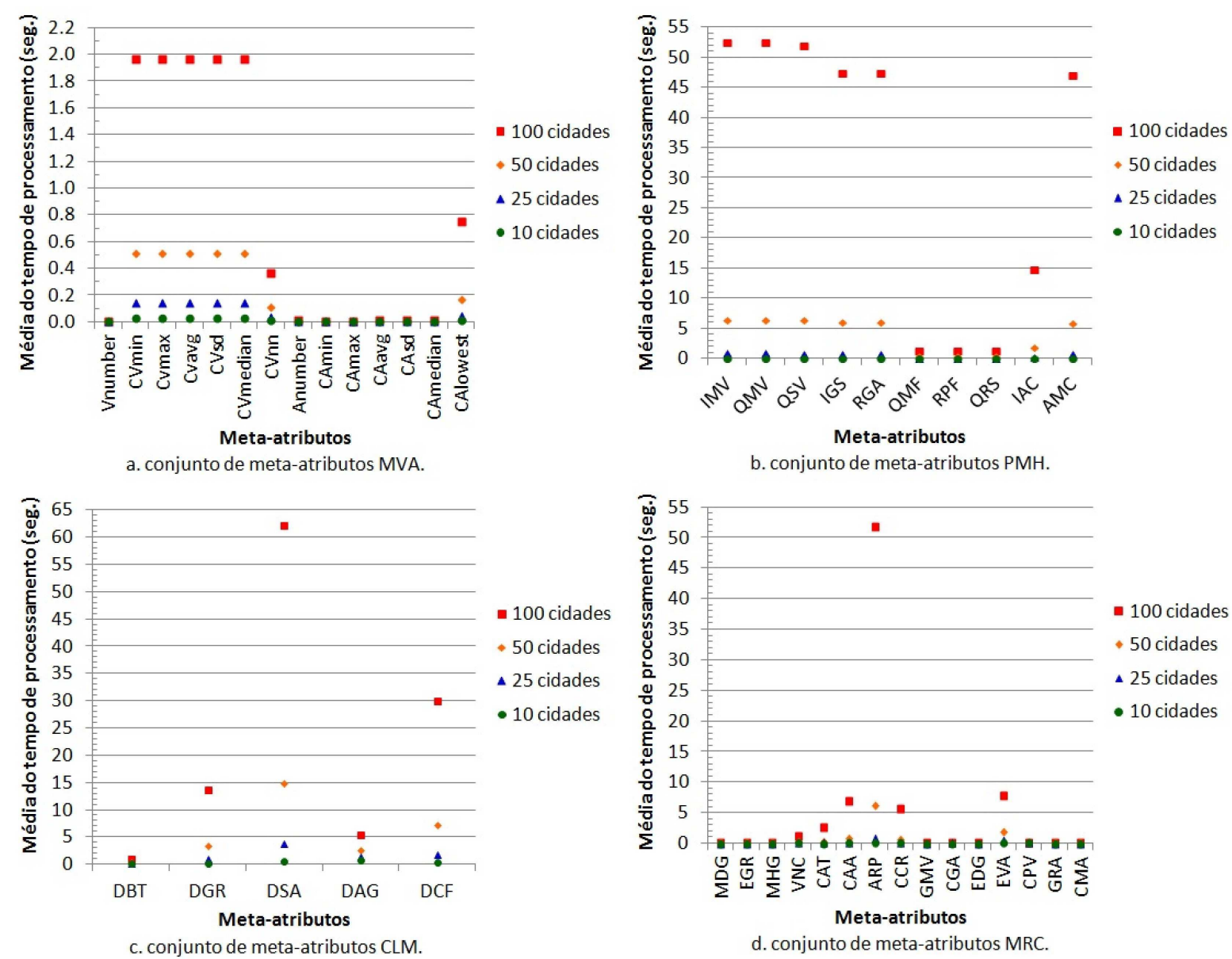

Figura 5.13: Média do tempo de geração dos meta-atributos para o cenário simétrico e fortemente conectado. 


\subsection{Considerações finais}

Este capítulo mostrou os resultados dos experimentos realizados para avaliar a capacidade preditiva dos meta-modelos induzidos para predizer as MHs mais promissoras para diferentes tipos de instâncias de PCV. Tais resultados indicaram que os meta-modelos induzidos tiveram um melhor desempenho em relação aos outros modelos mais simples, como aqueles que recomendam somente a classe majoritária.

Mais de uma MH pode ser recomendada para uma instância de PCV por um classificador multirrótulo. No entanto, esse tipo de recomendação não fornece informações sobre qual das MHs classificadas deve ser usada em primeiro lugar. Para suprir esse problema, os experimentos foram focados na recomendação de um ranking de $\mathrm{MHs}$, usando as adaptações de tradicionais técnicas de AM. Todos os meta-modelos induzidos a partir de técnicas de AM - perceptron multicamadas, $k$ vizinhos mais próximos e árvore de decisão foram testadas em instâncias não vistas durante o treinamento dos mesmos e tiveram uma boa acurácia de ranking.

Neste capítulo também foram descritos os resultados experimentais obtidos a partir de quatro conjuntos de meta-atributos e do procedimento de seleção de atributos. Um resumo sobre a seleção de atributos é descrito no Apêndice B. Em geral, O conjunto de meta-atributos extraídos a partir de algumas medidas de propriedades do grafo foi gerado mais rapidamente, além de proporcionar uma acurácia preditiva dos classificadores induzidos. 


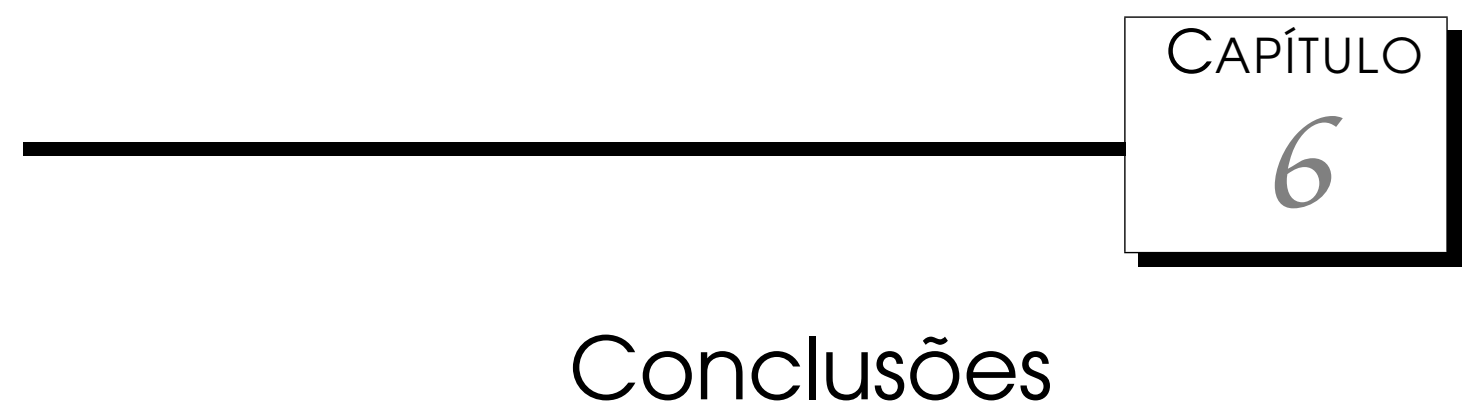

Esta tese investiga o uso de abordagens de meta-aprendizado para selecionar as meta-heurísticas (MH) mais promissoras para resolver novas instâncias do problema do caixeiro viajante (PCV). Problemas de otimização como o PCV são difíceis de serem resolvidos de maneira ótima, porque são problemas que computacionalmente pertencem à classe conhecida como NP-completo. Existem muitas MHs que podem ser aplicadas para tais problemas e que são capazes de encontrar boas soluções. Contudo, é difícil saber antecipadamente qual delas irá gerar a melhor solução para uma nova instância de PCV.

Baseado em um conjunto de meta-conhecimentos que são instâncias de PCV para as quais o desempenho de um conjunto de MHs é também previamente conhecido, técnicas de AM foram usadas para induzir modelos preditivos. Neste trabalho, os conceitos de meta-aprendizado foram aplicados para melhorar as soluções para problemas de otimização, particularmente para instâncias do PCV, fornecendo importantes contribuições. As principais contribuições estão descritas na Seção 6.1, enquanto que a Seção 6.2 apresenta algumas possibilidades de pesquisas que podem ser desenvolvidas a partir dos resultados descritos neste trabalho.

\subsection{Contribuições}

Há quase uma década, ainda havia um grande silêncio sobre o entendimento de como exatamente o desempenho relativo das MHs poderia ser influenciado a partir das características das instâncias de um problema de otimização (Stützle e Fernandes, 2004). O entendimento sobre essa questão começou a ser esclarecido a partir das ideias discutidas em (Smith-Miles, 2009), que 
mostra a importância de identificar as propriedades relevantes do problema e mapeá-las para o desempenho dos algoritmos. A busca por realizar esse mapeamento da melhor maneira possível é um dos objetivos da área conhecida como meta-aprendizado.

A principal contribuição científica do trabalho descrito nesta tese consiste no benefício que a comunidade de pesquisa operacional pode obter usando os conceitos de aprendizado de máquina, principalmente, os de metaaprendizado. Mais especificamente, o problema da seleção da $\mathrm{MH}$ mais promissora para novas instâncias do PCV, que aqui foi investigado sob diferentes aspectos de abordagem de meta-aprendizado, resultando nas seguintes contribuições:

- Proposta de meta-atributos para o PCV. Uma vez que o desempenho do modelo de meta-aprendizado depende dos meta-atributos usados para descrever os meta-exemplos, vários meta-atributos foram extraídos a partir de medições das propriedades do PCV. De modo geral, todos os quatro conjuntos de meta-atributos investigados em nossos experimentos permitiram que os modelos treinados tivessem bons desempenhos no conjunto dos meta-exemplos de teste. Apesar dos benefícios obtidos com o uso de tais conjuntos de meta-atributos, foi feita uma avaliação sobre o custo computacional para gerá-los. Os conjuntos de meta-atributos baseados em medidas de arestas e vértices foram os mais rápidos para serem calculados, não necessitando mais do que $20 \%$ do tempo para executar todas as MHs para uma dada instância de PCV. Os meta-atributos baseados nas execuções das versões simplificadas das MHs também foram gerados de maneira rápida, porém o tempo economizado reduz-se à medida que aumenta a complexidade do problema. Os outros dois conjuntos de meta-atributos, baseados em propriedades particulares de cada $\mathrm{MH}$ e em medidas de redes complexas, ainda precisam de mais investigações para serem usados, principalmente, para grandes instâncias de PCV. Por enquanto, o tempo computacional para calcular os valores de alguns desses meta-atributos é quadrático.

- Aplicação em diferentes cenários. Do ponto de vista da aplicação prática, as investigações experimentais geralmente simulam cenários em que um subconjunto de clientes (vértices) é revisitado em uma nova rota (Kanda et al., 2011 a; Smith-Miles et al., 2010). Neste caso, os meta-exemplos de PCV podem compartilhar uma parte da estrutura do problema (vértices e arestas). Além desse cenário, investigamos outro cenário em que esse compartilhamento não ocorre, ou seja, a recomendação da $\mathrm{MH}$ para indicar a rota para visitar novos clientes é baseada em visitas a clientes totalmente diferentes. Nesse segundo cenário, apesar do aprendizado ser 
mais difícil do que no primeiro, os modelos de meta-aprendizado mantiveram uma boa capacidade preditiva. Em relação às diferentes variações de PCV, nós investigamos experimentalmente quatro cenários resultantes da existência ou não de simetria entre as conexões das cidades adjacentes e do tipo de conectividade, isto é, se o problema é fortemente ou fracamente conectado. Em uma situação hipoteticamente ideal, o PCV é simétrico e fortemente conectado, mas um problema de PCV modelado a partir do mundo real é geralmente assimétrico e fracamente conectado. Nesse último cenário, o desempenho dos modelos de meta-aprendizado foi pior do que nos demais cenários devido à dificuldade das MHs encontrarem uma solução factível para muitas dessas instâncias.

- Classificação multirrótulo. Como diferentes MHs podem gerar soluções iguais para uma mesma instância de PCV, foram investigadas experimentalmente algumas técnicas de classificação multirrótulo. As técnicas investigadas manipulam o conjunto de dados com instâncias multirrótulo de modo a deixar esse conjunto somente com instâncias com rótulo único. O método mais simples é excluir todas as instâncias multirrótulo, mas o conjunto de dados resultante pode ficar com poucas instâncias sendo inapropriado para treinar um modelo preditivo. O método que decompõe a instância multirrótulo em várias instâncias com rótulo diferente e único torna o conjunto de dados inconsistente, dificultando o aprendizado do modelo. O método que transforma o problema de classificação multirrótulo em vários problemas de classificação foi o que apresentou melhores resultados. A desvantagem desse último método é o tempo computacional, pois a classificação para cada exemplo depende dos resultados dos $k$ classificadores, em que $k$ é o número de classes.

- Ranking de meta-heurística. A recomendação de um subconjunto de MHs por meio da classificação multirrótulo não indica qual das MHs recomendadas o usuário deve tentar primeiro. Com a finalidade de induzir um modelo preditivo que fornecesse uma ordem de preferência para o uso das MHs, aplicamos técnicas bem conhecidas de AM como perceptron multicamada (MLP), k vizinhos mais próximos (K-NN) e algoritmos de indução de árvore de decisão ( $\mathrm{AD}$ ), que possuem algoritmos adaptados para ranquear rótulos. Em geral, as técnicas tiveram desempenhos similares, sendo que cada uma tem seus aspectos positivos e negativos. É importante lembrar que o objetivo desse trabalho não foi comparar as diferentes técnicas de AM, mas mostrar que a partir de uma técnica de AM é possível induzir um modelo de meta-aprendizado capaz de predizer com uma boa acurácia o ranking de MHs para um dado PCV. 


\subsection{Trabalhos futuros}

Esse presente trabalho pode ser incrementado com novas pesquisas e experimentos de algumas ideias que não foram contempladas, tais como:

- Aplicação de meta-aprendizado em outros cenários de PCV. Na literatura podemos encontrar diversas variações de PCV como: múltiplo caixeiro, recolhimento de coleta, janela de tempo etc. A recomendação de metaheurísticas para tais cenários também poderia ser realizada por meio de um modelo de meta-aprendizado.

- Avaliar o meta-modelo em outros cenários de PCV diferentes daquele em que foi treinado. Se houver similaridade nas características do problema nos diferentes cenários e, principalmente, a mesma função de mapeamento dessas propriedades para o desempenho das $\mathrm{MHs}$, o meta-modelo tende a ter o mesmo desempenho preditivo.

- Considerar rankings com mais de um algoritmo na mesma posição. Duas ou mais MHs podem ter desempenho de otimização com valores absolutos diferentes, mas a diferença pode ser quase nula. Pois, independente da MH escolhida, a solução provida por qualquer uma dessas MHs vai ser praticamente a mesma para o problema de otimização.

- Novo critério para estabelecer o ranking de MHs. Nas instâncias fracamente conectadas pode ser interessante saber qual a probabilidade de cada $\mathrm{MH}$ encontrar uma solução factível. O valor dessa probabilidade pode ser usada para ponderar o valor da posição de ranking da $\mathrm{MH}$. Além disso, o valor do desvio-padrão das soluções encontradas pela $\mathrm{MH}$ também poderia ser considerada no cálculo da posição, já que o menor desvio-padrão indica que a provável solução obtida para o problema de otimização terá um valor será próximo à média.

- Estender a aplicação de meta-aprendizado para outros problemas de otimização. As primeiras ideias para identificar as características de outros problemas de otimização e relacioná-las com o desempenho dos algoritmos foram discutidas em (Smith-Miles, 2009; Smith-Miles e Lopes, 2012). A possibilidade de extrair propriedades relevantes de tais problemas e calcular rapidamente os valores de tais propriedades é importante para que um conjunto de meta-dados seja obtido. 


\section{Referências Bibliográficas}

Aha, D. W. (1992). Generalizing from case studies: a case study. Proceedings of the ninth international workshop on Machine learning, ML92, p. 1-10, San Francisco, CA, USA. Morgan Kaufmann Publishers Inc.

Ali, S.; Smith, K. A. (2006). On learning algorithm selection for classification. Applied Soft Computing, v.6, n.2, p.119-138.

Applegate, D.; Bixby, R.; Chvatal, V.; Cook, W. (2011). The Traveling Salesman Problem: A Computational Study. Princeton Series in Applied Mathematics. Princeton University Press.

Arenales, M.; Armentano, V.; Morabito, R.; Yanasse, H. (2007). Pesquisa Operacional. Elsevier, Rio de Janeiro.

Balas, E. (2004). The prize collecting traveling salesman problem and its applications. Gutin, G.; Punnen, A.; Du, D.-Z.; Pardalos, P. M., editores, The Traveling Salesman Problem and Its Variations, v. 12 de Combinatorial Optimization, p. 663-695. Springer US.

Barbagallo, S.; Lobetti Bodoni, M.; Medina, D.; Corno, F.; Prinetto, P.; Sonza Reorda, M. (1996). Scan insertion criteria for low design impact. Proceedings of the 14th IEEE VLSI Test Symposium, VTS '96, p. 26-31, Washington, DC, USA. IEEE Computer Society.

Bektas, T. (2006). The multiple traveling salesman problem: an overview of formulations and solution procedures. Omega, v.34, n.3, p.209-219.

Bell, J. E.; McMullen, P. R. (2004). Ant colony optimization techniques for the vehicle routing problem. Advanced Engineering Informatics, v.18, n.1, p.41 -48 .

Ben-Dor, A.; Chor, B. (1997). On constructing radiation hybrid maps (extended abstract). Proceedings of the first annual international conference on 
Computational molecular biology, RECOMB '97, p. 17-26, New York, NY, USA. ACM.

Bensusan, H.; Kalousis, A. (2001). Estimating the predictive accuracy of a classifier. Flach, P.; de Raedt, L., editores, Proceedings of the 12th European Conference on Machine Learning, p. 25-36. Springer.

Besten, M. d.; Stützle, T.; Dorigo, M. (2001). Design of iterated local search algorithms. Proceedings of the EvoWorkshops on Applications of Evolutionary Computing, p. 441-451, London, UK, UK. Springer-Verlag.

Bouckaert, R.; Frank, E.; Hall, M.; Kirkby, R.; Reutemann, P.; Seewald, A.; Scuse, D. (2008). WEKA Manual for Version 3-6-O. The University of Waikato, Hamilton, New Zealand.

Boutell, M.; J. Luo, X. S.; Brown, C. (2004). Learning multi-label scene classification. Pattern Recognition, v.37, p.1757-1771.

Brazdil, P.; Gama, J.; Henery, B. (1994). Characterizing the applicability of classification algorithms using meta-level learning. Proceedings of the European Conference on Machine Learning, p. 83-102, Secaucus, NJ, USA. Springer-Verlag New York, Inc.

Brazdil, P.; Giraud-Carrier, C.; Soares, C.; Vilalta, R. (2009). Metalearning: Application to Data Mining. Springer, Berlin, Germany.

Brazdil, P.; Soares, C.; Costa, J. (2003). Ranking learning algorithms: Using IBL and meta-learning on accuracy and time results. Machine Learning, v.50, p.251-257.

Bullnheimer, B.; Hartl, R.; Strauss, C. (1999). An improved ant system algorithm for the vehicle routing problem. Annals of Operations Research, v.89, p.319-328. 10.1023/A:1018940026670.

Burke, E.; Kendall, G.; Newall, J.; Hart, E.; Ross, P.; Schulenburg, S. (2003). Hyper-heuristics: An emerging direction in modern search technology. Glover, F.; Kochenberger, G., editores, Handbook of Metaheuristics, v. 57 de International Series in Operations Research \& Management Science, p. 457474. Springer New York.

Campello, R. J. G. B.; Hruschka, E. R. (2009). On comparing two sequences of numbers and its applications to clustering analysis. Information Sciences, v.179, n.8, p.1025-1039. 
Cerny, V. (1985). Thermodynamical approach to the traveling salesman problem: An efficient simulation algorithm. Journal of Optimization Theory and Applications, v.45, p.41-51.

Chlond, M. J. (2002). The traveling space telescope problem. INFORMS Transaction on Education, v.3, n.1, p.69-71.

Choo, C. W. (2003). A organização do conhecimento: como as organizações usam a informação para criar significado, construir conhecimento e tomar decisões. SENAC, São Paulo.

Cook, W. J.; Cunningham, W. H.; Pulleyblank, W. R.; Schrijver, A. (1998). Combinatorial Optimization. John Wiley \& Sons, New York.

Costa, L.; Rodrigues, F.; Travieso, G.; Boas, P. V. (2007). Characterization of complex networks: A survey of measurements. Advances in Physics, v.56, p. 167-242.

De Carvalho, A.; Freitas, A. (2009). A tutorial on multi-label classification techniques. Abraham, A.; Hassanien, A.-E.; Snasel, V., editores, Foundations of Computational Intelligence Volume 5, v. 205 de Studies in Computational Intelligence, p. 177-195. Springer Berlin / Heidelberg.

Dekel, O.; Manning, C. D.; Singer, Y. (2003). Log-Linear Models for Label Ranking. Advances in Neural Information Processing Systems. MIT Press.

Demšar, J. (2006). Statistical comparisons of classifiers over multiple data sets. J. Mach. Learn. Res., v.7, p.1-30.

Diestel, R. (2010). Graph Theory (Graduate Texts in Mathematics). Springer, London, Heidelberg, 4a. edição.

Dietterich, T. G. (1998). Approximate statistical tests for comparing supervised classification learning algorithms. Neural Comput., v.10, n.7, p.1895-1923.

Donati, A.; Montemanni, R.; Casagrande, N.; Rizzoli, A.; Cambardella, L. (2008). Time dependent vehicle routing problem with a multi ant colony system. European Journal of Operational Research, v.185, p.1174-1191.

Dorigo, M.; Gambardella, L. M. (1997). Ant Colony System: A Cooperative Learning Approach to the Traveling Salesman Problem. IEEE Transactions on Evolutionary Computation, v.1, n.1, p.53-66.

Dudoit, S.; Fridlyand, J.; Speed, T. P. (2002). Comparison of Discrimination Methods for the Classification of Tumors Using Gene Expression Data. Journal of the American Statistical Association, v.97, n.457, p.77-87. 
Edmonds, J. (1965). Maximum matching and a polyhedron with 0,1-vertices. Journal of Research of the National Burean of Standards, v.69B, p.125-130.

Elmohamed, M. A. S.; Coddington, P. D.; Fox, G. (1998). A comparison of annealing techniques for academic course scheduling. Selected papers from the Second International Conference on Practice and Theory of Automated Timetabling II, PATAT '97, p. 92-114, London, UK, UK. Springer-Verlag.

Faceli, K.; Lorena, A. C.; Gama, J.; De Carvalho, A. C. P. D. L. F. (2011). Inteligência artificial uma abordagem de aprendizado de máquina. LTC, Rio de Janeiro.

Feo, T.; Resende, M. (1995). Greedy randomized adaptive search procedures. Journal of Global Optimization, v.6, p.109-133.

Gavish, Bezalel; Graves, S. C. (1979). The travelling salesman problem and related problems, working paper or-078-78. Relatório Técnico OR 078-78, Massachusetts Institute of Technology, Operations Research Center.

Gendreau, M.; Potvin, J.-Y. (2010). Handbook of Metaheuristics. Springer, New York, 2a. edição.

Gilmore, P.; Gomory, R. (1964). Sequencing a one state-variable machine a solvable case of the traveling salesman problem. Operations Research, v.12, p.655-679.

Glover, F. (1989). Tabu search - part i. ORSA Journal on Computing, v.1, n.3, p.190-206.

Glover, F.; Taillard, E.; Taillard, E. (1993). A user's guide to tabu search. Annals of Operations Research, v.41, p.1-28.

Goldbarg, M.; Luna, H. (2005). Otimização combinatória e programação linear: modelos e algoritmos. Campus, Rio de Janeiro, 2a. edição.

Goldberg, D. (1989). Genetic Algorithms in Search, Optimization, and Machine Learning. Addison-Wesley Professional, Alabama.

Goldberg, D. E.; Lingle, R. (1985). Alleles, loci, and the traveling salesman problem. Grefenstette, J. J., editor, Proceedings of the First International Conference on Genetic Algorithms and Their Applications. Lawrence Erlbaum Associates, Publishers.

Gribkovskaia, I.; Laporte, G.; Shyshou, A. (2008). The single vehicle routing problem with deliveries and selective pickups. Computers Operations Research, v.35, n.9, p.2908-2924. 
Gutin, G.; Jakubowicz, H.; Ronen, S.; Zverovitch, A. (2005). Seismic vessel problem. Communications in DQM, p. 13-20.

Gutin, G.; Punnen, A. (2002). The Traveling Salesman Problem and Its Variations. Kluwer Academic Publishers, Netherlands.

Hall, M.; Frank, E.; Holmes, G.; Pfahringer, B.; Reutemann, P.; Witten, I. (2009). The weka data mining software: an update. SIGKDD Explorations Newsletter, v.11, n.1, p.10-18.

Han, A.; Zhu, D. (2006). A new DNA encoding method for traveling salesman problem. Lectures Notes in Computer Science, v.4115, p.328-335.

Han, J.; Kamber, M. (2000). Data Mining: Concepts and Techniques. Morgan Kaufmann.

Haykin, S. S. (2009). Neural networks and learning machines. Pearson Education inc, New York, 3a. edição.

Hemmelmayr, V. C.; Doerner, K. F.; Hartl, R. F. (2009). A variable neighborhood search heuristic for periodic routing problems. European Journal of Operational Research, v.195, n.3, p.791 - 802.

Holland, J. (1973). Genetic algorithms and the optimal allocations of trial. SIAM Journal of Computing, v.2, p.88-105.

Hung, K.-S.; Su, S.-F.; Lee, Z.-J. (2007). Improving ant colony optimization algorithms for solving traveling salesman problems. Journal of Advanced Computational Intelligence and Intelligent Informatics, v.11, n.4, p.433-442.

Ihaka, R.; Gentleman, R. (1996). R: A language for data analysis and graphics. Journal of Computational and Graphical Statistics, v.5, n.3, p.299-314.

Júnior, L. O. R. (2011). Seleção automática de heurísticas para alguns problemas da otimização combinatória. Tese (Doutorado), UFRJ/COPPE.

Kalousis, A. (2002). Algorithm Selection via Meta-Learning. Tese (Doutorado), University of Geneve, Department of Computer Science.

Kalousis, A.; Hilario, M. (2001). Feature selection for meta-learning. Proceedings of the 5th Pacific-Asia Conference on Knowledge Discovery and Data Mining, PAKDD '01, p. 222-233, London, UK, UK. Springer-Verlag.

Kanda, J.; De Carvalho, A.; Hruschka, E.; Soares, C. (2010). Using metalearning to classify traveling salesman problems. Proceedings of the 2010 Eleventh Brazilian Symposium on Neural Networks, SBRN '10, p. 73-78, Washington, DC, USA. IEEE Computer Society. 
Kanda, J.; De Carvalho, A.; Hruschka, E.; Soares, C. (2011a). Selection of algorithms to solve traveling salesman problems using meta-learning. International Journal of Hybrid Intelligent Systems, v.8, n.3, p.117-128.

Kanda, J.; Soares, C.; Hruschka, E.; Carvalho, A. (2012). A meta-learning approach to select meta-heuristics for the traveling salesman problem using MLP-based label ranking. Huang, T.; Zeng, Z.; Li, C.; Leung, C., editores, Neural Information Processing, v. 7665 de Lecture Notes in Computer Science, p. 488-495. Springer Berlin Heidelberg.

Kanda, J. Y.; De Carvalho, A. C.; Hruschka, E. R.; Soares, C. (2011b). Using meta-learning to recommend meta-heuristics for the traveling salesman problem. Machine Learning and Applications, Fourth International Conference on, v.1, p.346-351.

Karapetyan, D.; Gutin, G. (2011). Lin-kernighan heuristic adaptations for the generalized traveling salesman problem. European Journal of Operational Research, v.208, n.3, p.221-232.

Karapetyan, D.; Gutin, G. (2012). Efficient local search algorithms for known and new neighborhoods for the generalized traveling salesman problem. European Journal of Operational Research, v.219, n.2, p.234 - 251.

Kernighan, B. W.; Lin, S. (1970). An efficient heuristic procedure for partitioning graphs. The Bell system technical journal, v.49, n.1, p.291-307.

Kim, B.-I.; Jeong, S. (2009). A comparison of algorithms for origin-destination matrix generation on real road networks and an approximation approach. Computers and Industrial Engineering, v.56, n.1, p.70-76.

Kirkpatrick, S.; Gelatt, C.; Vecchi, M. (1983). Optimization by simulated annealing. Science, v.220, p.671-680.

Lenstra, J. (1974). Clustering a data array and the traveling-salesman problem. Operations Research, v.22, n.2, p.413-414.

Lim, A.; Wang, F.; Xu, Z. (2005). The capacitated traveling salesman problem with pickups and deliveries on a tree. Proceedings of the 16th international conference on Algorithms and Computation, ISAAC'05, p. 1061-1070, Berlin, Heidelberg. Springer-Verlag.

Lin, S.; Kernighan, B. (1973). An effective heuristic algorithm for the traveling salesman problem. Operations Research, v.21, p.498-516. 
Liu, Y.-H. (2010). Different initial solution generators in genetic algorithms for solving the probabilistic traveling salesman problem. Applied Mathematics and Computation, v.216, p.125-137.

Madsen, O. (1988). An application of traveling-salesman routines to solve pattern-allocation problems in the glass industry. Journal of the Operational Research Society, v.39, n.3, p.249-256.

Magirou, V. (1986). The efficient drilling of printed circuit boards. INTERFACES, v.16, p.13-23.

Mcculloch, W. S.; Pitts, W. H. (1943). A logical calculus of the ideas immanent in nervous activity. Bulletin of Mathematical Biophysics, v.5, p.115-133.

Menger, K. (1932). Das botenproblem. Ergebnisse Eines Mathematischen Kolloquiums, v.2, p.11-12.

Mestria, M.; Ochi, L. S.; de Lima Martins, S. (2012). GRASP with path relinking for the symmetric euclidean clustered traveling salesman problem. Computers \& Operations Research, v.1, p.--

Michie, D.; Spiegelhalter, D.; Taylor, C. (1994). Machine Learning, Neural and Statistical Classification. Ellis Horwood, New York.

Mirabi, M. (2011). An effective constructive heuristic to find near optimal solution for scheduling and traveling salesman problem. Australian Journal of Basic and Applied Sciences, v.5, p.484-491.

Mitchell, T. (1997). Machine Learning. McGraw Hill, New Tork.

Oncan, T.; Altinel, I. K.; Laporte, G. (2009). Invited review: A comparative analysis of several asymmetric traveling salesman problem formulations. Computers Operations Research, v.36, n.3, p.637-654.

Papadimitriou, C. H. (1977). The euclidean traveling salesman problem is NPcomplete. Theoretical Computer Science, v.4, n.3, p.237-244.

Park, J.; Kim, B.-I. (2010). The school bus routing problem: A review. European Journal of Operational Research, v.202, n.2, p.311-319.

Patvichaichod, S. (2011). An improved genetic algorithm for the traveling salesman problem with multi-relations. Journal of Computer Science, v.7, n.1, p.70-74.

Pearn, W.; Chou, J. (1999). Improved solutions for the Chinese postman problem on mixed networks. Computers \& Operations Research, v.26, n.8, p.819 -827 . 
Peng, Y.; Flach, P. A.; Brazdil, P.; Soares, C. (2002). Decision tree-based characterization for meta-learning. Bohanec, M.; Kasek, B.; Lavrac, N.; Mladenic, D., editores, ECML/PKDD'O2 workshop on Integration and Collaboration Aspects of Data Mining, Decision Support and Meta-Learning, p. 111-122. University of Helsinki.

Penna, P.; Subramanian, A.; Ochi, L. (2011). An Iterated Local Search heuristic for the Heterogeneous Fleet Vehicle Routing Problem. Journal of Heuristics, v.1, p.1-32.

Pohle, T.; Pampalk, E.; Widmer, G. (2005). Generating similarity-based playlists using traveling salesman algorithms. In Proceedings of the 8th International Conference on Digital Audio Effects (DAFx-05), p. 220-225, Madrid, Spain.

Reeves, C. R.; Yamada, T. (1998). Genetic algorithms, path relinking, and the flowshop sequencing problem. Evolutionary Computation, v.6, n.1, p.45-60.

Rego, C.; Gamboa, D.; Glover, F.; Osterman, C. (2011). Traveling salesman problem heuristics: Leading methods, implementations and latest advances. European Journal of Operational Research, v.211, n.3, p.427 - 441.

Reinelt, G. (1991). TSPLIB - a traveling salesman problem library. Informs Journal on Computing, v.3, n.4, p.376-384.

Rendell, L.; Sheshu, R.; Tcheng, D. (1987). Layered concept-learning and dynamically variable bias management. Proceedings of the 10th international joint conference on Artificial intelligence - Volume 1, IJCAI'87, p. 308-314, San Francisco, CA, USA. Morgan Kaufmann Publishers Inc.

Rice, J. (1976). The algorithm selection problem. Advances in Computers, v.15, p.65-118.

Rumelhart, D. E.; Mcclelland, J. L. (1986). Parallel distributed processing: explorations in the microstructure of cognition, vol. 1: foundations. MIT Press, Cambridge, MA, USA.

Schapire, R. E.; Singer, Y. (2000). BoosTexter: A Boosting-based System for Text Categorization. Machine Learning, v.39, n.2/3, p.135-168.

Seber, G.; Wild, C. (1989). Nonlinear Regression. John Wiley \& Sons, New York.

Shmoys, D.; Lenstra, J.; Kan, A.; Lawler, E. (1985). The Traveling Salesman Problem. Wiley Interscience Series in Discrete Mathematics. John Wiley \& Sons. 
Silva, M. M.; Subramanian, A.; Vidal, T.; Ochi, L. S. (2012). A simple and effective metaheuristic for the minimum latency problem. European Journal of Operational Research, v.221, n.3, p.513-520.

Smith, M. (1993). Neural Networks for Statistical Modeling. John Wiley \& Sons, Inc., New York, NY, USA.

Smith-Miles, K.; Lopes, L. (2012). Review: Measuring instance difficulty for combinatorial optimization problems. Computers and Operations Research, v.39, n.5, p.875-889.

Smith-Miles, K.; van Hemert, J.; Lim, X. Y. (2010). Understanding TSP difficulty by learning from evolved instances. Proceedings of the 4th international conference on Learning and intelligent optimization, LION'10, p. 266-280, Berlin, Heidelberg. Springer-Verlag.

Smith-Miles, K. A. (2008). Towards insightful algorithm selection for optimisation using meta-learning concepts. Proceedings of the IEEE International Joint Conference on Neural Networks 2008, p. 4118-4124.

Smith-Miles, K. A. (2009). Cross-disciplinary perspectives on meta-learning for algorithm selection. ACM Computing Surveys, v.41, n.1, p.6:1-6:25.

Spearman, C. (1904). The proof and measurement of association between two things. American Journal of Psychology, v.15, p.72-101.

Stützle, T. (1999). Local Search Algorithms for Combinatorial Problems - Analysis, Algorithms and New Applications. Tese (Doutorado), TU Darmstadt.

Stützle, T.; Fernandes, S. (2004). New benchmark instances for the QAP and the experimental analysis of algorithms. EvoCOP, p. 199-209.

Subramanian, A.; Drummond, L. M. A.; Bentes, C.; Ochi, L. S.; Farias, R. (2010). A parallel heuristic for the vehicle routing problem with simultaneous pickup and delivery. Comput. Oper. Res., v.37, n.11, p.1899-1911.

Subramanian, A.; Penna, P. H. V.; Uchoa, E.; Ochi, L. S. (2012). A hybrid algorithm for the heterogeneous fleet vehicle routing problem. European Journal of Operational Research, v.221, n.2, p.285 - 295.

Szwarcfiter, J. (1984). Grafos e Algoritmos Computacionais. Editora Campus, Rio de Janeiro.

Tan, P.-N.; Steinbach, M.; Kumar, V. (2006). Introduction to Data Mining. Addison Wesley, Boston. 
Todorovski, L.; Dzeroski, S. (1999). Experiments in meta-level learning with ILP. Proceedings of the Third European Conference on Principles of Data Mining and Knowledge Discovery, PKDD '99, p. 98-106, London, UK, UK. Springer-Verlag.

Tsoumakas, G.; Katakis, I. (2007). Multi-label classification: An overview. International Journal of Data Warehousing and Mining, v.3, n.3, p.1-13.

Vens, C.; Struyf, J.; Schietgat, L.; Dvzeroski, S.; Blockeel, H. (2008). Decision trees for hierarchical multi-label classification. Machine Learning, v.73, n.2, p. 185-214.

Vilalta, R.; Drissi, Y. (2002). A perspective view and survey of meta-learning. Artificial Intelligence Review, v.18, n.2, p.77-95.

Wang, X.; Regan, A. C. (2009). On the convergence of a new time window discretization method for the traveling salesman problem with time window constraints. Computers and Industrial Engineering, v.56, n.1, p.161 - 164.

Watts, D. (1999). Small worlds: the dynamics of networks between order and randomness. Princeton University Press,, Princeton.

Whitley, D.; Starkweather, T.; Shaner, D. (1991). The traveling salesman and sequence scheduling: Quality solutions using genetic edge recombination. Davis, L., editor, Handbook of Genetic Algorithms, p. 350-372. Springer New York.

Winston, W. (1994). Operations Research: Applications and Algorithms. International Thomson Publishing, Belmont, CA, 3a. edição.

Witten, I.; Frank, E. (2005). Data Mining: Pratical Machine Learning Tools and Techniques. Elsevier, San Francisco, CA, 2a. edição.

Wolpert, D.; Macready, W. (1997). No free lunch theorems for optimization. IEEE Transactions on Evolutionary Computation, v.1, p.67-82.

Xu, L.; Hutter, F.; Hoos, H. H.; Leyton-Brown, K. (2008). SATzilla: portfoliobased algorithm selection for SAT. Journal of Artificial Intelligence Research, v.32, n.1, p.565-606. 


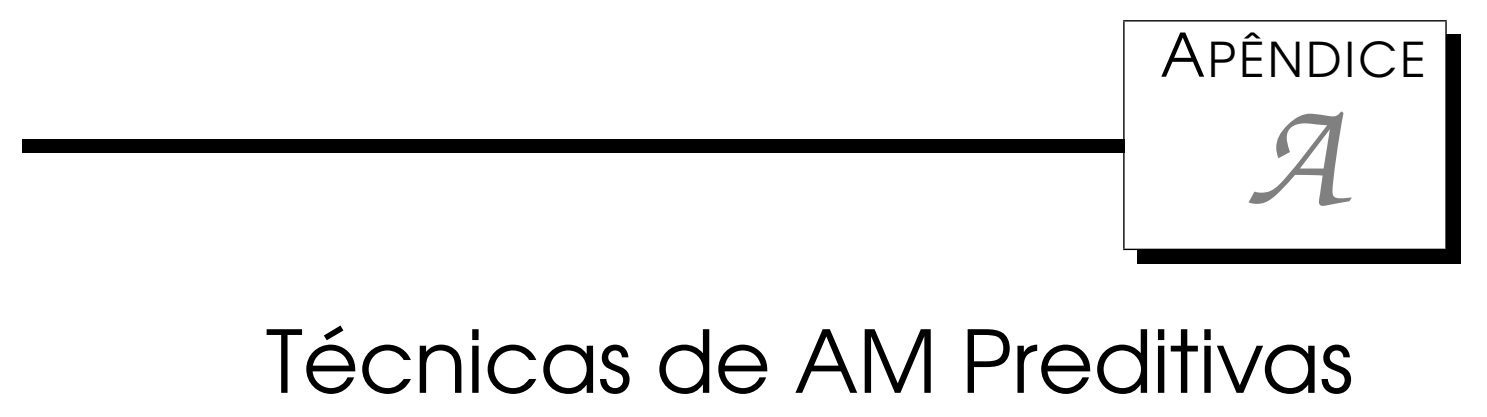

Nas últimas décadas, a tecnologia avançou tanto que, atualmente, existem vários dispositivos portáteis e remotos nos quais é possivel armazenar um grande volume de dados. Por outro lado, em muitas situações é difícil extrair informações, potencialmente, úteis a partir dos dados armazenados. Extrair informações úteis significa identificar padrões relevantes que estejam contidos em um conjunto de dados. A identificação de padrões facilita a predição de valores não triviais para novos dados que tenham alguma relação com o domínio dos dados armazenados. A tarefa de identificar possíveis padrões em um conjunto de dados pode ser conduzida por meio das técnicas de mineração de dados (Tan et al., 2006). No campo de mineração de dados, algoritmos de aprendizado de máquina (AM) são usados para descobrir padrões em uma base de dados. Existem vários tipos de base de dados, tais como: registro de manutenção de equipamentos, aplicações de empréstimos, transações financeiras e registros médicos (Witten e Frank, 2005).

Segundo Mitchell (1997), AM é uma área de pesquisa que investiga algoritmos capazes de melhorar o seu desempenho na realização de uma tarefa por meio de experiências adquiridas em situações anteriores.

Em um processo de aprendizado, um algoritmo de AM busca pela melhor hipótese contida em um espaço pré-definido de possíveis hipóteses. Entendese por hipótese o modo em que são descritas as relações entre os exemplos (objetos) contidos em um conjunto de dados. A estratégia de busca e a representação da hipótese encontrada definem a preferência ou viés do algoritmo de AM. O viés de um algoritmo restringe o conjunto de hipóteses que podem ser induzidas. Um algoritmo de AM sem viés não consegue generalizar o conhecimento adquirido durante o seu treinamento para aplicá-lo com sucesso em novos dados (Mitchell, 1997). 
Um algoritmo de AM pode adotar diferentes paradigmas de treinamento de acordo com a tarefa para a qual o algoritmo será aplicado.

Para as tarefas preditivas é geralmente aplicado o aprendizado supervisionado, no qual o valor do atributo alvo é previamente conhecido para todos os exemplos do conjunto de treinamento, e o modelo é induzido a partir do mapeamento entre os valores dos atributos e do atributo alvo (Mitchell, 1997).

Para as tarefas descritivas é geralmente adotado o aprendizado nãosupervisionado, no qual o valor do atributo alvo não é conhecido para os exemplos de treinamento. O modelo é induzido a partir do cálculo da similaridade entre os exemplos de treinamento com o objetivo de agrupar os mais similares. A similaridade é, em geral, calculada por meio de uma medida de distância (ex.: Euclidiana) (Faceli et al., 2011).

A Figura A.1 ilustra uma abordagem básica para induzir um modelo classificador. O conjunto de treinamento contém exemplos para os quais o valor do atributo alvo (classe) é conhecido. Esse conjunto é usado por uma técnica de AM para induzir um modelo preditivo, que idealmente deverá ser capaz de classificar corretamente novos exemplos de um conjunto de teste. A capacidade preditiva do modelo pode ser avaliada por meio de alguma medida como a taxa de acurácia (Tan et al., 2006).

Durante a indução do modelo, dois tipos de erros podem ocorrer: erro de treinamento, determinado pela taxa de classificação errada para os exemplos do conjunto de treinamento; e erro de teste, mensurado pela taxa de classificação errada no conjunto de teste (Tan et al., 2006).

Quanto menor a taxa de erro nos dois conjuntos - treinamento e teste melhor é o desempenho preditivo do modelo induzido. Se o modelo tem um fraco desempenho nos dois conjuntos é porque houve um underfitting (Figura A.2a). Uma das causas para esse fato é o número insuficiente de exemplos de treinamento. Se o modelo induzido apresenta uma taxa reduzida de erro no conjunto de treinamento e uma taxa elevada de erro no conjunto de teste pode estar ocorrendo um overfitting (Figura A.2b). Overfitting ocorre quando o modelo é super ajustado para os exemplos de treinamento, não tendo uma boa capacidade de generalização (Tan et al., 2006).

Uma técnica preditiva induz uma função a partir de um conjunto de exemplos previamente classificados. A classe dos exemplos assume valores num domínio conhecido. Esse domínio é um conjunto de valores nominais ou um conjunto infinito de valores, dependendo se o problema de aprendizado é modelado como uma tarefa de classificação ou de regressão, respectivamente. A função estimada é também conhecida como classificador (ou regressor), pois atribui uma das possíveis classes (ou um valor real) para um dado exemplo cuja classe é desconhecida (Dietterich, 1998). 


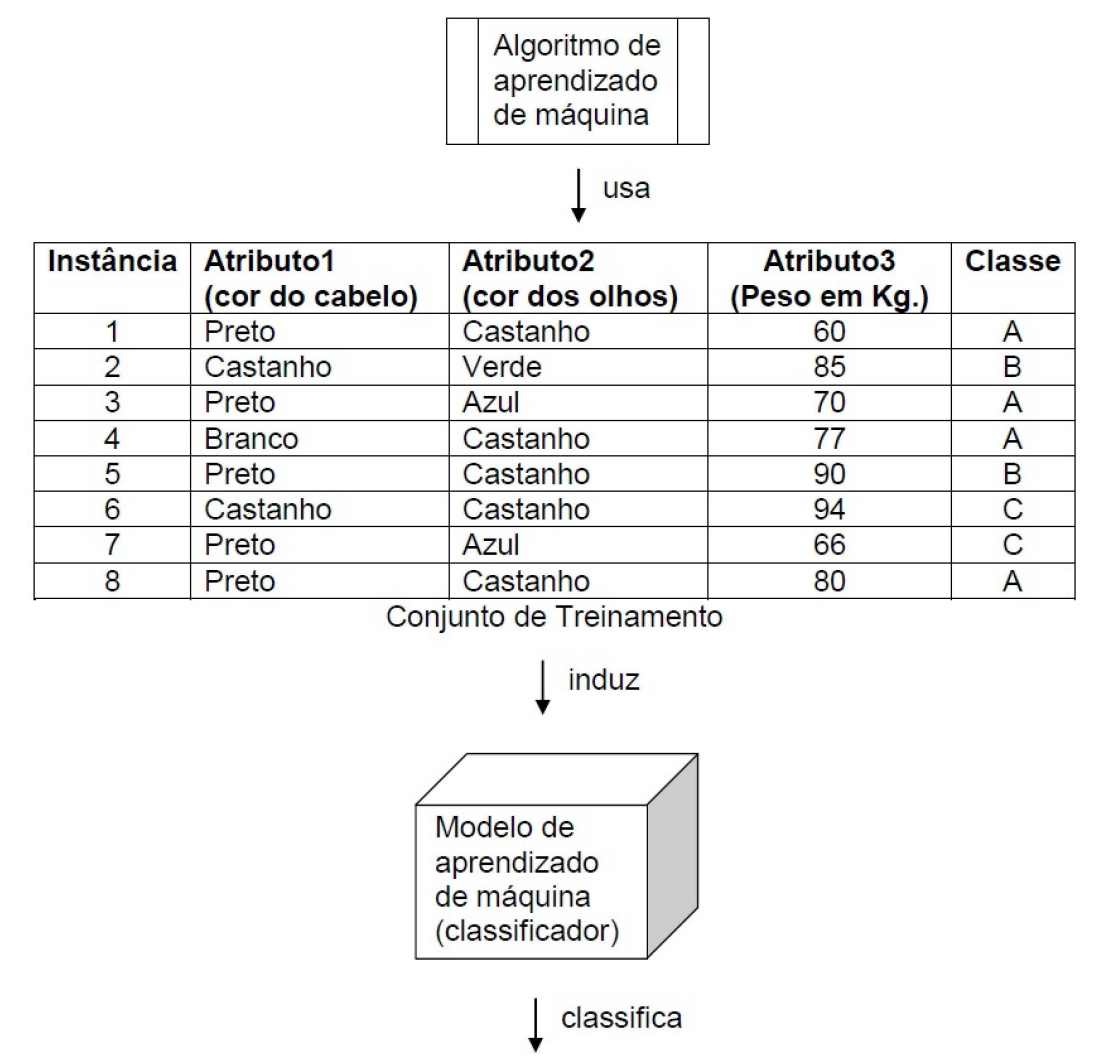

\begin{tabular}{|c|l|l|c|c|}
\hline Instância & $\begin{array}{l}\text { Atributo1 } \\
\text { (cor do cabelo) }\end{array}$ & $\begin{array}{l}\text { Atributo2 } \\
\text { (cor dos olhos) }\end{array}$ & $\begin{array}{c}\text { Atributo3 } \\
\text { (Peso em Kg.) }\end{array}$ & Classe \\
\hline 1 & preto & verde & 73 & $?$ \\
\hline 2 & branco & castanho & 90 & $?$ \\
\hline 3 & preto & castanho & 70 & $?$ \\
\hline \multicolumn{4}{|c}{ Conjunto de Teste } \\
\hline
\end{tabular}

Figura A.1: Abordagem básica para construir um modelo de classificação.

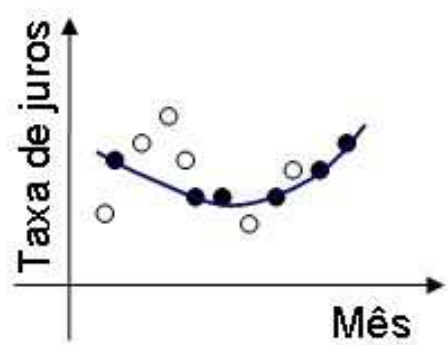

a) Underfitting.

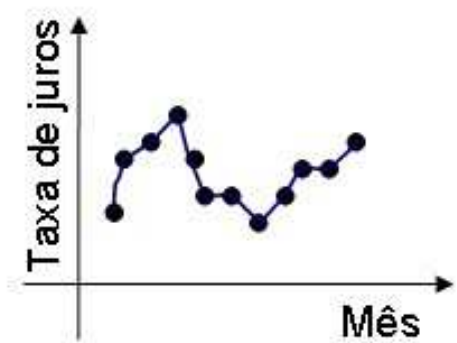

b) Overfitting.

Figura A.2: Erros de modelagem: underfitting e overfitting.

Os principais métodos de aprendizado baseados em técnicas preditivas são descritos a seguir:

\section{A. 1 Métodos baseados em distâncias}

Os métodos de AM baseados em distâncias considera que existe uma similaridade maior entre os exemplos relacionados ao mesmo conceito (classe). 
Geralmente, uma medida de distância é usada para calcular a similaridade entre os exemplos no espaço dos atributos de entrada (Tan et al., 2006).

O algoritmo de AM mais simples baseado em distância é o 1-vizinho mais próximo, que calcula a distância de um novo exemplo para todos os exemplos do conjunto de treinamento e classifica com a classe do exemplo mais próximo (Tan et al., 2006). Para calcular as distâncias entre os exemplos, diversas métricas podem ser usadas, como a Distância Euclidiana, que é calculada por meio da Equação A.1.

$$
d\left(x_{a}, x_{b}\right)=\sqrt{\sum_{i=1}^{m}\left(x_{a}^{i}-x_{b}^{i}\right)^{2}},
$$

onde $x_{a}$ e $x_{b}$ são exemplos descritos por $m$ atributos.

Ao invés de usar somente o vizinho mais próximo, o sucesso de classificação para um novo exemplo pode aumentar se for considerada a classe dos $k$ vizinhos mais próximos. Nesse caso, o novo exemplo pode ser classificado com a classe da maioria dos $k$ vizinhos selecionados. Uma alternativa para definir a classe para um novo exemplo é ponderar com pesos maiores os vizinhos que estejam mais próximos desse novo exemplo (Tan et al., 2006).

Os principais aspectos positivos do algoritmo $k$ vizinhos mais próximos são (Tan et al., 2006):

- simplicidade: somente os exemplos de treinamento são armazenados na memória;

- aplicabilidade: o algoritmo pode ser aplicado para diversos problemas, inclusive os mais complexos;

- incremental: novos exemplos de treinamento podem ser incluídos se forem armazenados na memória;

- capacidade preditiva: geralmente apresenta uma boa acurácia preditiva para diversos conjuntos de dados.

E os seus principais aspectos negativos são:

- preguiça: o algoritmo não obtém uma representação compacta dos exemplos;

- difícil interpretação: as regras de classificação induzidas pelo modelo a partir de um conjunto de dados não são explícitas;

- alto custo computacional: a distância do objeto de teste para cada um do conjunto de treinamento é sempre calculada; 
- Pouca robustez: o desempenho do algoritmo é afetado pela presença de atributos redundantes e irrelevantes;

- alta dimensionalidade: o espaço definido pelos atributos de um problema cresce exponencialmente com o número de atributos.

\section{A.2 Métodos probabilísticos}

Esses métodos assumem a probabilidade de um evento $A$ (ex. um paciente está doente) dado um evento $B$ ocorrer (ex. o resultado de exames realizados nesse paciente é positivo). No contexto de AM (Mitchell, 1997), a probabilidade é a frequência relativa de objetos que contém o valor de uma classe no conjunto de dados. Os objetos são descritos por um conjunto de valores de atributos de entrada que representa o evento $B$.

A estimativa da probabilidade $P(A \mid B)$ de que um evento $B$ ocorra para cada classe (ou evento $A$ ) pode ser calculada por meio do Teorema de Bayes dada na Equação A.2.

$$
P(A \mid B)=\frac{P(B \mid A) P(A)}{P(B)}
$$

em que:

$P(A)$ é a probabilidade a priori da classe,

$P(B \mid A)$ é a probabilidade de observar vários objetos que pertencem à classe, e $P(B)$ é a probabilidade de ocorrência desses objetos.

Para exemplificar o Teorema de Bayes, considere as seguintes informações:

- a probabilidade de um dado paciente ter contraído a doença é igual a 4\%;

- resultados de exames são positivos em $80 \%$ dos casos em pacientes com a mesma doença, e;

- em pacientes que não têm a doença, o resultado é negativo em $97 \%$ dos casos.

Os eventos observados para esse exemplo são:

$A$ : o paciente está doente; $\bar{A}$ : o paciente não está doente;

$B$ : o resultado do exame é positivo; $\bar{B}$ : o resultado do exame é negativo;

A partir dessas informações, desejamos saber qual o nível de certeza de que um paciente tenha contraído a doença, dado que o exame realizado no paciente para detectar essa doença indicou um resultado positivo $(P(A \mid B))$.

Primeiramente, vamos explicitar o valor de probabilidade para os eventos identificados:

$P(A)=0,04, P(\bar{A})=0,96, P(B \mid A)=0,80, P(\bar{B} \mid A)=0,20, P(\bar{B} \mid \bar{A})=0,97 \mathrm{e}$ $P(B \mid \bar{A})=0,03$.

O valor de probabilidade que desejamos obter é $P(A \mid B)$. 
Antes de calcular $P(A \mid B)$, precisamos encontrar o valor de $P(B)$. Para isso, podemos usar a lei da probabilidade total indicada na Equação A.3.

$$
P(B)=\sum_{i} P\left(B \mid A_{i}\right) \times P\left(A_{i}\right)
$$

Aplicando essa equação no exemplo ilustrado, temos: $P(B)=P(B \mid A) \times P(A)$ $+P(B \mid \bar{A}) \times P(\bar{A})$, e substituindo os termos da equação pelos valores de probabilidade, $P(B)=0,80 \times 0,04+0,03 \times 0,96=0,0608$.

Finalmente, para calcular a probabilidade desejada, podemos usar o Teorema de Bayes e, usando os valores conhecidos, temos:

$$
\begin{aligned}
& P(A \mid B)=(0,80 \times 0,04) / 0,0608 \\
& P(A \mid B)=0,5263
\end{aligned}
$$

Um classificador Naïve Bayes considera que, dado o valor de uma classe, os atributos de entrada de um exemplo são independentes entre si (Tan et al., 2006). Sendo assim, $\mathrm{P}\left(\bar{x} \mid y_{i}\right)$ pode ser decomposto no produto $\mathrm{P}\left(x_{1} \mid y_{i}\right) \times \ldots \times$ $\mathrm{P}\left(x_{d} \mid y_{i}\right)$, em que $x_{j}$ é $j$-ésimo atributo do exemplo $x$.

Os aspectos positivos de um classificador Naïve Bayes são (Tan et al., 2006):

- todas as probabilidades necessárias podem ser calculadas a partir do conjunto de treinamento;

- o processo de construção do modelo é bastante eficiente;

- a implementação é fácil e pode ser feita de forma incremental;

- robusto quanto à presença de ruídos e atributos irrelevantes.

Quanto ao seu principal aspecto negativo, a independência condicional para os atributos pode prejudicar o desempenho preditivo do classificador quando dois ou mais atributos forem correlacionados.

\section{A.3 Métodos baseados em procura}

Um problema de AM pode ser descrito como um problema de procura em um espaço de possiveis soluções. Um algoritmo de árvore de decisão (AD) é um exemplo que usa um método baseado em procura para resolver um dado problema.

A estratégia da $\mathrm{AD}$ é dividir um problema complexo em problemas mais simples, aplicando recursivamente a estratégia de dividir e conquistar. Uma $\mathrm{AD}$ é representada por um grafo acíclico direcionado, em que cada nó pode ser: nó de divisão ou nó folha. Cada nó folha tem exatamente uma aresta de entrada e nenhuma aresta de saída, sendo rotulado com um dos possíveis 
valores de classe. Um nó de divisão contém uma aresta de entrada e duas ou mais arestas de saída. Esse nó representa um teste condicional baseado nos valores de um atributo. Uma regra de divisão indica o poder do atributo para discriminar as classes, particionando o conjunto de objetos em subconjuntos.

Existem vários aspectos positivos em um modelo baseado em $\mathrm{AD}$ (Tan et al., 2006), tais como:

- Flexibilidade: não assume nenhuma distribuição para os dados e cobre exaustivamente todo o espaço dos objetos;

- Robustez: as árvores univariáveis são invariantes às transformações monótonas das variáveis de entrada, sendo bastante insensiveis a ruídos;

- Seleção de atributos: durante o processo de construção da árvore, os atributos usados para induzir o modelo são os mais relevantes;

- Interpretabilidade: todas as decisões são baseadas nos valores dos atributos, tornando fácil a interpretação do modelo;

- Baixo custo computacional: a complexidade de tempo de uma $\mathrm{AD}$ é linear em relação ao número de exemplos do conjunto de treinamento.

Em relação aos seus aspectos negativos, podemos citar:

- Replicação: testes dos atributos podem ser duplicados em diferentes ramos da árvore, não tornando a sua representação concisa;

- Valores ausentes: a inexistência do valor para um atributo prejudica a decisão sobre qual ramo da árvore que deve ser seguido;

- Atributos contínuos: uma ordenação deve ser feita para esse tipo de atributo para cada nó de divisão, demandando mais tempo computacional;

- Instabilidade: pequenas variações no conjunto de treinamento podem ter uma influência forte na árvore induzida.

\section{A.4 Métodos baseados em otimização}

Algumas técnicas de AM procuram a hipótese que descreve os dados por meio de uma função a ser otimizada. Nesse caso, o problema de aprendizado é formulado como um problema de otimização em que se deseja a minimização (ou maximização) de uma função objetivo (Faceli et al., 2011). Uma das técnicas de AM mais conhecidas que usa métodos baseados em otimização é a rede neural artificial (RNA). 
As RNAs são inspiradas nas redes neurais biológicas dos cérebros humanos. Os primeiros trabalhos em RNAs tinham o objetivo de conhecer o funcionamento do cérebro e usar esse conhecimento para aplicar em sistemas de aprendizado biologicamente plausiveis (Mcculloch e Pitts, 1943). RNAs são sistemas computacionais que possuem várias unidades de processamento simples e interconectadas. Essas unidades são denominadas neurônios artificiais que computam funções matemáticas (Haykin, 2009).

Os neurônios de uma RNA são organizados em duas ou mais camadas, sendo uma camada de saída e, no mínimo, uma camada escondida. Geralmente, a saída de cada neurônio em uma camada escondida está conectada à entrada de todos os neurônios da próxima camada. As conexões entre neurônios simulam as sinapses biológicas, em que cada neurônio pode ser excitado (valor positivo) ou inibido (valor negativo) dependendo da informação recebida. Um sinal é fornecido na entrada da RNA, sendo propagado para os demais neurônios subsequentes de camada em camada (Haykin, 2009).

As RNAs podem aprender associações entre os pares de vetores de entradasaída, usando um algoritmo de treinamento supervisionado, denominado back-propagation ou uma de suas variantes. Durante o aprendizado, a diferença entre os valores conhecidos e os valores de saída preditos é propagada para as camadas anteriores da rede a fim de ajustar os valores dos pesos associados às conexões da rede. Depois de treinado, a rede pode ser usada para predizer os valores de saída para um novo vetor de entrada (Rumelhart e Mcclelland, 1986).

Os principais aspectos positivos das RNAs são (Tan et al., 2006):

- aproximadores universais: redes neurais multicamadas podem ser usadas para aproximar qualquer função.

- robustez: atributos redundantes podem ser manipulados porque os pesos são automaticamente aprendidos durante o treinamento da rede;

E os principais aspectos negativos são:

- tempo elevado de treinamento: ocorre, especialmente, quando existem diversos neurônios na camada escondida, porém a classificação dos exemplos de teste é rápida;

- pouca compreensão: a dificuldade de entender as decisões das RNAs está relacionada com o fato do conhecimento ser armazenado em uma grande quantidade de parâmetros, para os quais é difícil saber antecipadamente a melhor configuração;

- convergência local: o método descendente gradiente usado para treinar os pesos de uma RNA frequentemente converge para algum mínimo local. 
Em muitos problemas de AM, cada exemplo do conjunto de dados deve ser classificado com um único rótulo. No entanto, há outros problemas como classificação multirrótulo, em que os exemplos podem ser classificados simultaneamente em mais de uma classe (De Carvalho e Freitas, 2009). Na próxima seção, são apresentados alguns métodos usados para resolver problemas de classificação multirrótulo.

\section{A.5 Classificação multirrótulo}

Existem vários exemplos de aplicações de classificação multirrótulo, tais como: diagnóstico médico, um paciente pode ter duas ou mais doenças ao mesmo tempo; bioinformática, proteínas podem ser classificadas ao mesmo tempo em cada uma das suas várias funções; classificação de texto, um documento pode ser classificado em diferentes categorias. Nesta tese, diferentes MHs podem ser recomendadas para uma nova instância do PCV.

Diversos métodos para problemas de classificação multirrótulo podem ser encontrados na literatura. Em nossos experimentos, foram usados dois métodos que transformam exemplos multirrótulos em exemplos com um único rótulo e um terceiro que consiste na eliminação dos exemplos multirrótulos. Esses métodos são brevemente descritos a seguir:

- Transformação baseada em rótulos (Tsoumakas e Katakis, 2007). Novos problemas de classificação são criados a partir dos diferentes rótulos que podem usados para classificar os exemplos de um conjunto de dados. Para cada rótulo, um novo problema de classificação binária é criado. Os exemplos associados a esse rótulo são classificados como positivo, e os demais são classificados como negativo.

O processo de transformação reversível é um aspecto positivo desse método. Pois, é possivel recuperar as classes do problema original a partir dos novos problemas. No entanto, esse método tem como principais aspectos negativos: a suposição de que as diferentes classes são independentes entre si e o maior tempo computacional para induzir os modelos cuja quantidade é o número de classes.

- Decomposição de rótulos (Boutell et al., 2004). Cada exemplo multirrótulo associado a $k$ rótulos é transformado em $k$ exemplos associados a um rótulo diferente. Desse modo, o número de exemplos do novo conjunto de dados é maior do que o número de exemplos do conjunto original. Apesar de ser induzido apenas um classificador a partir do novo conjunto de dados, tal conjunto não é muito apropriado para treinar o modelo preditivo. 
Pois, o conjunto de dados fica inconsistente devido aos exemplos diferentes que possuem valores iguais para os meta-atributos e valor diferente para a classe Esse é um tipo de inconsistência que prejudica a indução do modelo preditivo.

- Eliminação de exemplos multirrótulos (De Carvalho e Freitas, 2009). Um método mais simples é a eliminação de todos os exemplos multirrótulos. Embora o conjunto de dados resultante seja único e não contém dados inconsistentes, a eliminação de muitos exemplos multirrótulos pode prejudicar a indução do modelo. A quantidade de exemplos remanescentes pode ser insuficiente para o modelo adquirir uma boa capacidade de generalização. Além disso, a transformação irreversível do conjunto de dados é outro aspecto negativo desse método, já que não há como saber quais foram os exemplos excluídos.

Para ilustrar os efeitos do resultado de cada uma dessas três abordagens de classificação multirrótulo, considere o conjunto de dados mostrado na Tabela A. 1 .

Tabela A.1: Uma ilustração de conjunto de dados com exemplos multirrótulo.

\begin{tabular}{cl}
\hline Instância & Classe Multirrótulo \\
\hline 1 & $\{\mathrm{AM}, \mathrm{BD}\}$ \\
2 & $\{\mathrm{LP}\}$ \\
3 & $\{\mathrm{RE}\}$ \\
4 & $\{\mathrm{AM}, \mathrm{LP}, \mathrm{RE}\}$ \\
\hline
\end{tabular}

A Tabela A.2 mostra o resultado da transformação baseada nos rótulos das classes, que transforma o conjunto de dados com exemplos multirrótulo em "q" conjuntos de dados com exemplos classificados em uma única classe, em que "q" é o número de classes diferentes. Como no exemplo ilustrado existem quatro possiveis valores de classe, quatro conjuntos de dados novos são criados a partir do conjunto de dados original. Embora todos os conjuntos tenham os mesmos exemplos, a diferença está no modo como esses exemplos são classificados. Em cada conjunto novo, uma das classes é a classe positiva e as outras formam a classe negativa. Somente os exemplos 1 e 4 da Tabela A.2 são classificadas como "AM", por isso esses exemplos são classificados como “+” na "Base AM", enquanto que os demais são classificados como “-”.

Tabela A.3 mostra o resultado após a aplicação do método da decomposição dos rótulos. Perceba que a transformação resultou em diversos exemplos iguais com classe distinta.

Finalmente, a Tabela A.4 mostra o conjunto de dados resultante após a 
Tabela A.2: Transformação dos exemplos multirrótulo baseada no método de classificação binária dos rótulos.

\begin{tabular}{cccccccc}
\hline \multicolumn{2}{c}{ Base AM } & \multicolumn{2}{c}{ Base BD } & \multicolumn{2}{c}{ Base LP } & \multicolumn{2}{c}{ Base RE } \\
\hline Inst. & Classe & Inst. & Classe & Inst. & Classe & Inst. & Classe \\
\hline 1 & + & 1 & + & 1 & - & 1 & - \\
2 & - & 2 & - & 2 & + & 2 & - \\
3 & - & 3 & - & 3 & - & 3 & + \\
4 & + & 4 & - & 4 & + & 4 & + \\
\hline
\end{tabular}

Tabela A.3: Transformação dos exemplos multirrótulo baseada no método de decomposição dos rótulos.

\begin{tabular}{cl}
\hline Instância & Classe \\
\hline 1 & $\mathrm{AM}$ \\
1 & $\mathrm{BD}$ \\
2 & $\mathrm{LP}$ \\
3 & $\mathrm{RE}$ \\
4 & $\mathrm{AM}$ \\
4 & $\mathrm{LP}$ \\
4 & $\mathrm{RE}$ \\
\hline
\end{tabular}

eliminação das instâncias multirrótulo. No problema ilustrado, houve uma eliminação significativa de $50 \%$ das instâncias originais.

Tabela A.4: Transformação dos exemplos multirrótulo baseada no método de eliminação dos exemplos multirrótulo.

\begin{tabular}{cl}
\hline Instância & Classe \\
\hline 2 & $\mathrm{LP}$ \\
3 & $\mathrm{RE}$ \\
\hline
\end{tabular}

\section{Avaliação de uma classificação multirrótulo}

O desempenho preditivo de um modelo de AM para problemas de classificação multirrótulo deve ser avaliado a partir de métricas específicas, já que o classificador pode indicar corretamente apenas um subconjunto das classes verdadeiras para um dado exemplo multirrótulo.

Seja $X$ um conjunto de dados multirrótulo composto por $t$ exemplos multirrótulo $\left(x_{i}, y_{i}\right)$, com $i=1,2, \ldots, t$ e $y_{i} \subseteq K$, onde $K=\left\{k_{1}, \ldots, k_{q}\right\}$ é o conjunto de possíveis classes. Seja ainda $\hat{f}$ um classificador multirrótulo e $z_{i}=\hat{f}\left(x_{i}\right)$ um vetor binário com $c$ elementos que representa o conjunto de classes preditas por $f$ para o exemplo $x_{i}$. Para avaliar a qualidade da classificação, pode ser usada a medida HammingLoss (Schapire e Singer, 2000), dada na Equação 
A.4.

$$
\text { HammingLoss }(\hat{f}, X)=\frac{1}{n} \sum_{1}^{n} \frac{a\left(y_{i}, z_{i}\right)}{k}
$$

O valor $a\left(y_{i}, z_{i}\right)$ representa a distância de Hamming entre os vetores $y_{i}$; e $z_{i}$. Essa distância corresponde à operação "OU Exclusivo" da lógica booleana. Quanto menor o valor da medida HammingLoss, melhor é a classificação. A classificação perfeita ocorre quando o valor dessa medida é igual a zero. 


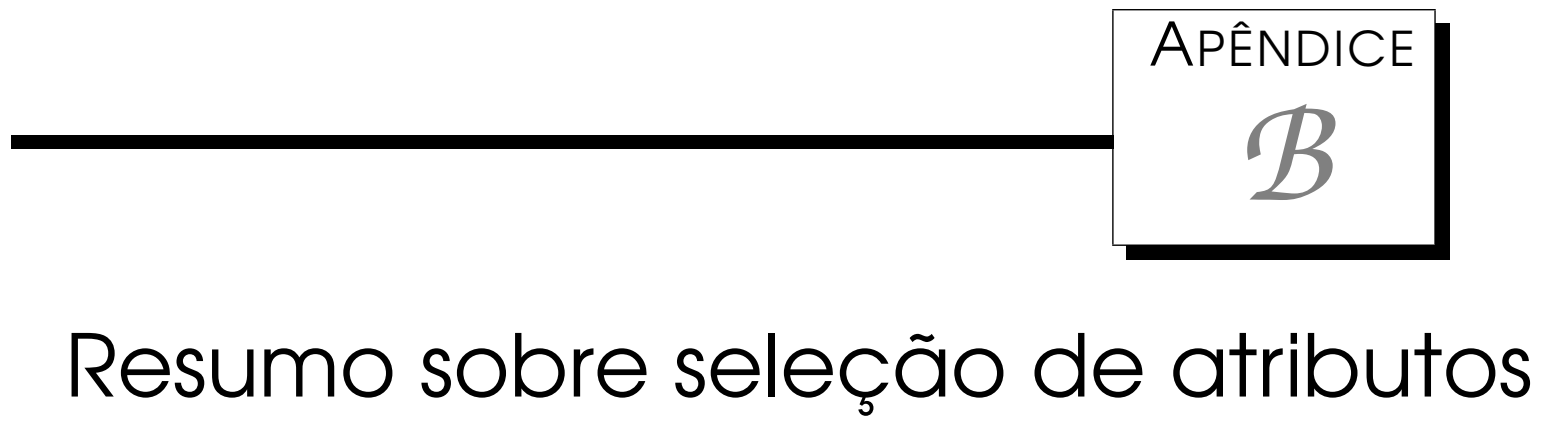

Usar um subconjunto de atributos ao invés do conjunto completo pode proporcionar a um modelo classificador resultados melhores em sua capacidade preditiva. Dentre os diversos atributos que podem ser mensurados para caracterizar os exemplos de um conjunto de dados, alguns podem ser irrelevantes, redundantes ou conter uma grande quantidade de ruídos. Em qualquer um desses casos, tais atributos podem influenciar de maneira indesejável uma predição equivocada do modelo para novos exemplos.

Os atributos irrelevantes são aqueles não possuem informações úteis que possam contribuir para o aprendizado do modelo (Mitchell, 1997). Por exemplo, se todos os exemplos de PCV usados para treinar o modelo têm um mesmo número de cidades, o uso de um meta-atributo que identifique o número de cidades não terá uma influência positiva no processo de aprendizado do modelo preditivo.

Os atributos redundantes são aqueles que possuem a mesma informação útil para a indução do modelo (Tan et al., 2006). Por exemplo, se somente exemplos de PCV fortemente conectados são usados para induzir o modelo, o número de arestas pode ser rapidamente calculado a partir do número de vértices. Desse modo, quando um atributo pode ser obtido a partir da combinação de outros atributos é considerado redundante, não sendo necessário usá-lo para descrever os exemplos do problema.

Um ruído pode ser definido como uma variância ou um erro aleatório no valor gerado ou mensurado para um atributo (Han e Kamber, 2000). Dados com ruídos podem conduzir o modelo a um (overfitting), já que o modelo pode ter sido induzido a partir de alguma propriedade particular do ruído. A eliminação de dados com ruídos também pode ser um problema quando informações 
relevantes são excluídas. É importante salientar que nem sempre é possível afirmar que um valor de um atributo indica, ou não, um ruído. Para detectar e remover ruídos, existem diversas técnicas de pré-processamento que podem ser encontradas em (Tan et al., 2006).

Uma seleção de atributos mais relevantes pode ser obtida a partir da ordenação de todos os atributos ou da seleção de um subconjunto de atributos. Alguns detalhes sobre essas duas formas de seleção são descritos a seguir:

- Ordenação: os atributos são ordenados de acordo com a sua relevância, que pode ser medida a partir de algum critério pré-estabelecido. Os atributos mais relevantes que estão no topo da lista ordenada são selecionados para que sejam usados como parâmetros de entrada de um modelo preditivo. A relevância de um atributo pode indicar o seu poder discriminatório dos exemplos do conjunto de meta-dados em relação às possiveis classes. Em tarefas de regressão, um atributo é considerado relevante quando pode prever, com a maior precisão possível, o valor da saída desejada. O aspecto positivo da ordenação está no tempo computacional linear em relação ao número de atributos. No entanto, alguns atributos podem ser menos relevantes quando usados sozinhos, e mais relevantes quando usados em composição com outros.

- Seleção de subconjunto: um subconjunto de atributos mutuamente relevantes é selecionado. O aspecto positivo desse procedimento é que não despreza a correlação entre os atributos pertencentes ao subconjunto selecionado. Em relação ao seu aspecto negativo, o custo computacional cresce com o aumento do número de atributos, podendo tornar intratável quando esse número é muito grande. Um subconjunto selecionado $\operatorname{com} j$ atributos dificilmente é constituído pelos $j$ melhores atributos indicados pela seleção de ordenação.

Dentre as abordagens que podem ser usados para processar a seleção de atributos (Tan et al., 2006), temos:

- Seleção baseada em filtro: Essa abordagem é executada durante a etapa de pré-processamento com o objetivo de selecionar um subconjunto de atributos sem considerar o algoritmo de aprendizado a ser aplicado no conjunto de dados. Dentre os seus principais aspectos positivos estão: os atributos selecionados podem ser usados por diferentes algoritmos de AM; custo computacional relativamente baixo e a abordagem pode ser aplicada para conjunto com grande quantidade de dados.

- Seleção baseada em wrapper: A principal característica dessa abordagem é que a seleção de atributos é feita pelo próprio algoritmo de AM, como 
por exemplo, algoritmos que usam a técnica Naïve Bayes. Para selecionar o subconjunto de atributos, diversos subconjuntos são usados para descrever um conjunto de dados submetido ao algoritmo de aprendizado. O subconjunto selecionado de atributos é aquele com o qual o algoritmo apresentou a menor taxa de erro.

- Seleção embutida: o processo de seleção do subconjunto de atributos está embutido no algoritmo de aprendizado, como por exemplo, as árvores de decisão. O principal aspecto positivo dessa abordagem é o rápido processamento, uma vez que os algoritmos de AM não precisam ser retreinados para cada novo conjunto de dados. 